\title{
Experimentelle Untersuchungen über die Variabilität der Verdauungsröhre.
}

\author{
Von \\ Dr. Edward Babák, \\ Priratdozenten und Assistenten am physiologischen Institut d. bühm. Universität Prag. \\ Eingegangen am 26. März 1906.
}

\section{Einleitung.}

Über die Beziehungen der Verdaungsröhre zur Nahrung wurden bisher fast ausschließlich nur physiologische Erfahrungen gesammelt, und zwar größtenteils chemisch-physiologische (über die Secretion der Verdauungssäfte und ihre Einwirkung auf die Nahrungsstoffe, über die Resorption der Verdauungsprodukte usw.). Die morphologischphysiologischen Untersuchungen berücksichtigten vorzugsweise die cytologischen Änderungen bei der secretorischen Tätigkeit der Verdauungsdrüsen.

Über die vielseitige Beziehung der Nahrungsstoffe zur Verdaungsröhre, wie sie unzweideutig zutage tritt, weun man allgemein-biologischen Standpunkt einnimmt, wurde kaum nachgedacht, um so weniger nachgeforscht. Ich versuche in dieser allgemeinen Einleitung eine Reihe ron diesen Beziehungen aufzuftuhren, ohne Anspruch zu machen die hierher gehörige Problemgruppe zu erschöpfen: denn ich will in dieser Abhandlung hauptsächlich die Ergebnisse meiner experimentellen Untersuchungen klarlegen.

1) Die Verdauungsröhre stellt im Tierkörper eine verhältnismäßig große inner e $\mathrm{Ob}$ erfläc he dar, welche dazu dient, die aufgenommenen chemischen Verbindungen, größtenteils nach chemischen Änderungen derselben zu resorbieren und in geeignetem Zustande dem ïbrigen Körper vorzulegen, wo sie als Stoff- und Energiequelle benutzt werden. Die rohen Nahrungsstoffe, wie sie die Außenwelt zur Verfuggung stellt, werden also durch die Tätigkeit der Ver- 
daunngsröhre zu den speziellen eigentlichen Nahrungsstoffen rerwandelt: solche kommen in dem Blute und in der Lymphe vor.

Diese Verdaungsarbeit, welche durch die Wand der Verdauungsröhre verrichtet wird, richtet sich nach der Natur der aufgenommenen Nahrungsstoffe. Sehr klein und eng ist sie wohl bei der Verdauung der Nahrungssalze; sie besteht bier eigentlich in der Absorption der Salzlösungen. Allerdings besteht schon hier kaum eine einfache physikalich-chemische Beziehung; neuerdings versucht es hauptsächlich HöBer (PFLÜG. Arch. f. Physiol. Bd. 74, 94 usw.) die Absorption der Salzlösungen auf Grund der bekannten physikalischchemischen Regeln zu erklären, ohne aktive, vitale Beteiligung der lebenden Epithelzellen. Aber es ist noch sehr fraglich, ob man in diesem Falle die Darmwand nur für eine Diffusionsmembran usw. halten darf.

Die Kohlehydrate und Fette werden größtenteils chemisch rerändert und zwar durch die Verdauungssäte, welche sich in die Höhle der Verdauungsröhre aus den Drüsen derselben ergießen. Die zusammengesetzten Kohlehydrate werden durch Enzyme der Drüsensecrete gespalten und in die Blutbahn gelangt nur verduinnte Traubenzuckerlösung. Die Fette werden durch Enzymwirkung in Glyzerin und Fettsäuren gespalten; die Spaltungsprodukte werden in die Epithelzelleu absorbiert, wo dann weitere chemische İnderungen gesehehen; in der Lymphbahn erscheinen kleine Fettkügelehen, welche sich wohl gewöhnlich in ihrer Zusammensetzung: als spezifisches Fett der gegebenen Tierspecies erweisen.

Bei den Eiweißkörpern kommt die dreifache Tätigkeit der Darmwand noch mehr zum Vorschein. Diese höchst komplizierten Stickstoffverbindungen werden durch die Enzymeinwirkung der Verdauungssäfte in Proteosen und Peptone gespalten, welche absorbiert werden; in den Zellen der Darmwand werden diese Spaltungsprodukte durch synthesierende Lebenstiitigkeit derselleen in specifische Proteine der gegebenen Tierspecies umgewandelt.

Die secernierende, resorbierende und assimilatorische Taitigkeit der Verdaungsröhre richtet sich nach den aufgenommenen Nahrungsstoffen: und zwar sowohl in quantitativer als auch qualitativer Hinsicht. Um nur die auffallendsten Beispiele anzufuhren: es gibt gewisse stickstoffhaltige Extraktivstoffe (z. B. im Fleisch), welche in kleiner Mlenge anwesend eine hochgradige Secretion der: Verdauungssäfte hervorrufen, wïhrend riele Nahrungsstoffe nur uubedentend als secretorische Reize einwirken. Es kann auch die 
qualitative Zusammensetzung des Verdauungssaftes durch die qualitativen Verschiedenheiten der Nahrungsstoffe geändert werden.

Und es ist ohne Zweifel, daß anch die Resorptionstätigkeit weitgehende Beeinflussung erleidet je nach der Quantität und Qualität der Nahrung bzw. ihrer durch die Einwirkung der Verdauungssäfte entstandenen Prodnkte.

Nenerdings wird in der Physiologie sehr viel iiber die assimilatorische Tätigkeit der Darmwand nachgedacht und experimentiert. Es sind dies besonders die artfremden Proteine und ihre Umwandlung: in arteigne Proteinstoffe des Blutes, welche die Aufmerksamkeit vieler Forscher heranziehen. Über die Art dieses Geschehens, wodurch die Synthese der resorbierten Spaltungsprodukte der Eiweißkörper zustande kommt, liegen keine Erfahrungen vor; doch iber die Tatsache dieses Geschehens herrscht kein Zweifel. Man kennt einerseits die Spaltungsprodukte im Innern des Darmkanals und ihre Absorption; anderseits aber findet man keine Spur von diesen Stoffen in den aus der Darmwand führenden Blut- und Lymphbahnen, ebenfalls werden sie nicht in der Darmwand selbst aufgespeichert.

In Anbetracht der weiter angefühten Ergebnisse meiner experimentellen Untersuchungen will ich etwas breiter dieses Problem beleuchten, und zwar auf Grund einiger ausgewählten Arbeiten.

SALrioli (1) hat gefunden, daB die im Innern einer Darmschlinge (mit kïnstlicher Blutcirculation) befindlichen Peptone verschwinden und daß der Inhalt der Darmschlinge nunmehr durch Hitze coagulierbar ist, d. h. Proteine besitzt. Neumesster (2) hat bewiesen, daß die zum defibrinierten Blute beigemischten Peptone oder Albumosen nach ganz kurzer Zeit und zwar in verhältnismäßig bedeutenden Mengen verschwinden, wenn man dazu lebensfrische Darmstiicke gibt. - HoFMeIster (3) hat beobachtet, daß der eine Teil des Magens von eben getötetem Hunde frisch untersucht viel Pepton enthält, während der andre nach zweistündiger Aufbewahrung fast kein Pepton besitzt; diese umwandelnde Eigenschaft der Magenschleimhaut wurde aber zerstört, wenn letztere einen Moment anf $60^{\circ}$ erwärmt wurde. GLAEssser (4) hat gefunden, daß die Magenschleimhat des Hundes bei voller Verdanungstätigkeit viel Albumosen enthält, deren Menge aber sich weiterhin vermindert, wogegen die Menge der durch Hitze coagulierbaren Proteine ansteigt. Es scheint hierdurch die Regeneration ron (höchstwahrscheinlich artgleichen) Proteinen aus Albumosen bewiesen zu sein, wenigstens für die Magenschleimhaut. Über die Darmschleimhaut 
gibt es bisher keine eindeutige Erfahrungen: nach einigen Autorea können hier sogar ans sehr einfachen Produkten der weitgehenden tryptischen Spaltung Proteine rekonstruiert werden: andre Forscher sehen aber in den kristallinischen Amidstoffen der tryptischen Verdauung keine Bausteine für die Eiweißsynthese, sondern sie halten dieselben für Zersetzungsprodukte der ubermäßig zugefuhrten Eiweißkörper, obne Bedeutung für die eigentliche Ernährung; usw.

Trotz den mangelhaften Erfahrungen über die assimilierende 'Tätigkeit der Schleimhaut der Verdauungsröhre besteht kein Zweifel dariuber, daß man berechtigt ist derselben weitreichende synthetisierende Fähigkeiten zuzuschreiben. Nach HayblrGens (5) Erwägungen »stellt uns der Verdauungsapparat mit seinen Anhängen das Schutzorgan für den ganzen Organismus dar, indem er für den ganzen Körper die Assimilation übernimmt . "Die Verdauungszellen berauben die Nahrungsstoffe ihrer reizenden Wirkung und überfubren sie in Formen, die ihrer Art eigentümlich sind." „Die Ernährung wird mit einem Reiz, mit einer Störung eingeleitet, mit einer Gefahr für die biochemische Integrität» der Verdauungszellen. Die spezifischen Blntproteine, welche der Ernährung der rerschiedenen Organe dienen, werden in der Schleimhaut der Verdaungssiöhre bereitet und zwar durch Verarbeitung der absorbierten Spaltungsprodukte der artfremden Eiweißkörper, welche selbst direkt ins Blut („parenteral «) eingefuhrt sich als giftig erweisen würden.

Da es nun durch verschiedene Untersuchungen (und zwar sowohl physikalischer und chemischer, als auch hauptsächlich »biologischer * Art, d. h. durch die Präzipitinmethode usw.) bewiesen wurde, dalb es eine Unzahl von Eiweißkörperu gibt, daß z. B. die Blutplasmaproteine der verschiedenen Species verschieden sind, wie auch z. B. die Muskeleiweißkörper verschiedener Tierklassen sich unterscheiden lassen -ist es sicher zu erwarten, dab auch die Verarbeitung der verschiedenen Eiweißkörper sehr mannigfach ausfallen wird. Man kann z. B. dafürhalten, daß nicht nur die secernierende und absorbierende, sondern anch besonders die assimilierende Tätigkeit der Verdauungsröhre sich nicht nur quantitativ, sondern auch qualitativ anders gestalten wird, wenn das Tier Eiweißkörper artverwandter Qualität aufnimmt, als wenn es sich von artfremden Eiweibstoffen ernährt.

Demzufolge ist eine sehr komplizierte und durchgreifende Einwirkung der Nahrung a uf die Verdaungsröhre anzunehmen. Da man aber sehr auffällige Änderungen in der morphologischen Beschaffenheit der Drüsenzellen bei der secretorischen Tütig- 
keit beschrieben hat, kann man auch erwarten, daß langandauernde Ernährug mit sehr verschiedenartig zusammengesetzter Nahrung infolge sehr versehiedenartiger Beeinflussung der secernierenden, absorbierenden und assimilierenden Tätigkeit der Verdaungsröhre auch auffallende morphologische ïnderungen derselben verursachen wird. Denn es besteht gewiß eine sehr enge Beziehung zwischen der physiologischen Funktion und dem Wachstums- und Gestaltungsgeschehen.

2) Wir haben bisher nur iber funktionelle Beziehungen der Verdauungsröhre zu den Nahrungsstoffen gehandelt.

Die aufgenommene Nahrung stellt aber auch allgemein eine komplizierte Reizquelle dar, abgesehen von der secernierenden, resorbierenden und assimilierenden Tätigkeit der Verdauungsröhre, wie dieselben durch die Nahrungsstoffe ausgelöst werden. Der Darminhalt kann hauptsächlich mechanisch und chemisch die Darmoberfläche beeinflussen (nebstdem allerdings auch osmotisch). Ich meine hier also den direkten Einfluß des Darminhalts auf die benachbarte Darmfläche (wogegen die secretorischen Erscheinungen reflectorischer Natur zu sein pflegen; über die Auslösung der resorbierenden und assimilierenden Tätigkeit ist es schwer etwas Bestimmtes auszusagen).

Der mechanische Einfluß kann einerseits in Druckwirkung bestehen, welche groß sein wird, wenn voluminöse Nahrungsmassen einverleibt werden, anderseits in Reibung, wenn die Nahrungspartikel ranh, spitzig usw. sind und gar wenn ebensolche unverdauliche Teilchen in der Nahrung vorkommen.

Die chemische Einwirkung kann ebenfalls nicht nur von den Nahrungsstoffen, sondern auch von allerlei beigemischten Stoffen herrühren, welche ohne Bedentung für die Ernährung sein können.

3) Nicht nur die aufgenommenen Nahrungsstoffe sowie die ihnen beigemischten unverdaulichen Stoffe beeinflussen die Darmoberfläche, sondern auch die verschiedenartigen Spaltungsprodukte, welche durch die Enzymeinwirkung der Verdaunngssäfte entstehen, sowie die Zersetzungsprodukte der weiteren chemischen Prozesse, welche an die Einwirkung der Darmsecrete anknüpfen und für die Ernährung direkt ohne Belang sein können (Gärungen, Fäulnisprozesse usw.). Daß diese sämtlichen Beeinflussungen je nach der Beschaffenheit der Nahrung sehr hochgradig verschieden sein werden, und zwar sowohl in quantitativer als auch qualitativer Hinsicht, ist unzweifelhaft, wenn man die Ergebnisse der chemisch-physiologischen 
Untersuchungen über die Zersetzungsprodukte im Darmkanal in Betracht nimmt.

4) Durch die verschiedene Beschaffenheit des Darminhaltes wird nicht nur die äußerste Zellenlage - die Darmepithelien beeinflußt, sondern auch die tieferen Schichtender Schleimhaut, die Muskelsehichten (direkt - oder auch indirekt, dureh Vermittelung des Nervensystems) und das Stützgewebe künnten dabei gewissen Einwirkungen ausgesetzt sein. Man kennt bisher allerdings nur einige funktionelle Erscheinungen dieser Art, z. B. die Einwirkung. der Cellulose, der Hornspäne usw., sowie verschiedener chemischen und osmotischen Agentien auf die Peristaltik. -

Es ist also die Beziehung der Verdauungsröhre zu der Nahrung. änßerst kompliziert und es läßt sich glauben, daß die Analys dieser Verhältnisse auf große Schwierigkeiten stoßen wird. --

Der geschilderten Aufgabe des vielseitig tätigen Vermittlers zwischen der Außenwelt, woher die nötigen Nahrungsstoffe herrïhren, und den einzelnen Organen des Körpers ist wohl die Verdaungsröhre sehr gut angepaßt. Wie weit diese Angepaßtheit der Darmepithelien reicht, läßt sich schon darans ersehen, daß es so schwer gelingt, durch die Nabrungsstoffe den Tierorganismus irgendwie qualitatir zu verändern, obwohl es auf den ersten Blick scheinen möchte, daß es unter den rerschiedenen Wirkungsweisen, welche die Außenwelt anf den tierischen Körper ausübt, keine tiefgreifendere gibt als die chemische Zusammensetzung der Nahrung (denn die Wirkungen des Lichtes treten bei den Tieren größtenteils weit in den Hintergrund, die Wärmeeinflisse rerursachen in weiten Grenzen nur quantitative Änderungen des Lebensgeschehens und die osmotischen Erscheinungen kommen gewiß ebenfalls nur nebensächlich zur Geltung).

Eine jede Tierspecies ist im ganzen einer gewissen Nahrung angepaßt, wobei es allerdings hochgradige Differenzen gibt, indem sich manche Tierarten vou Nahrungsstoffen ungemein verschiedener Herkunft ernähren, wogegen wieder andre auf äußerst enge Grenzen beschränkt sind. Um nur ein Beispiel von allgemeiner Bedeutung anzuführen: unter den verschiedenen Tierklassen findet man strenge Pflanzenfresser und Fleischfresser neben Omniroren. Wir finden nun, wenn wir z. B. gewisse pflanzenfressende Säuger mit fleischfressenden vergleichen, ganze Reihen von speziellen Anpassungsmerkmalen, welche sowohl morphologiseher Art (Beschaffenbeit der Zähne, des ganzen 
Darmkanals usw.) als auch physiologischer Art (Verdauungstätigkeit, Aufsuchung der Nabrung usw.) sind. Wir werden uns weiter besonders mit der Länge der Verdauungsröhre als einem auffallenden Zeichen von Anpassung zu der Nahrung beschäftigen.

Diese Merkmale ron Angepaßtsein zur Nahrungsbeschaffenheit finden wir in den Ergebnissen der deskriptiven morphologischen und physiologischen Forschung in verhältnismäßig befriedigender Weise beschrieben.

Wenn man aber die Frage nach dem Anpassungsgeschehen zur Nahrungsbeschaffenheit aufstellt, findet man - wie treiter angeführt werden wird - nur höchst spärliche und ungenügende Beobachtungen. Wir beruhren hiermit ein Gebiet, wo die Morphologie und Physiologie zusammenfließen und auf dem erst während kurzer Zeit gearbeitet wird.

Und doch ist die Frage nach dem Anpassungsgeschehen und wodurch wohl das Angepaßtsein zustande gekommen ist, ron ganz hervorragender Bedeutung.

Über die Änderungen der physiologischen Lebenstätigkeiten der Verdauungsröhre als Folgen der verschiedenen Nahrungszusammensetzung ist ja schon manches bekannt; man könnte doch - bei der intimen Beziehung der physiologischen Funktion und dem Wachstumsund Gestaltungsgeschehen - durch geeignete fortgesetzte Ernährung mit verschiedenartiger Nahrung bei geeigneten Versuchstieren morphologische Verschiedenheiten erzielen, als Ergebnis der tiefgreifenden Beeinflussung (in causaler Hinsicht) and Anpassung (in teleologischer Hinsicht). -

Daß ich in meinen experimentellen Untersuchungen iiber die "physiologische Morphologie* der Verdaungssöhre von Anfang an positive Ergebnisse erhalten habe, dies wurde wahrscheinlich durch die glückliche Wahl der Versuchstiere und die Anordnung der Versuche bedingt. Die Luckenhaftigkeit und Einseitigkeit der bisherigen Ergebnisse fühle ich selbst am besten; doch es läßt sich nun hoffen, daß in Aubetracht dieser ersten systematischen Untersuchungen über diesen Problemkomplex, durch welche wenigstens die Möglichkeit der erfolgreichen experimentellen Behandlung der betreffenden Fragen bewiesen wurde, das Interesse zahlreicher Forscher geweckt sein wird, so daß wir in baldiger Zukunft über weit vollkommenere Erfahrungen verfügen werden. 


\section{Die morphologischen Beziehungen der Verdauungsröhre zur Beschaffen- heit der Nahrung im Lichte der deskriptiven Forschung.}

Ich will hier in aller Kürze die vergleichend-anatomischen Kenntnisse uber die Beziebungen der Verdauungsröhre zur Nahrung erwähnen, wobei ich auf meine erste Abhandlung über diesen Gegenstand verweise (6).

Diese Angaben berïhren hauptsächlich die Längenunterschiede des Darmkanals bei fleisch- und pflanzenfressenden Wirbeltieren. Im allgemeinen besitzen die Pflanzenfresser eine weit längere Verdauungsröbre als die Fleischfresser. Dies fällt besonders bei den Säugetieren auf, wo nach den Angaben von GuRLT (nach 7), Ellenberger (8), Thanhoffer (9), Gegenbalr (10) u. a. die Wiederkäuer im Vordergrunde stehen; beim Schafe und bei der Ziege beträgt die Darmlänge in Körperlängen ansgedrückt 26-28, beim Rinde 20; dem gegenüber bei den Raubtieren nur 4 (Wolf;, 6 (Hund), 4 (Katze). Die Beziehung der Darmlänge wird weiter durch folgende Vergleichszahlen illnstriert: 15 (Dromedar, Schwein), 10-12 (Pferd, Esel), 10 (Kaninchen), 3 (Fledermaus). Nach der zusammenfassenden Abhandlung von BLOCH (11) hat der Elefant verhältnismäßig kurze Darmröhre $(20 \mathrm{~m})$, wenn man ihn mit dem ebenfalls pflanzenfressenden Schafe $(32 \mathrm{~m})$ vergleicht; die Giraffe zeichnet sich durch außerordentliche Darmlänge von $76 \mathrm{~m}$ aus. Als Abweichung von der Regel wird der Seehund angeführt, da er eine auffallend große relative Darmlänge besitzen soll, obwohl er sich von $\gg$ Fleisch $\star$ ernährt.

Bei den Vögeln (7) sollen die Fleischfresser im allgemeinen den kürzesten Darmkanal besitzen, bis nur 1,7 der Körperlänge, den längsten die Pflanzenfresser, bis 8 Körperlängen; derjenige der Omnivoren steht in der Mitte. Nach Ellenberger und Bacm (12, beträgt die Gesamtlänge des Darmkanals beim Huhn 5-6 Körperlängen, bei den Gänsen und Enten $4-5$ von Schnabelspitze zum letzten Schwanzwirbel gerechnet), beim Adler 3. Doch es gibt wie aus der Zusammenstellung von GADow (13) ersichtlich ist - bei den Vögeln sehr verwickelte Verhältnisse, indem die Entwicklung der Blinddärme und andre Umstände die Länge der Verdauungsröhre zugleich bedingen; so kommen z. B. unter den Warmbluterfleisch fressenden Vögeln zwei Typen vor, der eine mit Darm von mittlerer Länge und Weite ohne Blinddärme, der andre mit kurzem, weitem 
Darm mit langen Blinddärmen; die Fisch- und Aasfresser sollen entweder sehr lange und enge, oder kurze und weite Verdaungsröhre, und zwar ohne Blinddärme besitzen. Die Vügel, welche von griunen Pflanzenteilen leben, haben einen langen und weiten Darmkanal mit großen Blinddärmen; reine Cerealienfresser einen langen und engen Darmkanal ohne Blinddärme; reine Insektenfresser einen sehr kurzen und ziemlich weiten Darmkanal ohne Blinddärme, ähnlich wie reine Fruchtfresser usw. Übrigens betont auch Gegexiacr bei den Säugetieren, daß zwischen den einzelnen Abteilungen der Verdauungsröhre (z. B. zwischen dem Magen und Cöcum) gewisse Beziehungen bestehen.

Über die Verhältnisse bei niederen Wirbeltieren gibt GEGENBaUR (10, an, daß die Darmwindungen bei den Amphibien gegenüber den Fischen höher entwickelt sind; die höheren Reptilien besitzen einen vielgewundenen Darmkanal. - Bei den Anurenlarven hebt er die Inpassung des Mitteldarms an die Nahrung hervor.

Bei den Reptilien hat Lösxberg (14) sebr gründlich die morphologischen Strukturen der Verdauungsröhre in ihren Beziehungen zur Nahrung studiert. Ich werde aus seiner Abhandlung nur einige Angaben zitieren, welche fiur den Gegenstand unsrer Untersuchungen Bedeutung haben. - Bei der Vergleichung der relativen Darmlängen stöBt man bei den Reptilien auf die Schwierigkeit, daß die Gestalt des Körpers - wenn er lang und schlank oder kurz und breit ist hochgradig die Länge des Darmkanals beeinflußt. Es wird also geboten, womöglich nur gleich gebaute, aber sich verschiedenartig ernährende Tiere zu vergleichen. Da findet man z. B., daß bei den insektenfressenden Geckoniden, welche in änßerer Gestalt einander sehr ähnlich sind, die relativen Darmlängen übereinstimmend ausfallen: Die Durchschnittslänge des Dünndarms beträgt $111{ }_{j 0}$, diejenige des Dickdarms $30^{0}, 0$ der Körperlänge (bis zur Kloakenöffnung: gemessen). Bei Ptycho:oon ist der kurze Dünndarm durch längeren Dickdarm kompensiert, umgekehrt bei Hemidactylus und Gecko. - Die schlankeren auf Bäumen lebenden Agamoiden besitzen im Durchschnitt eine relative Darmlänge von $87 \%$, ungefähr $100^{\circ}, 0$ usw. Der pflanzenfressende Agamoide Cromastix hat zwar die relative Darmlänge wenig vergrößert $(131 \%)$, aber es findet bei ihm dazu noch eine bedentende Verlängerung des Dickdarms statt auf $88 \%$.. Die insektenfressenden Iguaniden weisen eine relative Diinndarmlänge zwischen $114-126 \%$, Dickdarnlänge 28-59\% auf, während die pflanzenfressenden Iguaniaden - außer 
Brachylophus - sich durch außerordentlich langen Duinndarm 180 bis $291 \%$ und Dickdarm 88-143\% auszeichnen. - Der fleischfressende Varanus hat den Dünndarm ungefähr so lang, wie die insektenfressenden Tiere derselben Gestalt. - Bei den Tejiden bat der sarcound carpophage Tupinambis teguixin Dünndarmlänge $95^{\circ} 0$, Dickdarmlänge $86 \%$ (der Autor rechnet diese bedeutende Entwicklung des Dickdarms dem pflanzlichen Anteil der Nahrung zu); der insektenfressende Cnemidophorus sexlineatus $78 \%$ und $36 \%$, der grïßtenteils pflanzenfressende Cnemidophorus murinus $1670^{\circ}$ und $46 \%$. Die insectivore Lacerta muralis weist die Zahlen $91^{\circ}{ }_{0}$ und $31^{\circ}{ }_{0}$, Lacerta riridis $80 \%$ und $25 \%$ auf, während bei der omnivoren Lacerta Galloti $163 \%$ and $42 \%$ gemessen werden. Nach Lönvberg lassen diese Befunde keinen Zweifel ubbrig, daß die Änderung. der Kost diese Erscheinungen zur Folge hat. Die Pflanzenkost muß, um ausgenutzt zu werden, längere Zeit in der Verdanungsröhre aufgehalten werden und dies wird erzielt durch die Verlängerung derselben.

Lönnberg macht auf zweierlei Art der Verdaunng der Pflanzennahrung aufmerksam: einige Tiere verdauen die Pflanzenkost sozusagen anf dieselbe Weise wie das Fleisch, d. h. sie haben in ihrem Verdauungstractus keine spezifischen Adaptationen zur gründlichen Ausnutzung der Pflanzenteile, und sie verdauen daher nicht z. B. die Cellulose. Diese Tiere sind also, obwobl sie sich von Pflanzen ernäbren, vielmehr doch nur »Fleischfresser *, und sie sind eigentlich omnivor (z. B. Cnemidophorus muralis, Lacerta Galloti). Dann ist es vorteilhaft, daß der Inhalt des etwas verlängerten Dünndarms einige Zeit im Colon verweile, damit daraus die Nahrungsstoffe womöglich resorbiert werden künnten: das lange Cöcum ron Tupinambis teguixin mag in Beziehung zu diesen Verhältnissen gebracht werden.

Die eigentlichen Pflanzenfresser besitzen aber spezifische Anpassungen, besonders in der Ansbildung großer Reservoire, in deneu der Darminhalt längere Zeit verweilt und wo mit Hilfe von bakteriellen Fermentationen usw. die Cellulose und andre sonst unverdauliche Stoffe zersetzt und zum großen Teil resorbiert werden. Fir ein solches Laboratorium darf man auch den ungemein weiten Sack halten, welchen bei Uromastix das Cöcum und Colon bilden; rielleicht noch bessere Einrichtungen werden durch die komplizierten ralvularen Dickdarmorgane der pflanzenfressenden Iguaniden dargestellt.

In seiner inhaltsreichen Abhandlung hat LösNBERG versucht, auch spezielle Fälle der morphologischen Struktur der Verdaungsröhre als Anpassungsfolgen zu erklären, so z. B. den verhältnismäßig. 
(im Vergleich mit den verwandten Pflanzenfressern) sehr langen und engen Dickdarm des algenfressenden Iguaniden Amblyrhynchus: nach diesem Forscher handelt es sich hier um die spezielle Anpassung zu der abweichenden Zusammensetzung der Algenkost gegenuiber andern Formen der Pflanzennahrung. Lönnberg ließ $B$ die Cellulosemenge der betreffenden Algen bestimmen und da stellte es sich heraus, da $B$ diese Pflanzen weit besser verdaulich sind als Phanerogamen, indem sie weit weniger Cellulose besitzen. Zudem weicht nach Mörnen diese Cellulose sehr weit von der mechanischen Beschaffenheit der Cellulose der Phanerogamen; in dem Darmkanal entsteht aus den Algen eine dünne Flüssigkeit: es ist also rorteilhaft, wenn diese in dem langen und engen Dickdarm womöglich große Kontaktfläche findet; die Dickdarmoberfläche ist nebstdem durch zahlreiche quere Falten vergrößert.

Der Autor macht auf Grund dieser Beobachtung den Versuch, das Vorkommen sehr langer und enger Verdauungsröhren bei den mit Fischen sich ernährenden Sängetieren und Vögeln - welche als Ausnahmen gegenüber der Regel, daß die Fleischfresser kurze Darmröhren besitzen, gelten - zu erklären: es würde sich um die Anpassung zum dünnflüssigen Darminhalte handeln.

Löxnbergs deskriptive Untersuchungen halte ich für eins der besten Beispiele, wie man anch ohne experimentelle Anordnungen wichtige und brauchbare Erfahrungen über die Beziehung der Nahrung zur Beschaffenheit der Verdauungsröhre gewinnen kann.

Bei den Wirbellosen kann man kaum als Regel aufstellen, daß die pflanzenfressenden Tiere derselben Gruppe längere Verdauungsröhre besitzen als die Fleischfresser. So findet man z. B. die systematische Untersuchung von Werner (15) über die relative Darmlänge bei Orthopteren, wo der Zusammenhang der Darmlänge mit der Nahrung geleugnet wird. Die pflanzenfressenden Acridier haben einen kurzen Darm, der nur in wenigen Fällen die Länge des Tieres selber iiberragt, während die insektenfressenden Locustiden teilweise einen sehr langen und meist schneckenförmig gerollten Darm besitzen (namentlich Barlitistes und Phaneroptera). Der Verfasser wendet sich gegen die gänzlich widersprechende Angabe von LaNG (Lehrb. der vergl. Anat. II. 1889) iuber die Darmlänge der Acridier. - Mit den Locustiden stimmen noch Gryllodeen und Blattiden tiberein, indem ihre Darmlänge ungefähr 2 Körperlängen beträgt. - Doch der pflanzenfressende Gryllus besitzt wiederum einen langen Darm. Der Verfasser sucht demnach eine andre "Erklärung « als durch die Beziehung 
zur Nahrung: lange, schlanke Tiere haben einen wenig gewundenen Darm (Schlangen, Blindschleiche usw.), kurze, gedrungene, einen stark gewundenen, daher auch relativ längeren Darm; die Locustiden und gerade die mit dem längsten Darm versehenen Formen haben eine kurze, gedrungene Körpergestalt. Man ist wohl berechtigt anzunehmen, daß der Darm in seiner morphologischen Ausbildung durch die äußere Form des Körpers beeinflußt werde und nicht umgekehrt.

Über die Verdauungsröhre der Arthropoden finde ich eine $\mathrm{Zu}$ sammenfassung bei v. FürTH (16; : es kommt vielfach, ebenso wie es bei höheren Tieren der Fall ist, bei Pflanzenfressern ein längerer Darm vor als bei Fleischfressern. Nach Brederuany haben die teilweise fleischfressenden Larven der Hydrophilen einen kurzen, geraden Darm, aber der entwickelte Käfer besitzt einen außerordentlich langen, gewundenen Darm. Freilich gibt es auch Raubinsekten, welche ungeachtet der Fleischnahrung einen sehr langen Darm besitzen, während andre, wie die Orthopteren und Raupen, trotz der vegetabilischen Nahrung einen geraden, relativ kurzen Darmkanal haben; in diesem Falle soll eine größere Weite die fehlende Länge ersetzen. Auch weiß man, daß gerade diese Insekten durch ihre Gier sich auszeichnen; durch eine große Menge von Nahrung müssen sie ersetzen, was ihnen durch unvollständige Ausnützung derselben verloren geht.

Nach Sussdorf (17) kann man eine Beziehung zwischen der Entwicklung der einzelnen Darmabschnitte und ihrer physiologischen Funktion aufstellen. Die chemische Verdaunng, d. i. die Lösung und Aufsaugung der Nährstoffe der Pflanzennahrung, vollzieht sich nur zum geringen Teil, die der animalischen Kost dagegen fast ausschließlich im Magen. Beim Fleischfresser hat somit der Dünndarm nur noch einen kleinen Teil der Nährstoffe zu lösen und aufzusaugen, der Dickdarm die Anfgabe der Ausstoßung der hier übrigens sehr spärlichen unverdaulichen Reste (die Excremente der Carnivoren bilden 10\% der festen Bestandteile der Nahrung:; beim Pflanzenfresser fällt die Verdauung der Nährstoffe noch zu einem recht erheblichen Teile dem Darm zu, wobei der Dickdarm nicht nur die Befürderung der äußerst reichen, etwa $40 \%$ Unverdauliches und Lnverdantes der Nahrung enthaltenden Kotmassen äbernimmt, sondern auch zur Stätte des Verdauungsvorganges wird. Hiernach richtet sich seine änßere Gestaltung und innere Geräumigkeit. Je weniger der Dickdarm lüst und anfsaugt, um so kitrzer ist er und umgekehrt; bei ganz ausgesprochenen Fleischfressern, wie dem Löwen und Seehund, erreicht er nur $3 \%$, bei den Pflanzenfressern dagegen $25-40 \%$ und beim 
Hunde $20^{0}{ }_{0}$ der ganzen Darmlänge. - Im weiteren Abschnitt wird uber die ontogenetische Entwicklung der Drehungen und Knickungen der Verdauungsröhre berichtet. -

Die Urteile der deskriptiven Forscher über die Beziehung der Ernährungsweise zur Beschaffenheit der Verdauungsröhre sind oft sehr ungeniigend begründet und zu sehr allgemein und unklar ansgedrïckt. So glaubt Nuns (18) die relativ lange Verdauungsröhre bzw. den Mitteldarm der Vügel und Säugetiere darauf beziehen zu müssen, daß diese Tiere im Vergleich mit den Fischen und Amphibien in derselben Zeit viel mehr Nahrung aufnehmen. Gegenbaur (10) führt die sehr beträchtlichen Verschiedenheiten in der Länge des Mitteldarms bei Vögeln auf die Art der Nahrung zuriick. OpPEL (7) behauptet, daß die Wahl der Nahrung von der Organisation des Speisekanals und des gesamten Körpers überhaupt abhängen muß und die Nahrungsmittel die Art der Organisation nicht bestimmen können. Nach demselben Forscher herrscht keine bestimmtere Gesetzmäßigkeit weder zwischen der Lebensart und der Länge des Darmkanals, noch zwischen seiner Weite und Länge.

Ich will mich gar nicht erschöpfend mit den verschiedenen Angaben und Urteilen der vergleichenden Anatomen über die Beziehung der Verdaungsröhre zur Nahrung beschäftigen. Es gibt hier so wenig tiefer gehender Analyse, sowie systematischer Bearbeitung des Problems, daß es unmöglich ist, allgemeinere Regeln aufzustellen. So werden z. B. unter den Fleischfressern gewöhnlich sämtliche Tiere gemeint, welche sich mit Nahrung tierischer Herkunft ernähren. Doch es herrschen ungeheure Unterschiede in der chemischen Zusammensetzung der tierischen Nahrungsstoffe sowie in der mechanischen Wirkungsweise der Nahrung; z. B. ein insektenfressendes Sängetier erhält eine durchaus verschiedene Nahrung als ein andres, welches vom Säugetierblut lebt oder ganze Fische verschluckt usw. Von sehr vielen Tieren weiß man ïberhaupt nicht genan, wie ihre Nahrung beschaffen ist, trotzdem werden sie oft mit großer Bestimmtheit zu ausschließlichen Pflanzenfressern, oder Fleischfressern gerechnet, oder wiederum für Tiere gehalten, welche gemischte Nahrung aufnehmen, obwohl es dabei nur eine zufällige Beobachtung war, welche über diese Einreihung entschieden hat. -

Über die Grenzen der normalen Variabilität der Verdauungsröhre findet man besonders beim Menschen häufigere Angaben. Der Darmkanal des Menschen wird in Beziehung gebracht mit der gemischten Nahrung: seine relative Länge wird auf 6 Kopf-Ferse-Längen 
(Spigelius nach 7) oder 10 Kopfscheitel-Sitzhöcker-Längen (Hexning) gerechnet, diejenige der Affen auf 6 . Die durchschnittliche Länge des Dünndarms wird ungefähr zwischen 7 und $8 \mathrm{~m}$ angegeben, des Dickdarms 1,2--1,6 m. Nach SAPPey (19) beträgt die Darmlänge bei Weißen von mittlerer Statur 9,6 m, wovon $8,0 \mathrm{~m}$ auf den Diunndarm, 1,6 $\mathrm{m}$ auf den Dickdarm kommen: nach den Lntersuchungen ron Chudzisski an neun Negern betrug die Gesamtlänge durchschnittlich $8,7 \mathrm{~m}$, dabei ergaben sich aber bei den einzelnen Individuen bezüglich der Darmlänge große Schwankungen. Wenn uiberhaupt die Darmlänge durch diejenige des Körpers beeinflußt wird, so kann dieser Einfluß doch nur ein ganz untergeordneter sein (Wiedershems). Jene geringe Gesamtlänge des Negerdarms beruht auf der relativen Kürze des Diirndarms der schwarzen Rasse, denn der Dickdarm soll beim Schwarzen sogar noch etwas länger sein als beim Weißen.

Nach BLOCH (11) soll nichts im Körper größeren Variationen unterliegen als die Lünge des Darmes. Bei einer und derselben Mensehenrasse kommen 100\% Differenzen auf; MEcKel hat bei den Deutschen als extreme Zahlen 5,35 und $10,31 \mathrm{~m}$ gefunden, TareNETZKY bei den Russen 6,0 und $12,07 \mathrm{~m}$. Über die geschlechtlichen Differenzen sind sehr widersprechende Angaben rorhanden. - Die größte Darmlänge (Dünndarm) beim Menschen soll nach KüTTxer $18,19 \mathrm{~m}$ sein; es scheint keine Beziehung zu herrschen weder zur Körperlänge noch zu dem Körpergewichte.

Auch bei den Tieren kommt hohe Variabilität der Darmlänge vor. Crampe hat bei den Tauben als Extremzahlen 0,96 und 1,3 m gefunden; meistens soll sich die Darmlänge zwischen 1,05 und $1,15 \mathrm{~m}$ bewegen. - Die durchschnittliche Darmlänge von 100 verschieden großen Hunden war $8,05 \mathrm{~m}$. -

Endlich gehören in diesen Abschnitt auch einige Angaben über den vermeintlichen direkten EinfluB der Nahrung auf die Entwicklung des Darmkanals, welche aber keine exakte Begründung besitzen.

Darwin (20) erzählt nach Datbenton, daß der Darmkanal der Hauskatzen weiter und um ein Drittel länger ist als bei wilden Katzen derselben Größe: und dies soll offenbar die Folge von ihrer weniger strengen carnivoren Kost sein. Nach BLoch $(11)$ besitzt die wilde Katze einen kürzeren Darmkanal als die Hauskatze, dafür ist aber derselbe wiederum weiter, worin man eine Art von Kompensation* erblicken soll. Nach GurLrs Augaben (7) beträgt die Länge des Darmkanals beim Wolf 4 Körperlängen, beim Haushund 5-6. In einem Nach- 
trag Gegexbacks zur Abhandlung von H. Laxpois (nach 7) wird die Meinung ausgesprochen, daß die größere Länge des Darmkanals bei domestizierten Carnivoren gewiB das Produkt der mehr omnivoren Lebensweise sei. Nach Bıoch (11) hat Cuvier beobachtet, daß der Darmkanal der Hauskatze zweimal so lang war als derjenige der wilden Katze; es soll auch das Wildschwein kürzere Verdauungsröhre besitzen als die domestizierten Tiere; dasselbe wird auch rom wilden Kaninchen und andern wildlebenden Tieren behauptet in bezug anf die domestizierten Tiere. Bei der Besprechung der oben angefuhrten Aussage Darwiss meint Kassowitz (21), daß es in hohem Grade wahrscheinlich ist, daß die Verlängerung des Darmkanals der Hauskatze wenigstens zum Teil durch die mechanische Wirkung der gemischten und daher auch voluminösen Nahrung zustande kommt, obwohl an diesem Unterschiede in der Länge auch schon die Vererbung beteiligt sein könnte; derselbe Autor zitiert Rokitaxskys Befund oberhalb einer Darmstenose, bei welcher neben der Erweiterung der Höhle und der Verdickung der Wandungen mit Einschluß der Muskelschicht anch noch eine Verlängerung der oberhalb der Stenose gelegenen Darmabschnitte bestand.

Die hochgradige Variabilität der Darmkanalläinge selbst beim Menschen wird von BLoch (11) mit der Beschaffenheit der Nahrung. in Zusammenhang gebracht; zum Beleg werden Tarenerzkys Angaben zitiert, daß man bei den Kindern der niedersten Volksschichten in Rußland sehr langen Darmkanal antrifft, bis $5-6 \mathrm{~m}$ bei der Körperlänge unterhalb $52 \mathrm{~cm}$. -

Nebst den Beziehungen der Darmlänge zur Nahrung werden noch andre angeführt; z. B. soll die Dicke der Darmwand bei den fleischfressenden Säugetieren größer sein als bei den pflanzenfressenden (22). Es bestehen auch Unterschiede in der Größenentwicklung der Leber bei den Fleischfressern und Pflanzenfressern usw.

\section{Die bisherigen experimentellen Untersuchungen über die Einwirkung der Nahrung auf die Beschaffenheit der Verdauungsröhre.}

Trotz vielem Nachsuchen finde ich die diesbeziglichen experimentellen Lntersuchungen sehr selten and durtitig.

In der zusammenfassenden SExPERschen Schrift über die Existenzbedingungen der Tiere (23) wird tiber einige ältere Untersuchungen berichtet, welche den Einfluß der Nahrung anf die Struktur des Vogel- 
magens berühren. Es soll Hcxter gelungen sein die innere Magenhaut der Seemöve (Larus tridactylus) durch ein Jahr fortgesetzte Fütterung mit Körnern in die Hornhaut zu rerwandeln, wie sie den Magen der Körnerfresser auszeichnet, wobei auch die Muskelschicht bedeutend verdickt wurde; dies soll nach EDMonstone auch bei einem Raben, nach MÉxÉtriÉs bei einer Eule erzielt worden sein.

Brandes (24) kritisiert diese Fälle und hält sie für nicht beweisend. Er fuibrt weiter Holmakixs Fütterungsrersuche an Tauben an; dieser Forscher fütterte Tauben mit Fibrin oder Fleisch; schon nach 6-8 Tagen wurde die Muskelschicht des Magens dumner und weicher, was HoLsigREx der allgemeinen Abmagerung zurechnet; er glaubt aber, man könnte bei geeigneter Versuchsanordnung den Taubenmagen bedeutend verändern. Sechs Tauben (und zwar völlig ausgewachsene) wurden mehrere Jahre lang nur mit Fleisch ernährt: ibre Krallen und ihr Schnabel haben sich mächtiger entwickelt, die Schnabelspitze wurde nach unten gekrümmt wie bei Raubvögeln. Nach zwei Jahren wurde bei einer von diesen Tauben ein typischer Taubenmagen gefunden, dessen Querdurchmesser etwas kleiner und die Mnskelbäuche etwas diunner waren; diese Veränderung rechnet aber der Autor dem Umstande zit, daß die Magenwand durch einen Glassplitter durchbohrt wurde. Über die andern Tauben liegt keine Nachricht vor.

Brandes selbst hat eine junge Nesttaube isoliert und 7 Monate lang nur mit rohem Fleisch gefüttert, wobei auch keine Möglichkeit derselben geboten wurde, Sand und Steinchen zu verschlucken; das Tier besaß einen typischen Muskelmagen. Doch Braxdes führt an, daB bei den Mastgänsen, die mit sog. Nudeln gefüttert werden, die Muskulatur des gewaltig ausgedehnten Magens schwächer und die Cuticula weicher wird. W. Rocx $(59 \mathrm{c}$ tritt jedoch seiner Deutung, daß in der bezüglichen Änderung des Gänsemagens keine Anpassungserscheinung rorläge, entgegen.

Kassowrtz (21) meint - indem er die Sempersehen Angaben bespricht --, daß die hornartige Innenhaut des Magens der körnerfressenden Vögel wenigstens zum Teil infolge des Druckes der harten Körper entsteht, und daß die muskulösen Elemente deshalb vermehrt und verstärkt werden, weil sie einer stärkeren Dehnung durch den voluminöseren und resistenteren Mageninhalt ausgesetzt sind.

Über das Problem der Beziehung der Darmlänge zur Nahrung wird von BRANDEs behauptet, daß niemand zweifeln wird, daß solche Angaben (über die Verlängerung des Darmkanals der Fleischfresser 
durch Darreichung von pflanzlicher Nahrung) anf unzuverlässige Experimente zuriickzufithren sind. Doch er führt keine solche Experimente an.

Über eine diesbezigliche Untersuchung wird aber in der schon oben zitierten Zusammenstellung der Literatur von BLoci (11) gesprochen. Es kann nach ihm die Art der Nahrung die Länge des Uarmkanals beeinflussen, aber man darf diesen Einfluß nicht überschätzen, denn es gibt sogar von der liegel, daß die Fleischfresser kiirzere Darmröhre besitzen als Pflanzenfresser, auffallende Ansnahmen. Es soll Craure den Einfluß der Nabrung auf die Länge des Darmkanals studiert und gefunden haben, dak es keineswegs »die Natur der Nahrungsstoffe ist, welche auf die Dimensionen der Verdanungsiöhre EinfluB ausübt, sondern ihre Form; beim Tiere, welches große Mengen von Nahrung zu sich nimmt, erweitert sich die Darmröhre; bei demjenigen aber, welches kleine Nahrungsmengen aufnimmt oder eine leicht verdauliche Nahrung, wird der Darmkanal gar nicht veraindert;. Und weiter wird wiederum die Behauptung aufgestellt, daß sich der Einflul' der Nahrung auf die Beschaffenheit des Darmkanals experimentell beweisen läßt: "man hat von zwei jungen Hunden desselben Alters den einen mit Milch, den andern mit Milch, Kartoffeln und Fleisch ernährt; nach zwei Momaten hat man beim ersten die Länge des Dỉnndarms $1,96 \mathrm{~m}$, beim zweiten 2,23 m gemessen «. Wer diese Versuche durchgefiihrt hat, ist in dem Berichte nicht angegeben. - Endlich wird bemerkt, daß auch die pathologischen Zustände (z. B. die Darm- und selbst die Lungentuberknlose) die Darmlänge beeinflussen sollen.

In einer von scinen Pablikationen über die Variabilität der Heischfressenden Hühner gibt Hocssay (25) an, daß der Darmkanal der Tiere der zweiten fleischfressenden Generation im Vergleiche mit dem Gewichte ein wenig verkiirzt wird; ebenfalls der Blinddarm, der Vormagen, Magen und Pancreas werden verkleinert (wogegen die Blutmenge, das Herz und die Leber fast unverändert bleiben, die Nieren, Jungen und Milz etwas anwachsen). Diese Veränderungen sind beim Übergange von der körucrfressenden zur ersten fleischfressenden Generation größer als heim Übergange von dieser zur zweiten Heischfressenden Generation (27).

Weiss (26) hat vier Enten durch 41,2 Momate mit Pferdefleisch, zwei mit Korn und Mais grefüttert. Die fleischfressenden Tiere hatten gröBeres Gewicht, aber waren nicht so stark und lebendig: ihr Gefieder war minder entwickelt nsw. Im Magen und Pancreas wurlen 
histologische Differenzen gefunden; der Darm zeichnete sich durch lange Zotten aus. Die Muskulatur des Vormagens war unverändert, wogegen sie im Magen stark reduziert war. - Um die Erblichkeit dieser Veränderungen studieren zu können, wählte dann dieser Forscher Mäuse zu Fütterungsversuchen; doch dieselben sind ihm bei Pferdefleischfütterung während 2-3 Monate gestorben.

NoÉs Arbeit (28) war mir nicht zugänglich. Über die Experimente von Yuvg, sofern sie dem Objekte und Problem nach mit den meinigen übereinstimmen, wird weiter berichtet. -

Über die Wirkung der Tätigkeit auf die Beschaffenheit der Verdaungsröhre und die Folgen des Hungerns liegen schon ebenfalls einige Erfahrungen vor.

Barfurth $(29,30)$ hat beobachtet, daß der Hunger die letzten Stadien der Verwandlung bei Rana fusca (sowie Rana esculenta und Bufo vulgaris) abkürtt. Da bei der Metamorphose die Kiemen, der Schwanz und die Haut oberhalb der Vorderextremitäten resorbiert werden und der lange Darmkanal stark sich verkiirzt, erklärt BarFurTH die rasche Verwandlung der hungernden Larven durch Beschleunigung dieser Reductionsprozesse. Nun ist es bekannt, daß die Kaulquappen wenig Nahrung zu sich nehmen, nachdem die hinteren Extremitäten einmal vollständig herausgebildet sind; und wäbrend der eigentlichen Metamorphose fressen sie uberhaupt nicht: der Autor hat also in seinen Versuchen den normal vorkommenden Faktor verstärkt. - Ebenfalls Amblystoma und Urodela überhaupt fasten während der Metamorphose, sowie manche Wirbellosen.

YuvG (31) hat systematische Untersuchungen angestellt über die Änderungen der Verdauungsröhre bei Fischen und Amphibien infolge des Hungerns. Mit FuHRMans hat er sichergestellt, daß bei Esox lucius und Lota vulgaris nach 10 oder 12 Monaten die Verdauungsröhre bis um ${ }_{1 / 6}$ ihrer normalen Länge verkürzt wird. Bei Herbstfröschen (und zwar Rana esc.) betrug die relative Darmlänge 3,65 bei den Weibchen, 3,14 bei den Männchen: nach 6 Monaten Fastens sank dieselbe auf 3,02 bzw. 2,77 herab. - Die kleine absolute sowie relative Verkürzung des Darmkanals, welche dieser Forscher während der Ausbildung der hinteren Extremitaiten bemerkt hatte (s. IV. 3. D), bringt derselbe mit der während dieser Zeit stattfindenden verminderten Nahrungsaufnahme in Zusammenhang, und die nachherige, kurze Zeit dauernde kleine Verlängerung der Verdaunngsröhre mit »neu erwachtem Appetit. der Versuchstiere. - Bei womöglich absoluter Inanition hat YuNG gefunden, daß nach 2 Monaten der Darmkanal 
sich von den Wahrscheinlichkeitslängen $116 \mathrm{~mm}$ bei Pflanzenfiessern und 78 bei Fleischfressern auf $68 \mathrm{~mm}$ bzw. $59 \mathrm{~mm}$ verkürzt hatte: *es handelt sich hier offenbar um die Folgen der Inaktivität Die aus unbekannten Griinden hungernden Kaulquappen, wie sie hier und da angetroffen werden, zeigen ebenfalls eine auffallend kurze Darmröhre (nach I Lxas und meinen Messungen). - Bei diesen Hungerversuchen ist allerdings die Inaktivitätsatrophie der Verdauungsröhre mit den Folgen der allgemeinen Inanition verquickt.

\section{Eigne Versuche.}

\section{Die Wahl der Versuchstiere.}

Die Untersuchungen uiber die Veränderlichkeit der Verdauungsröhre durch die Nahrung erfordern, daß man die Möglichkeit habe, bei den womöglich weitgehendsten Unterschieden in der mechanischen und chemischen Beschaffenheit der Nahrung die Ernährung der Tiere immer ausreichend zu haben. Denn ohne die geniugende Menge der ausnützbaren Nabrungsstoffe kann man kaum hoffen normale Ergebnisse zu erhalten.

Die Ausnutzbarkeit der Nahrung aber ist hochgradig von der biologischen Beschafienheit der Verdauungsorgane abhängig: ich meine hier die schon angeborene Angepaßtheit des Verdauungsapparates zur gewissen Art der Nahrung, wie dieselbe durch die morphologische Struktur und physiologische Verdauungstätigkeit bedingt ist. Es sind manche Tiere von Haus aus ungeeignet sehr hochgradige Unterschiede in der Zusammensetzung der Nahrung ohne Schaden zu vertragen. So ist z. B. ein typischer Pflanzenfresser kaum mit Fleischnahrung, ein typischer Fleischfresser kaum mit Pflanzennahrung normal zu ernähren. Ich erinnere nur an einige Beispiele. Als Weiss (26) is versucht hatte die Mänse mit Pferdefleisch zu ernähren, sind ihm seine Tiere in kurzer Zeit ausgestorben. Houssay (27) beobachtete, daB die dritte fleischfressende Generation der Hühner gegenuber der zweiten kleiner wird und daß besonders die Anzahl der entwicklungsfähigen Eier ungemein herabsinkt: und es handelt sich doch in diesem Falle um Tiere, welche nicht strenge Pflanzenfresser sind. Pagis (33) beschrieb einen Bock, welcher die Herde auf den Schlachtplatz zu fuihren pflegt: ein solches Tier, mignard genannt, lebt frei und gewöhnt sich oft Blut der geschlachteten Genossen und andrer Tiere zu trinken und selbst Fleisch zu fressen, wobei er die gewöhuliche Nahrung abweist. Der erwähnte Bock hat allmählich nicht nur das 
trockene, sondern auch das grüne Pflanzenfutter abgewiesen und nährte sich hauptsiichlich von dem intrathoracalen Fett der Kälber, zarten Rindfleisch und Blut. Er sah immer elender aus und wurde endlich geschlachtet; die Verdaungsröhre sah normal aus; aber die Leber war ungemein vergrößert und enthielt viel Fett, ebenfalls die Muskeln waren sehr fett; der Antor ist der Neinung, dall das Tier nicht imstande war sich der Fleichnahrung zu adaptieren und besonders die großen Mengen von liett zu assimilieren (d. h. in das arteigne Fett zu verwandeln) ${ }^{1}{ }$.

Die löchste Wahrscheinlichkeit für die normale Ernährung mit der versehiedenartigsten Nahrung bieten die Omnivoren dar. Die Zusammensetzung ihrer Nahrung variiert sehon in den normalen Verhältnissen in sehr weiten Grenzen, so daß sie vielleicht schon in der Natur manchmal lïngere Zeit iiberwiegend von Pflanzenteilen, andermal von tierischen Nahrungsstoffen zu leben pflegen. Nährt man die omnivoren Tiere mit kiunstlicher Nahrung und zwar einmal aussehließlich mit Pflanzennahrung, andermal ausschließlich mit Fleischnahrung, so ändert man eigentlich nur die quantitativen Verhältnisse der ïblichen gemischten Nahrung.

Diesem Umstande, daß ich nämlich die omniroren Froschlarven zu meinen Fütterungsversuchen benuitzt hatte, glaube ich

1) Nach W. L. Distant (34) bestehen zahlreiche Ausnahmen von der Regel, daß die Pflanzenfresser aussehließlich von Pflanzennahrung, und Fleisehfresser von tierischer Nahrung leben. Bonvalot sah in Tibet l'ferde, welche sich vom rohen Fleisch ernährten. Die kleinen Pferderassen der Shetlandinseln fressen sehr begierig Fische; nachdem 180 Stick von ihnen nach den Vereinigten Staateu uiberfuhrt worden waren, lebten sie die erste Zeit frei am Meeresufer und man sah sie da sehr oft nebst Salzpflanzen die Fische fressen; allmählich konnte man sie auf gewönliche l'flanzen und auf Korn gewöhneu. aber sie behielten die Begierde nach Fischkost und selbst ihre Nachkommen nahmen mit großem Behagen den dargebotenen Fisch anf. - Auf Kantschatka sollen nicht nur Menschen, sondern fast siintliche 'Tiere besonders im Winter nur von Fischen lebeu. In Winter 1894/5 sollten sich nach DisTANT die Hirsche mit Kaninchen ernährt haben. - Der pflanzenfressende Affe von Siidafrika. Sclectma, soll in verschiedenen Gegenden Lämmer morden und die in ihrem Magen vorhandene Milch trinken. Eine Umwandlung des pflanzeufressenden Payageis ron Neuseeland. Vestor notabilis, in ein gefahrliches Raubtier wurde, wie bekannt, etwa in den siebziger Jahren des 19. Jahrhunderts beobachtet. - Und umgekehrt: die Hyïne soll sich in Ägypten auch von Mais ernähren und dadurch oft großen Schaden anrichten; ähnliches wird von manchen fleischfressenden Vögeln 'z. B. Spreo bicolor; angegeben. Distant fiihrt auch bei Amphibien cin Beispiel an: einige junge Exemplare von Salamandra maculatı wurden in einem Aquarium iiber ein Jahr vergessen und lebten whimend dieser Zeit ron Algen. 
auch die Erfolge meiner Untersnchungen hauptsächlich zuschreiben zu müssen.

Man hat früher die Froschlarven allgemein fuir phytophag gehalten. Dem gegenüber wird angeführt (35), daß der Darminhalt der Frosehlarven von Rana esculenta, Bombinator igneus, Pelobatrs fuscus, IIyla u. a. aus Schlammerde besteht, wo viele Infusorien, Rädertierchen, Daphniden, und auch Diatomaceen sich befinden: es werden die Froschlarven für zoophag erklïrt. Nach dem, was weiter nach meinen Beobachtungen angefiilht werden wird, kann man die Kaulquappen von Rara fusca, esculenta usw. als omnivor bezeichnen: denn sie nehmen beiderlei Nahrung zu sich, falls sie die stetige Gelegenheit dazu haben, und gedeihen vielleicht bei dieser gemischten Nahrung am besten.

Tach den älteren Versuchen Ycngs $(36,37)$ sind die mit Pflanzennahrung (Anacharis und Spirogyra) gefuitterten Kaulquappen nur in der ersten Zeit gewachsen; später aber hörten sie auf zu fressen, ihre Sterblichkeit wurde immer großer, die Entwicklung wurde sistiert und die letzte Larve ist nach 3 Monaten gestorben, nur so grob und entwickelt wie sie am Ende des ersten Monats war. -- Doch auch die mit gewisser tierischen Nahrung gefütterten Gruppen, nämlich die mit Eihüllen und flïssigem Hïhnereiereiweiß ernährten gelangten nicht zur Metamorphose. Die mit Rindfleisch und nach ihnen die mit Fischfleisch gefütterte Gruppe gediehen am besten; in der Mitte blieben zwei Gruppen, von denen die eine mit coaguliertem Hühnereiereiweiß, die andre mit Hiihnereierdotter sich nährte.

Dem gegenüber gibt Bonv (nach 36) an, daß man die Kaulquappen von Rana fusca in gewisser Anzahl bis zur Metamorphose auch bei reiner Pflanzenkost erziehen kann, was ich vollständig bestätige. In dem nächsten Abschnitt wird über meine Pflanzenfütterungseinrichtung berichtet; ich glaube Yungs Einwendung gegen BorN bei meinen Versuchen beseitigt zu haben (nämlich, daß Bonss Versuchstiere doch nur keine ausschließliche Pflanzenkost besaßen). -

Der zweite Punkt, welcher bei den Untersuchungen über die Einwirkung der Nahrung auf die Beschaffenheit des Darmkanals zu berücksichtigen ist, betrifft die Zeit, durch welche die verschiedenartige Nahrung auf die Verdaungssöhre einwirkt. In meinen Versuchen wurden die Tiere während ibres ganzen Lebens mit den einzelnen Nabrungsarten ernährt; nur ausnahmsweise wurde mit der künstlichen Ernährung erst bei schon etwas ausgewachsenen Tieren angefangen, oder die Ernährung wurde verändert, um die nachherige Einwirkung auf die Verdaungsröhre zu bestimmen. 
Im ganzen kann ich mit voliem Rechte meine Untersuchungen für normal bezeichnen, d. h. es wurden durch die kiunstlichen Ernährungsbedingungen gewöhnlich keine Störungen des Allgemeinbefindens der Tiere und keine pathologischen Erscheinungen hervorgerufen. Über einige Ausnahmen (besonders bei der Fütterung mit Präparaten von pflanzlichen und tierischen Eiweißkörpern, mit Pferdefleisch usw.) wird weiter berichtet.

2. Die Züchtung der Froschlarven, ihre Fütterung, Messung usw.

Zu den Fütterungsversuchen dienten mir in der ersten Reihe Kaulquappen von Rana fusca Rösel (Rana temporaria aut.), dann diejenigen von Rana arvalis Nilsson (R. temporaria Linné); einige Versnche wurden auch mit Larven von Rana esculenta und Pelobates fuscus gemacht.

Die Laichklumpen wurden in seichtem Wasser auf großen Porzellan- oder gläsernen Schüsseln mit dem ausgepreßten Inhalt der aufgeschnittenen Hoden in Berührung gebracht. Besonders in der Mitte der Laichzeit hat sich die Mehrzahl der Eier entwickelt, während die zuerst gelegten Laichklumpen zuwcilen, diejenigen rom Ende der Laichperiode regelmäßig ungünstigere Befruchtungs- und Entwicklungsbedingungen zeigten; aus den letzten Laichklumpen habe ich anch weit zahlreichere Mißbildungen erhalten, als aus den übrigen.

Nachdem die Entwicklnng der Embryonen in den Eihüllen fortgeschritten war, ersehienen an den sich nicht entwickelnden Eiern sowie an den abgestorbenen ersten Entwicklungsstadien Symptome von Zersetzung; es wurden daher diese abgestorbenen Teile unter kräftigem Wasserstrom vorsichtig entfernt, wobei es gewöhnlich zugleich gelang, die jungen Larven aus den verdiunten Eihüllen ohne Schädigung zu befreien. Dann wurden sämtliche Hüllenreste sowie tote, verwundete oder auffällig abnorm sich entwickelnde Tiere entfernt und die Versuchstiere in reinem, stehendem, seichtem Wasser zunächst ohne jede Nahrung gehalten.

Nachdem die äußeren Kiemenbüschel verschwunden waren, sah man die hungernden Tiere lebhaft die Nahrung suchen; falls in dem Gefäße ein abgestorbenes Tier oder ein Fetzen von Eihiillen sich befand, begannen sie daran zu nagen. Erst in dieser Zeit in der Regel wurde mit der künstlichen Fütterung begonnen. Wurde den hungernden Tieren ein Stück von fein zerriebenem Froschfleisch ins Aquarium geworfen, so ließ sich zuerst ganz regelmäßig eine repulsive Ein- 
wirkung beobachten: wenu die Larven damit in Beriihrung kameu oder sogar wenn sie sich dazu nur näherten, so liefen sie rasch davon; aber allmählich verschwand diese abstoßende Einwirkung; sie zeigte sich bei frisch rorgelegter Nahrung zwar auch bei ailteren Larven, doch sie danerte lier nur wenige Sekunden: dann wurde der Fleischklumpen von den allerseits zusammenlaufenden so dicht besetzt, daß man ihn iiberhaupt nicht sehen komnte, und der von radiür abstehenden schwänzen wimmelnde Klumpen wurde am Boden des Aquariums hinund hergerollt. Ïhnliche FreBlust zeigten übrigens auch die mit künstlichem Nahrungsgemisch ernährten Tiere: wurde z. B. in das Gefïß der mit Pflanzenproteinsubstanz gefütterten Larven ein Stück des mit ein wenig Wasser und kleinem Stiickehen Froschfleisch · (oft auch ohne die Fleischzngabe!) gemachten Teiges geworfen, so versammelte sich in der Kürze die Mehrzahl der Zöglinge ringsum, ebenso um den Celluloseballen, auch wenn nachher das ibliche Stuickchen Fleisch darin nicht enthalten war usw. Diese Freßlust macht die Froschlarcen zu unvergleichlich geeigneten Versuchstieren.

Zur Fütterung wurde womöglich frisches Fleisch benützt; handelte es sich um Fütterung mit Frosch-, Fisch-, Krebs- oder Muschelfleisch, so wurden die betreffenden Tiere getötet, die lebenden Muskeln fein zerrieben und den Froschlarven nur in solcher Menge dargereicht, welche für den ganzen Tag (höchstens auch über die Nacht auf den zweiten Tag) genïgen konnte; gewöhnlich fand man am Morgen des zweiten Tages nur unbedeutende Reste der Nahrung am Boden der Gefäße. Das Pferdefleisch wurde womöglich frisch gekauft; es läßt sich nicht bestimmen, ob die störenden Folgen der Pferdefleischfütterung, welche weiter besprochen werden, davon herrührten, daß das Fleisch doch nur nicht immer vollständig frisch war, oder ob dem Pferdefleisch überhaupt - bei seiner ausschließlichen Verwendung - eine toxische Einwirkung zukommt für diese Auffassung würden Angaben verschiedener Autoren zeugen, z. B. PFL̈̈GER).

Die Fütterung mit reinem zerriebenem Froschfleisch wird in meinen sämtlichen Versuchsreihen zum Ausgangspunkt gemacht: die mit Froschfleisch ernährten Versuchstiere sind Kontrolltiere, Zeugen. Mit ihnen werden die mit Fisch-, Krebs-, Muschel-, Pferdefleisch gefutterten verglichen, sowie die mit Pflanzenteilen und Pflanzenproteinsubstanz ernährten: bei den analytischen Experimenten, wo die Finwirkung von Glaspulver, Cellulose, Keratin, Pflanzenproteinsubstanz usw. anf die Verdaunngsröhre untersucht wurde, habe 
ich diesen Stoffen ein Stiickchen Froschfleisch leigemengt, um in dieser Form das nötige Minimum von Eiweikkörpern (oder wenigstens von Salzen: bei der Fitterung mit Pflanzenproteinprïparaten\} $z u$ sichern. Indem ich damn diese Tiere mit den ausschließlich mit Froschfleisch ernährten Tieren vergleiche, besitze ich die Möglichkeit den Einfluß der Beimengungen zu bestimmen. Über die nühere Einrichtung dieser Fitterungsversuche (die Menge der künstlichen Ciemische usw.) wird an den zugehörigen Stellen berichtet.

Ls wird empfohlen, die Versuchstiere zuweilen einige Stunden oder den ganzen Tag hungern zu lassen, womach die Tiere mit grober Begier die frisch dargebotene Kost verzehren. -

Bei der Pflanzenfitterung habe ich reingewaschene Stucke von Stellarit medin verwendet, welebe jederzeit leicht frisch zu bekommen ist und sehr gut von den Froschlarven, besonders wenn dieselben etwas ausgewachsener sind, verzehrt wird; nicht nur die Bläter und jungen Köpfe, sondern auch die Stengel werden abgenagt. In den Aquarien kann es kaum zu störender Entwicklung von mikroskopischer Fauna kommen, da das Wasser gerwöhnlich tïglich erneut, die Wände der Gefäße gereinigt und die Nahrung frisch vorgelegt wurde. Die ganz jungen Kaulquappen sind allerdings mit schwachem Hornzäbnchenapparat ansgeriustet, so daß ihnen die verhältnism:ißig harten T'eile der bentitzten Futterpflanze viele Schwierigkeiten bereiten: sie können sich in der ersten Zeit nicht genug Nahrung abnagen und sehen deswegen dürftig aus. Nach einiger Zeit aber gedeiben anch sie sebr gut.

Die mit gemischter Kost gefütterten 'Tiere batten nicht nur täglich frisches Fleisch zur Verfügnng, sowie die Ptlanzenteile von Slellarin media, sondern sie nïhrten sich auch von den Algen und mikroskopischen Tieren, welche an den Gefüßänden and an den Pflanzenteilen üppig gediehen; diese Aquarien wurden nur selten gereinigt. Die Versuchstiere nahmen beiderlei Nahrung zu sich, wogegen die an ansschließliche Fleischkost gewöhnten Tiere die ihnen dargebotene Pflanzenkost verschmiilten und oft tagelaug nnangetastet lieken: endlich aber fingen sie auch davon zu essen an. Die ausschließlich mit Pflanzenteilen gefütterten Larven aber versammeln sich bald um ein in ihr Aquarium geworfenes Stiick Fleisch. Ans diesen Beobachtungen ist also zu sehen, daß den Froschlarven doch nur die tierische Nahrung besser »mundet", obzwar sie, wenn reichliche Fleischkost vorliegt, die Pflanzenkost mitfressen. -

Die Excremente wurden womöglich zweimal täglich entfernt; es diente dazu eine Heberohrvorrichtung mit ausgiebigem Zug, wobei 
es allerdings viele Mühe gab, die in allen Richtungen umherwimmelnden Tiere von der Miundung der Rïhre fernzuhalten. Nebstdem wurden die Gefäße nach einigen Tagen immer rein ausgewaschen. -

Auf die geschilderte Weise gelang es mir durchwegs die Gleichartigkeit der Nahrung zu wahren. Dies habe ich bei den pflanzenund fleischfressenden Tieren selbst mikroskopisch feststellen können: auf den Serienschnitten von Fleischfressern konnte ich im Darminhalt nur selr selten eine Diatomee oder Bruchstiicke von Algenfaden antreffen; und bei den Pflanzenfressern fand ich nur ausnahmsweise Reste von Tieren. Die einigemal gefundenen Stiickchen von quergestreiften Muskelfasern rïhrten von den gewöhnlich nachts gestorbenen und verzehrten Genossen her; am Tage wurde jedes verwundete oder kranke oder gestorbene Tier nicht nur bei den Pflanzenfresseru, sondern iiberhaupt in sämtlichen Aquarien sorgfiiltig entfernt; dies ist im ganzen leicht durchzufiihren, weil sich um das sterbende Tier bald Anhäufungen der Genossen zeigen, wie um die Nahrungsballen. Übrigens gewann ich bald solche Gewandtheit, daß mir selbst unter hundert Tieren beim kurzen Überlblick sogleich sellst kleine abnorme Erscheinungen auffielen.

Die Beseitigung der sterbenden oder kranken, verwundeten) Tiere ist auch bei den mit Froschfleisch ernährten Kaulqualpen dringend nötig, denn ich halte es für möglich, daf durch wiederholte Verzehrung der sterbenden Genossen in den betreffenden Aquarien die Entwicklung von Kannibalismus gefördert werden könnte. Selbst bei fleißiger Durchmusterung der Gefäße und Entfernung aller beschïdigten Individuen habe ich in einigen Fällen beobachtet, daß sich die Tiere oft gegenseitig überfielen; oft ließ sich hier an dem überfallenen Individuum kein Zeichen von Verwundung oder Krankheit wahrnehmen. Zwei von solchen Aquarien - die glücklicherweise nicht zu den Ernährungsversuchen gedient haben - sind mir durch den stets in ihnen herrschenden Kannibalismus sogar ausgestorben.

Auch bei unbedeutender Verwundung, z. B. der Schwanzspitze, wird die Froschlarve von den übrigen fortwährend gejagt, die Wunde wird abgenagt und selbst der ganze Schwanz gefressen; mehrmals habe ich solche schwanzlose lebende Körper einige Tage am Boden einiger Aquarien beobachtet, wo sie sich weiter ernährten, aber gewöhnlich stirbt ein solches Tier in kurzer Zeit. - Die sterbenden, nnverwundeten Tiere, sowie die toten werden von allen Seiten überfallen. Da auch die kranken Tiere verzehrt werden, muß man in dieser Hinsicht sehr sorgfältig sein; trotzdem habe ich einige traurige 
Epidemien gesehen, wo mir in einigen Stunden oder Tagen die bisher üppig gedeilhenden Aquarien ausgestorben sind; einigemal gelang es durch ausdauernde Bemühungen die Krankheit einzuschränken, doch die kleinen Reste der großen Kolonien führten ganze Wochen kümmerliches Dasein, ehe sie sich erholten. Durch diese plützlichen verheerenden Epidemien wurde ich in den letzten zwei Jahren gezwungen, jede Versuchsreihe wenigstens zweimal anzustellen; ohne diese Maßregeln wäre ich wiederholt gezwungen worden, die Wiederholung der Versuche auf das künftige Jahr zu versehieben.

In den ersten Jahren erzog ich die Versuchstiere im stehenden Wasser. Durch die erwähnten Epidemien überrascht glaubte ich dieser Gefahr durch fließendes Wasser vorbeugen zu können. Aber trotzdem wurde ich keineswegs von schweren Verlusten verschont. Ende des letzten Jahres benutzte ich filtriertes Leitungswasser (durch Berkfeldsche Filter), wodureh der Gesundheitszustand der Versuchstiere vielleicht verbessert wurde.

Im ganzen gedeihen die Froschlarven doch nur besser in stehendem Wasser oder in solchem, welches nur sehr langsam ausgetauscht wird. Ich habe gewisse Versuchsanordnungen besonders in dieser Richtung getroffen.

Lim das Wasser nur ganz allmählich und konstant auszutauschen, habe ich mir in den letzten Versuchsreihen folgende Einrichtung hergestellt: in einem großen Centralgefäße, welches nur als Reservoir dient, wird durch starken Strom fortwährende Leitungswassercirculation erhalten; ringsum stehen die kleineren Versuchsaquarien, von denen jedes selbständig aus dem Reservoir Wasser schöpft und dasselbe selbständig tropfenweise in den Abführtrogen abgibt. Die Wasserzuführung geschieht autonatisch durch $n$-förmige Heberöhren, deren beide Enden aufwärts umgebogen sind; je nachdem, wie weit nach oben die umgebogenen Euden reichen, oder wie lange metallene Aufsatzröhren daran aufgesteckt werden, kann man bei konstantem Nivean im centralen Gefäße die Wasserzufuhr in jedes Aquarium regulieren; die Heberöhren fließen niemals aus; wenn durch ein ebenso beschaffenes großes Heberohr die Wasserhöhe im Reservoir konstant erhalten bleibt, kann man den ganzen Tag in sämtlichen Versuchsaquarien allmählichen Wasseraustausch unterhalten, denn durch ebensolche Heberöhren wird aus denselben ebensoviel Wasser abgefuhrt, als aus dem Reservoir ihnen zufließt. Auf den in die Versuchsaquarien hineinragenden Enden der Abführheberöhren werden aus Drahtnetz verfertigte kappenartige Aufsütze angebracht, welche 
zwar kleinere Partikel (der Excremente, der Nahrung) durchlassen, aber den Versuchstieren den Weg sperren. Diese Aufsätze sind leicht zu reinigen und in Menge vorrätig. -

Bei den Füterungsversuchen müssen sämtliche Aquarien, deren Versuchstiere man bei verschiedenartiger Fütterung miteinander vergleichen will, unter gleichen übrigen Bedingungen stehen: also der Wasseraustausch, die Umgebungstemperatur usw. muissen womöglich gleich sein. Da auch der Gefäßumfang von großer Bedeutung für die Größenentwicklung der Tiere ist, worüber ich ebenfalls besondere Untersuchungen angestellt habe, ist es erwünscht, die Versuchs- und Kontrolltiere derselben Reihe in gleich großen Aquarien, und womöglich auch in gleicher Anzahl zu züchten.

Um die Resultate der Untersuchungen womöglich unabhängig von etwaiger zufälliger Disposition der Nachkommenschaft eines und desselben Froschpaares zu machen, sowie um die Ergebnisse überhaupt zu befestigen und mich - wie schon früher angeführt wurde - vor den drohenden Epidemien zu sichern, wiederholte ich denselben Fütterungsversuch wenigstens noch einmal an Froschlarven einer andern Herkunft.

Die Anzahl der Tiere, welche aus den Eiern eines und desselben Frosches großwachsen, ist manchmal sehr beschränkt; demzufolge konnte ich oft die jungen Kaulquappen nur in zwei Abteilungen einteilen, von denen die eine als Kontrollabteilung diente, während die andre mit der Nahrung gefüttert wurde, deren Einwirkung ich feststellen wollte. Diese Versuchsanordnung leidet allerdings an dem Übel, daß man dann sehr zahlreiche Kontrollaquarien besitzt und daß man sehr viele Kontrollmessungen ausführen muß; dies ist eine erschöpfende Arbeit, besonders in der Zeit, wo die Metamorphose sämtlicher Tiere sich nähert.

Das Hauptgewicht meiner Versuchsanordnung liegt im großen statistischen Materiale. In den Versuchsreihen, wo es sich besonders darum handelte, womöglich zahlreiche Individuen in jeder von mehreren Abteilungen zu besitzen, und wo es fast unmöglich war, zu jedem Versuchsaquarium ein besonderes Kontrollaquarium einzurichten, vermischte ich Larven von drei oder mehreren Fröschen und verteilte sie dann in die erforderliche Anzahl der Abteilungen: es existierte also nur ein einziges Kontrollaquarium für mehrere Versuchsaquarien. Die statistische Bearbeitung des Materials verschiedener Herkunft verleiht den Ergebnissen, falls sie gleichsinnig sind, eine entscheidende Bedeutung. - 
Die auffälligsten Änderungen, welche durch verschiedenartige Nahrung im Vergleich mit den Koutrolltieren hervorgebracht werden, bestehen in der Entwicklung des Darmkanals in die Lïnge und in die Weite. Man nulb aber gleichzeitig die Correlationsbeziehungen zwischen der Entwicklung der Verdauungsrühre und der Körpergröße beachten, sowie die Beziehung der Verdaungssöhre zu den einzelnen Hauptstadien der allgemeinen Entwicklung.

Die diesbezuiglichen Messungen wurden fast sämtlich - einige der ersten Versuchsreihen ausgenommen - an lebenden Tieren vorgenommen. Die konservierten Tiere bereiten besonders bei der Messung der Darmlänge sehr große Schwierigkeiten, indem der dünnwandige Darmknäuel, welchen man behufs der Messung auscinanderrollen muß, sehr leicht anch bei der größten Schonung reißt. (Die Einwände, welche man gegen die Messungen des konservierten Materials machen künnte rom Standpunkte der störenden Einwirkung der Konservationsfliissigkeit, sind dagegen ohne Bedeutung: die $4^{0}, 0$ ige Formaldehydlïsung ruft keine hochgradige Schrumpfung usw. der Tiere hervor und besonders keine Störung der morphologisehen Verbältnisse bei verschiedenen Versuchstieren, demzufolge stimmen auch die Ergebnisse der Messumgen des konservierten Materials im ganzen mit jenen ïberein, welche am lebenden Material gewonnen wurden.)

Die zu messenden Tiere, wurden g’ewöhnlich zu drei oder vier auf eine Weile (2-4 Minuten) in $4^{\circ}$ ige Formaldehydlösung gegeben, wonach ich sie in physiologische Kochsalzlösung iiberführte. Die Tiere zeigen dann in der Regel keine (wenigstens keine störenden) Bewegungen. Dann wurden sie nacheinander in einem mit Paraftinboden versehenen und mit Kochsalzlösung gefüllten Porzellanschüsselchen gemessen. Eine Nadel wurde dem in der Rückenlage befindlichen Tiere dureh die Mundöffnung und durch den Schädel gesteckt und im Paraffinboden befestigt. Mit einem Zirkel wurde dann 1) die ganze Lünge des Tieres vom vorderen Kopfrande bis zur Schwanzspitze gemessen; 2) die »Körperlänge « rom vorderen Kopfrande zur Afteröffunng; da aber die Afteröffinung in den späteren Entwicklungsstadien sich proximalwärts verschiebt, wählte ich in den späteren Untersuchungen, wo ailtere Tiere gemessen wurden, einen, wie es scheint, festeren Punkt: die "Körperlïnge" bedeutet hier die Entfernung des vorderen Kopfrandes von dem Punkte, wo sich die Medianlinie mit der die Mittelpunkte der Insertionen beider hinteren Extremitäten verbindenden Linie schneidet; 3) die Länge der Extremitätenstummel oder hei den älteren Tieren auch die Längen der 
einzelnen Extremitätenabschnitte. Dies $\mathrm{Ma} \beta$ gibt uns in Verbindung mit dem 2) (Körperlänge) den Aufschluß ther die Entwicklungsstufe des betreffenden Tieres, allerdings nur annähernd: bei einem verlältnismäßig kurzen Körper bedeuten die verhältnismäßig groß ausgewachsenen Extremitätenglieder, daß das Tier sich der Metamorphose nühert usw. Bei gewisser Einuibung ist es leicht, Tiere derselben Größie und annähernd desselben Entwicklungsstadiums auszusuchen. Es bereitet auch keine Schwierigkeit, schon äußerlich ein im Beginn der Metamorphose befindliches Tier zu erkennen inicht nur die vollständig entwickelten und bei der Lokomotion tätigen hinteren Extremitäten sind hier von Bedeutung, sondern besonders die Lmmodellierung des Kopfes und die Veränderungen der Bauchgegend; endlich auch die vorderen Extremitäten, welche die Kiemenhaut anzuspannen heginnen).

Durch einen Schnitt wurde dann die Bauchwand von unten bis in die Kiemengegend aufgeschnitten und die beiden Lappen derselben mittels zwei Nadeln rechts und links im l'araffinboden befestigt und so der Darmknäuel eutblößt. Was Herz zeigte oft noch schwache Bewegungen. Nun wurde mit zwei feinen Nadeln der Darmknäuel entrollt, aus der Leibeshöhle hinausgezogen und an geeigneten Stellen durch drei oder vier Nadeln im entrollten Zustande locker aufgehalten. Die Auseinanderrollung der Verdauungsröhre geschieht ohne jede Gewalt und ohne zu reißen (wenn die Tiere aber mehr als 5 Minuten in Formaldehydlösung verbleiben, so werlen die Darmwände brüchig). Man darf die befestigenden Nadeln gar nicht in die Verdauungsröhre einstecken, sonst wird sie leicht durchgetrennt; man darf auch gar nicht die entrollte Darmröhre spannen, denn es läßt sich nicht erwarten, daß man die Spannung bei verschiedenen Tieren gleich macht, und anderseits droht die Gefahr, daß die zarte Darmröhre reißen wird, wodurch die Messung mehr Zeit erfordert und unsicherer wird. Es genigt, nur so weit den Zug auszuuiben, daß die nachgiebige Verdauungsröhre ungefăhr ein Dreieck oder Viereck darstellt, in dessen Winkeln die Nadeh im Paraffinboden eingesteckt sind. Proximal verbleibt der aus der Leibeshöhle entfernte Darmkanal in Verbindung nit dem Munddarm, und der Enddarm wird ebenfalls in Verbindung mit der Afteröflnung belassen. Dies crleichtert die Durchfiuhrung der Messung, und nebstdem kann dann das ganze Tier für kiunftige Bearbeitung konserviert werden. - Es kann nun leicht mittels eines Zirkels die ganze Darmlänge rom Rachen bis zur Aftergegend gemessen werden; es stellte sich mir als besonders vorteilhat heraus, einen 
gewissen Abstand der Zirkelspitzen (z. B. $3 \mathrm{~mm}$ ) auf die Verdaunngsröhre einzntragen und so auch die kleinen Krimmungen in Rechnung zu nehmen. Bald gewann ich eine solche Übung, daß die Resultate ganz verlässig waren, wie ich mich durch Kontrollversuche überzengt habe: die Ergebnisse der wiederholten Messungen differierten um $1-2{ }^{\circ} 0$, was bei der statistischen Bearbeitung gar keine Bedeutung hat. - Einige Vorsicht erfordert die Messung der Verdauungsröhre dort, wo dieselbe zwei Umbiegungen an der Leber macht; man muß hier mittels einer Nadel die Leber in die nötigen Stellungen geben, damit die Verdauungsröhre zugänglich werde.

Die angeführten Messungen eines Tieres erforderten nach der Einuibung etwa 3--4 Minuten.

An einem Bruchteile des konservierten Materials wiederholte ich später die Messungen, welche soeben geschildert wurden, und nebstdem unternahm ich auch die Durchmesserbestimmungen. Zu diesem Zweck wurde der aus dem Körper vollständig herausgenommene Darmkanal in kleine Stiicke geteilt, von denen jedes womöglich gleichen Durchmesser an beiden Enden besaß; je nachdem der Durchmesser der Verdaungsröhre sich in den verschiedenen Abteilungen stark änderte oder gleichmäßig aussah, betrug die Länge derselben etwa 2-15 $\mathrm{mm}$. Nachdem einzeln ihre Längen bestimmt wurden, schätzte ich dann die Durchmesser der beiden Enden ab, entweder mittels eines Mikrometers, oder, was rascher durchzuführen ist, mittels einer Skala von Drahtstuickchen bestimmter Dicke. Aus Drähten von 0,2-1,3 mm Durchmesser verfertigte ich mir diese Skala so, daß ich dieselben in einen prismatischen Paraffinblock einschmolz, und zwar so, daß die äußeren Enden eine Reihe parallel und horizontal liegender Stäbchen bildete. Diese Meßvorrichtung war in der Kochsalzlösung untergetaucht: unter dem Präparationsmikroskop näherte ich dann die Stückchen der Verdauungsröhre zu den einzelnen Drïhten, und so konnte ich den Durchmesser auf $0,02-0,03 \mathrm{~mm}$ gut abschïtzen. Dabei habe ich allerdings von der sich ändernden Darmwanddicke abgesehen; ein jedes Stiuck der Darmröhre betrachtete ich als cylindrische Röhre, was man ohne großen Fehler tun darf, falls man einen durchschnittlichen Durchmesser einrechnet. Indem dann die Oberflächen sowie Inhalte der einzelnen Darmstuicke zusammengerechnet wurden, erhielt ich annähernd die ganze Oberfläche und den Darmkanalinhalt; daraus läßt sich leicht der durchschnittliche Durchmesser berechnen. Bei der statistischen Anlage der Versuche sind auch diese Maße sehr gut verwendbar. 
Um mich über die etwaigen histologischen und cytologischen Abweichungen der Verdaungssröhre sowie der zugehörigen Drüsenorgane usw. bei verschiedenartiger Ernährung zu orientieren, verfertigte ich von einer Anzahl von Tieren jeder Hauptabteilung Serienschnitte; solche wurden auch aus einzelnen Hauptabschnitten der herausgenommenen Verdauungsröhre, Leber usw. hergestellt und ihre Bilder mit Zeichenapparat gezeichnet, um die Beschaffenheit und Größe der Muskelschichten, der Epithelien, der Kerne usw. miteinander vergleichen zu können. -

Es müssen noch einige Bemerkungen angeführt werden, welche sich auf die Ausschließung sehr abnormaler Tiere von der Bestimmung der Durchschnittswerte beziehen. Yung (31) berichtet mit Recht, daß es zwischen den Versuchstieren, auch wenn dieselben von demselben Elternpaare abstammen und in denselben Lebensbedingungen heranwachsen, einzelne Individuen gibt, welche entweder als Riesen oder als Zwerge von der Mehrzabl sich unterscheiden; solche vereinzelte Extreme, welche auf den ersten Blick auffallen, habe ich ebenfalls wie er bei der Bestimmung der Durchschnittswerte ausgeschlossen. Ich kann aber noch eine andre Erscheinung erwähnen: es kommen unter den äußerlich ganz durchschnittlich aussehenden Tieren solche vor, bei denen man erst nach der Eröffnung der Bauchhöhle ganz abnorm gestaltete Verdauungsröhre findet; dieselbe pflegt auffallend kurz und sehr weit zu sein, und zwar dermaßen, daß man fast nicht glauben möchte, daß es sich um Tiere derselben Species und gar um Geschwister handelt. So z. B. erscheint unter 45 Tieren eines Aquariums, welche durchschnittliche Darmlänge von $93 \mathrm{~mm}$ besitzen, ein Exemplar mit der Darmlänge $46 \mathrm{~mm}$, während unter den andern die kleinste Darmlänge $84 \mathrm{~mm}$ beträgt. Ohne Zweifel ist es berechtigt, auch solche Ausnahmsfälle von der Durchschnittsbestimmung auszuschließen, obzwar dieselben kaum als krank anzusehen sind. - Ebenfalls wie YUNG konnte ich auch Froschlarven beobachten, welche die Verdauungsröhre mächtig mit Gas erweitert hatten, so daß sie auf der Oberfläche schwebten; auch kamen Tiere vor, welche aufgehört hatten, Nahrung aufzunehmen: ihre Bauchgegend erschien nach einigen Wochen des Hungerns stark eingefallen, so daß sie ganz eigentümlich aussahen; ihre Verdauungsröhre war gewöhnlich fast leer und reduziert. Diese Tiere habe ich wie Yeng als kranke in die Durchschnittswerte nicht gerechnet. Nebstdem wurde noch als ofter vorkommend noch dreierlei Art von kranken Tieren beobachtet, von denen YUNG nicht berichtet: 
die eine Art hielt sich ausdauernd an der Wasseroberfläche und nur selten und anf kurze Weile sah man sie untertauchen; im hinteren Abschnitt der Bauchhöhle schimmerte durch die Körperwände ein BluterguB durch. Einigemal glanbte ich das Auftreten solcher Kranken mit nachheriger Epidemie in Zusammenhang bringen zn können. Die andre Art war sehr bizarr deformiert: es hat sich bei ihnen in der Körperhöhle eine solche Menge von serüser Flüssigkeit angehüuft, daß die Verdauungsröhre auf einen winzigen Raum zusammengedrückt wurde, die Bauchwïnde prall aufgespannt wurden und endlich zersprangen. Die dritte Art endlich zeigte eine Deformation des Schwanzes: derselbe war in seinem proximalen Drittel rechts oder links ansgebogen; diese Deformation hat sich gewöhnlich mit der fortschreitenden Entwicklung vergrößert, so daß manchmal die Schwanzspitze auf der einen oder andern Rumpfseite nach vorn gerichtet war, wodurch allerdings die Jocomotion sehr litt; in der Mehrzahl der Fialle aber folgte nach der ersten Umbiegmong eine zweite, wodurch der hintere Abschnitt des Schwanzes wieder mehr oder weniger genau in die Medianlinie gelangte. Die Deformation reichte oft his in den Hinterteil des Rumpfes, wodurch die Messung: seiner Länge erschwert war; da bei hochgradigem Betrag dieser Verungestaltung auch die allgemeine Entwicklung und besonders die Entwicklung der Darmröhre gestört war, mußten ebenfalls diese Fälle bei Berechnung der Durchsehnittswerte unberiicksichtigt bleiben. Diese zuletzt erwähnte Anomalie scheint mit der Fleischfütterung iiberhaupt, und anf der ersten Stelle mit Pferdefleischfittterung in Zusammenhang zu sein; von den übrigen Tieren wiesen dieselbe öfters noch die mit Pflanzenfibrin und Semmel ermährten Larven auf.

3. Über dic Längeentwicklung der Verdaungoröhre in Beziehnng zu der Körpergröße und zu der allgemeinen Körperentwicklung.

Bei den Lntersuchungen über den Einfluß der äuBcren Faktoren - der Nahrung - auf die Verdaumgsröhre muß man auch die inneren Faktoren beachten, welehe bei meinen Versuchstieren besonders auf zweierlei Weise sich kundgeien: es besteht eine gewisse Bezichung zwischen der Körpergröße und der Länge der Verda u ungsröbre cinerseits; und anderseits ist eine gew isse Beziehnng zwischender Entwicklungsstufe und der Länge der Verdauungs göhre zu verzeichnen: wir haben mit ehen nicht nur wachsenden, souderu emhryonaleu, progressir sich entw inkelnden Organismen zu tun. 
Die Beziehung zwischen der Körpergröße und der Längeentwicklung der Darmröhre ist bisher ungenügend beleuchtet. Systematische Untersuchungen über diese Frage hat Nox́ (30) angestellt, und zwar an Igeln und Meerschweinchen. Der »durchschnittliche Koeffizient der Darmkanallänge«, d. h. die Länge der Verdauungsröhre auf $1 \mathrm{~kg}$ Körpergewicht berechnet, verändert sich mit der wachsenden Körpergröße. Z. B. bei den Igeln beträgt derselbe etwa $17 \mathrm{~m}$ bei neugeborenen Tieren (Körpergewicht 16-22 g), und nur 2,27 $\mathrm{m}$ bei den größten (Körpergewicht $1020 \mathrm{~g}$ ). Dieser Koeffizient bleibt fast derselbe bei den künstlich mit Fleisch ernährten Tieren wie bei den frisch gefangenen. Der Autor meint überhaupt, daß die Art der Ernährung bei der Entwicklung der Darmröhre eine völlig untergeordnete Rolle spielt im Vergleich mit der korrelativen Beziehung der Körpergröße: er findet dafür z. B. darin den Beweis, daß das pflanzenfressende Meerschweinchen fast dieselben Koeffizienten aufweist wie der fleischfressende Igel (beim Körpergewicht $76 \mathrm{~g}$ fand er den Koeffizient etwa $15 \mathrm{~m}$, beim Körpergewicht $825 \mathrm{~g}$ nur 3,28 m zwischen diesen Extremen bewegen sich die übrigen Zahlen). Bei der Maus von $13,5 \mathrm{~g}$ Gewicht führt er den Koeffizient $33 \mathrm{~m}$ an, beim Pferde von $500 \mathrm{~kg}$ nur $0,06 \mathrm{~m}$.

Bei der Besprechung der normalen Variabilität der Verdaunngsröhre beim Menschen wurde oben (s. Abt. II) die Behauptung berührt, daß die Darmlänge durch die Körpergröße, wenn überhaupt, nur unbedeutend beeinflußt wird. - In BLochs Abhandlung (11) wird nach Carus das Verhältnis der Darmlänge zur Körperlänge beim Kinde 7-8:1, beim Erwachsenen 5,5:1 angeführt; nach BENEKE ist dasselbe 5,7:1 beim Neugeborenen, 5,1:1 beim siebenjährigen Kinde, 4,7:1 beim Erwachsenen.

Beztiglich der Beziehung zwischen der Entwicklung des Körpers iiberhaupt und derjenigen des Darmkanals berichten Fermi und REperro (22), daß die Länge der Verdaungssöhre beim Kuhfötus nur 12, bei der Kuh 20 Körperlängen beträgt (ähnlich beim Schweinfötus und heim Schwein: 12 und 14).

A. Im folgenden will ich ẹinige statistische Angaben aus meinen Versuchsreihen anftihren, und zwar berühren dieselben sämtlich die Kontrolltiere, d. h. die mit Froschfleisch ernährten Kaulquappen (Tab. 1).

Man sieht, daß die relative Darmlänge bei jeder (um $1 \mathrm{~mm}$ ) Vergrößerung der Körperlänge merklich sich vergrößert; nur bei dem Übergange von $15 \mathrm{zu} 16 \mathrm{~mm}$ besteht eine Ausnahme: doch diese läßt sich leicht begreifen: bei dieser Größe sind die Tiere schon am 


\section{Tabelle 1.}

Die Veränderung der durchschnittlichen Darmlänge mit der fortschreitenden Entwicklung und wachsenden Körperlänge; Versuchszeit 1904. (Bezeichnung F 1904.)

\begin{tabular}{|c|c|c|c|}
\hline $\begin{array}{c}\text { Durchschnittliche } \\
\text { Körperlange } \\
\text { in } \mathrm{mm}\end{array}$ & $\begin{array}{c}\text { Anz:ihl } \\
\text { der } \\
\text { Versuchstiere }\end{array}$ & $\begin{array}{c}\text { Durchschnittliche } \\
\text { Darmlänge } \\
\text { in } \mathrm{mm}\end{array}$ & $\begin{array}{l}\text { Verhaltnis der } \\
\text { barmlänge zur } \\
\text { Körrerlänge }=1\end{array}$ \\
\hline $6.0-6,5$ & 6 & 25 & 4,0 \\
\hline $7,0-7,5$ & 9 & 31 & 4,3 \\
\hline $8,0-8, \tilde{0}$ & $\tilde{0}$ & 41 & 4,9 \\
\hline $9,0-9, \overline{5}$ & 8 & 48 & $\tilde{5}, 1$ \\
\hline $10,0-10,5$ & 13 & 58 & $\tilde{5}, 6$ \\
\hline $11,0-11,5$ & 12 & 68 & 6.0 \\
\hline $12,0-12, \tilde{5}$ & 33 & 74 & $6.1)$ \\
\hline $13,0-13,5$ & 25 & 78 & 6,0 \\
\hline $14,0-14.5$ & 11 & 102 & 7,1 \\
\hline $15,0-15,5$ & 3 & 114 & 7,4 \\
\hline $16,0-16, \tilde{5}$ & 3 & 109 & 6,9 \\
\hline
\end{tabular}

Anfange der Metamorphose, wobei es zur sehr starken Verkürzung der Verdauungsröhre kommt. Die steigende Verlängerung der Darmröhre mit zunehmender Körperlänge ist allerdings sehr unregelmäßig, wie aus den Relationszahlen ersichtlich ist: die relative Darmlänge bleibt zwischen $11-13,5 \mathrm{~mm}$ Körperlänge dieselbe, $d$. h. es handelt sich hier am proportionelles Wachstum der Darmlänge mit der Körperlänge, wogegen bei kleineren sowie höheren Körpergrößezahlen die Darmlänge sich weit rascher vergrößert als die Körperlänge.

Ungefähr goleiche Verhältnisse zeigen anch die iibrigen zahlreichen Tiergruppen. Man kann nun versuchen einerseits die Bezielung der

$$
\text { Tabelle } 2 \text {. }
$$

Die Veränderung der durchschnittlichen Darmlänge mit der fortschreitenden Entwicklung und wachsenden Körperlänge; Versuchszeit 1905. (Bezeichnung F 1905).

\begin{tabular}{|c|c|c|c|}
\hline $\begin{array}{l}\text { Durchschnittliche } \\
\text { Korper]änge } \\
\text { in mm }\end{array}$ & $\begin{array}{c}\text { Auzahl } \\
\text { fler } \\
\text { Versuchstiere }\end{array}$ & $\begin{array}{c}\text { Duruhschnittliche } \\
\text { Darmlänge } \\
\text { in } \mathrm{mm}\end{array}$ & $\begin{array}{c}\text { Verbāltnis der } \\
\text { Jarmlänge zur } \\
\text { Kirperlänre }(=1)\end{array}$ \\
\hline $8.0-9,5$ & ¿อ̃ & 51 & 5.8 \\
\hline $10,0-10,5$ & 39 & 63 & 6.1 \\
\hline $11,0-11, \overline{0}$ & 64 & 77 & 6.8 \\
\hline $12,0-12,5$ & 48 & 87 & 7,1 \\
\hline $13.0-13, \tilde{0}$ & 6 & 95 & 7,2 \\
\hline $14,0-14.5$ & 6 & 103 & 7,2 \\
\hline
\end{tabular}


Körperlänge zur Darmlänge, anderseits die Beziehung der fortschreitenden allgemeinen Körperentwicklung zur Darmlänge auseinanderzuhalten: denn diese beiderlei Beziehnngen sind in dem soeben angeführten Beispiele vermengt. Dies wollen wir unternehmen an der Hand der Tabellen 2 und 3.

\section{Tabelle 3.}

Die Veränderung der durchschnittlichen Darmlänge bei der wachsenden Körpergröße, aber bei ungefähr demselben Entwicklıngsstadium. Versuchszeit 1905. (Bezeichnung F 1905.)

\begin{tabular}{|c|c|c|c|c|}
\hline \multirow{2}{*}{$\begin{array}{l}\text { Durehschnitt- } \\
\text { liche } \\
\text { hurperlänge } \\
\text { in mm }\end{array}$} & \multicolumn{2}{|c|}{$\begin{array}{l}\text { Froschlarven mit hinteren Extremi- } \\
\text { täten von } 0-2.5 \mathrm{~mm} \text { Lănge: }\end{array}$} & \multicolumn{2}{|c|}{$\begin{array}{l}\text { Froschlarven mit hinteren Extremi- } \\
\text { täten von } 3,0-4,5 \mathrm{~mm} \text { Isänge: }\end{array}$} \\
\hline & $\begin{array}{l}\text { durchschnittliche } \\
\text { Darmlänge } \\
\text { in } \mathrm{mm}\end{array}$ & $\begin{array}{c}\text { Verhältnis der } \\
\text { Darmlänge zur } \\
\text { Körperlānge = } 1\end{array}$ & $\begin{array}{l}\text { durchschnittliche } \\
\text { Darmlänge } \\
\text { in } \mathrm{mm}\end{array}$ & $\begin{array}{l}\text { Verhâltnis der } \\
\text { Darmlänge zur } \\
\text { Körperliange = } 1\end{array}$ \\
\hline $9,0-9,5$ & 54 & 5,8 & 一 & - \\
\hline $10,0-10, \tilde{s}$ & 60 & 5,9 & 67 & $6, \check{a}$ \\
\hline $11,0-11,5$ & 74 & 6,6 & 78 & 6,9 \\
\hline $12.0-12,5$ & 83 & 6,8 & 88 & 7,2 \\
\hline $13,0-13, \overline{5}$ & 89 & 6,7 & 98 & 7,4 \\
\hline
\end{tabular}

Die Tabelle 2 erinnert uns durchweg an Tabelle 1; die Darmläng:e vergrößert sich mit der wachsenden Körperlänge, und zwar zuerst rascher, später annähernd proportional.

B. Die Tabelle 3 bezieht sich auf dieselben Versuchstiere wie die Tabelle 2, aber dieselben sind nicht nur nach der Körperlänge, sondern auch nach den Entwicklungsstadien und zwar in zwei Abteilungen gesondert: die erste Gruppe enthält jüngere Entwicklungsstadien, die zweite ältere; als Kriterium dient hierbei die Entwicklung der hinteren Extremitäten. Nun finden wir - indem wir besonders die Relationszahlen betrachten -, daß die älteren Entwicklungsstadien bei derselben Körpergröße verhältnismäßig längere Verdauungsröhren besitzen als die »jüngeren " Froschlarven. Doch auch nach der Ausscheidung des Faktors der progressiven Entwicklung besteht unzweideutig der andre Faktor: die Verdauungsröhre verlängert sich mit der wachsenden Körperlänge und zwar im ganzen schneller (besonders ist dies bei den kleineren Körpergrößezahlen zu sehen). (Den Anteil der beiden Faktoren kann man zablenmäßig abschätzen: bei den Tieren der Körpergröße $9 \mathrm{~mm}$ bis zur Körpergröße 13,5 mm verlängert sich die Darmröhre um 65\%, falls Tiere derselben jungen Entwicklungsstufe vorliegen. Der Unterschied 
steigt auf $82 \%$ an, wenn man auch auf ailtere Entwicklungsstufen Rücksicht nimmt: es würde also auf die Beziehung zur Entwicklung etwa $17 \%$ ausfallen.) S. auch Tab. 8.

C. Wie schon oben bemerkt wurde und wie ich an anderm Orte ausflihrlicher schildern werde, tubt die Größe des Milieu, in welchem die Froschlarven erzogen werden, einen auffälligen Einfluß auf ihre Körpergröße. Ich fuhre jetzt die Tabellen 4-7 an, in welchen man sogleich die soeben besprochene Beziehung zwischen der Körperlänge und Darmlänge wiederum findet:

\section{Tabelle 4.}

Durchschnittswerte der Körperlänge und Darmlänge der in verschieden großen Behältern großgezogenen Froschlarven. Versuchszeit 1904.

(Bezeichnung F I u. II, 1904.)

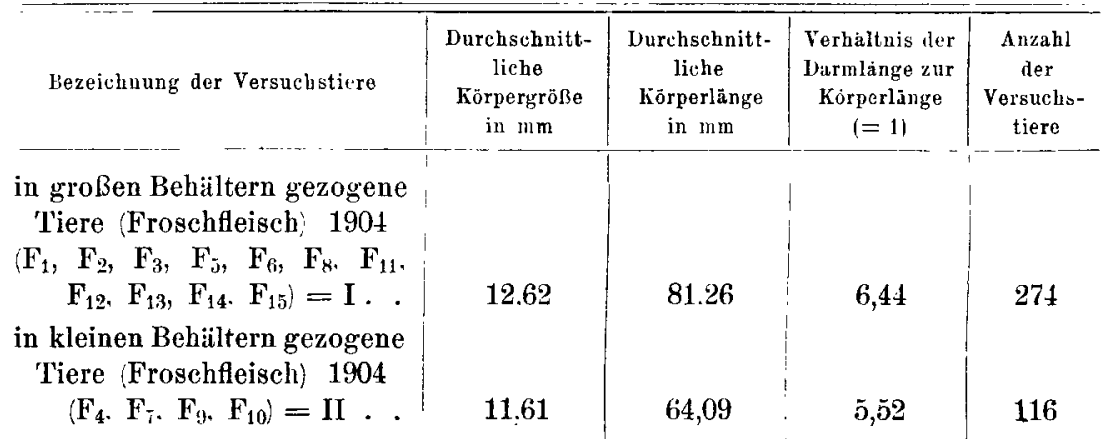

Die Tabelle 4 enthält eine allgemeine Übersicht der Körper- und Darmlängeentwicklung bei zwei Gruppen der Versuchstiere, welche einer Reihe von Versuchsanordnungen 1904 angehören. Eine Gruppe, I. bezeichnet, besteht aus elf in großen (und zwar gleich großen; Aquarien erzogenen Abteilungen; die zweite, II bezeichnet, aus vier in kleinen (aber gleich großen) Behältern gepflegten Tierabteilungen. Die durchschnittliche Körpergröße der Versuchstiere Gruppe I ist um $1 \mathrm{~mm}$ größer als bei der Gruppe II; auch die absolute Darmlïnge ist bei den in großen Behältern gezichteten Tieren durchschnittlich größer und zwar wie die Relationszahlen beweisen, ist dic Iifferenz der Darmlängen höher als diejenige der Körperlängen. Da es sich um berleutende Anzahl von Versuchstieren handelt, sind diese Durchschnittswerte von großer Bedeutung.

Die Tabelle 5 illustriert die Beziehung zwischen der Körperlänge und der Darmlïnge hei den »großen Versuchstieren der Gruppe I. Man sieht wieder die in den vorangehenden Beispielen ausgedrtickte 
Experimentelle Untersuchungen über die Variabilitiit der Verdaunngsröhre. 647

Tabelle 5 .

Verhältnis der Darmlänge zur Körperlänge bei der Gruppe I (F 1904).

\begin{tabular}{|c|c|c|c|}
\hline $\begin{array}{c}\text { Darrisibnittliche } \\
\text { Kơrperlinge } \\
\text { in mm }\end{array}$ & $\begin{array}{c}\text { Anzahl } \\
\text { Mer } \\
\text { Versuchstiere }\end{array}$ & $\begin{array}{l}\text { Durchschnittliche } \\
\text { Darmlange } \\
\text { in } \mathrm{mm}\end{array}$ & $\begin{array}{c}\text { Verbältuis der } \\
\text { Iarmlānge zur } \\
\text { Korperlänge }(=1 \text {, }\end{array}$ \\
\hline $9.0-9, \tilde{5}$ & 2 & 42 & 4.6 \\
\hline $10.0-10,5$ & 9 & 51 & 5,0 \\
\hline $11,0-11.5$ & 42 & 68 & 6,0 \\
\hline $12,0-12,5$ & 76 & 78 & 6,4 \\
\hline $13,0-13,5$ & 105 & 88 & 6.6 \\
\hline $14.0-14.5$ & 29 & 99 & 7.0 \\
\hline
\end{tabular}

anfangs schnelle, sp:iter langsamere Längeentwicklung des Darmkanals; dieselbe aber schreitet durchwegs rascher als die Kürperlïngeentwicklung.

Tabelle 6 .

Verhältnis der Darmlänge zur Körperlänge bei der Gruppe II (F 1904).

\begin{tabular}{c|c|c|c}
\hline $\begin{array}{c}\text { Durrhschnittliche } \\
\text { Korperlänge } \\
\text { in mm }\end{array}$ & $\begin{array}{c}\text { Anzahl } \\
\text { der } \\
\text { Versuchstiore }\end{array}$ & $\begin{array}{c}\text { Durchschnittliche } \\
\text { Darmlängo } \\
\text { in mun }\end{array}$ & $\begin{array}{c}\text { Verhältuis der } \\
\text { Darmlinge zur } \\
\text { Kürerlinge (=1) }\end{array}$ \\
\hline $9.0-9.5$ & 2 & 42 & $\mathbf{4 , 6}$ \\
$10.0-10.5$ & 15 & 55 & 5,4 \\
$11,0-11.5$ & 45 & 62 & 5.5 \\
$12,0-12.5$ & 44 & 67 & 5.5 \\
$13.0-13,5$ & 9 & 75 & 5,7
\end{tabular}

Die Tabelle 6 bezieht sich auf :ihnliche Verbailtnisse bei den »kleinen«Versuchstieren der Gruppe II. Im ganzen finden wir da wieder vollkommene Ähnlichkeit mit den vorangehenden Beispielen; es fiillt aber beim Vergleich mit der Tabelle 5 zweierlei ins Auge: erstens wird die Darmlänge sehr bald fast nur proportional der Körperlünge vergrößert, zweitens besitzen die gleich großen Tiere der beiden Gruppen (Körperlänge 11,0-13,5) augenscheinlich ungleich lange Verdaungsröhren: dieselben sind bei den in großen Behältern gezluchteten Tieren länger. Es besteht kein Zweifel, daß hier irgendwelche Beeinflussung der Korrelationsbeziehungen zwischen der Körperlänge sowie der fortschreitenden Entwicklung auf der einen Seite und der Darmlängeentwicklung anf der andern Seite vorliegt. Die äußeren Lèbensverhältnisse gestalten sich verschiedenartig in den großen und kleinen Aquarien, auch wenn die Temperatur, Nahrungs- 
weise, Nahrungsmenge usw. gleich sind: und dadurch finden wir danu die inneren Korrelationsbeziehungen der Organismen beeinflußt. Man könnte vielleicht die vorhandene Erscheinung dahin deuten, daß in den kleinen Behältern durch gewisse - derzeit nicht analysierte - Bedingungen das Längewachstum der Verdaungsröhre gleichsam gehemmt wird. Doch es ist schwer anzugeben, ob diese Erscheinung primär ist, so daß es hiernach zur Hemmung des allgemeinen Wachstums kommt. Die Beziehung der Verdauungsrölıre zum ganzen Körper ist bei den wachsenden und gleichzeitig sich. entwickelnden Kaulquappen sehr kompliziert; es miissen speziell gerichtete Untersuchungen darüber angestellt werden.

\section{Tabelle 7.}

Verhältnis der Darmlänge und Körperlänge.

(Gruppe I und II zusammen, 1904.)

\begin{tabular}{|c|c|c|c|}
\hline $\begin{array}{l}\text { 1) wrehsehnittliche } \\
\text { Kirperlitnge } \\
\text { in } \mathrm{mm}\end{array}$ & $\begin{array}{c}\text { Anzahl } \\
\text { der } \\
\text { Versachstiere }\end{array}$ & $\begin{array}{l}\text { Durehschnittliche } \\
\text { Darmlänge } \\
\text { in mm }\end{array}$ & $\begin{array}{l}\text { Verhaltnis der } \\
\text { Darmlinge zur } \\
\text { Korperlinge }=1\end{array}$ \\
\hline $9 . \tilde{\boldsymbol{o}}$ & 3 & $4 \tilde{5}$ & 4.7 \\
\hline 10.0 & 10 & 49 & 4,9 \\
\hline 10.5 & 14 & 57 & 5.4 \\
\hline 11,0 & 37 & 62 & 5,6 \\
\hline 11,5 & 50 & 67 & 5.8 \\
\hline 12,0 & 65 & 70 & 5.9 \\
\hline 12,5 & 55 & 79 & 6.3 \\
\hline 13,0 & 68 & $8 \tilde{5}$ & 6.5 \\
\hline $13, \check{b}$ & 46 & 89 & 6.6 \\
\hline 14,0 & 24 & 98 & 7.0 \\
\hline 14.5 & 5 & 105 & 7.2 \\
\hline 15,0 & 5 & 99 & 6.6 \\
\hline
\end{tabular}

Die Tabelle 7 enthält eine mehr detaillierte Übersicht über die Beziehung der Körperlänge und der Darmlänge bei den Gruppen I und II (zusammengerechnet). Auch bei dieser Zusammenstellung der beiden, wie soeben auseinandergesetzt wurde, in gewisser Hinsicht abweichenden Tiergruppen besteht das vorher gefundene Verhältnis: bis zur Metamorphose verlängert sich die Verdaungsröhre der wachsenden Kaulquappen verhältnismäßig schneller als die Körperlänge.

D. In meiner ersten Publikation über das auf dieser Stelle behandelte Problem (6) beschrieb ich auf Grund des damals allerdings noch kleinen Materials die Änderung der relativen Darmlänge mit dem Alter der Froschlarven so, daß dieselbe anfangs mit dem Alter 
(ich füge nun zu: und der Körpergrößej ansteigt, daß sie aber a bz u nehmen beginnt, wenn sich die hinteren Extremitäten ibrer vollkommenen Ausbildung nähern und sich an den Lokomotionsbewegungen beteiligen, also schon längere Zeit vor der (eigentlichen) Metamorphose. Nach Yuvgs Lntersuchungen (31) gibt es aber zur Zeit, wo die hinteren Extremitäten hervorzusprossen beginnen, eine kleine Verminderung wie der absoluten als auch der relativen Darmlïnge; es.kann nach diesem Forscher diese Erscheinung dadurch bedingt sein, daß bei der Sprossung der Extremititenanlagen die Tiere weniger Nahrung aufnehmen und sich also im Zustande einer Inanition befinden. Nachdem aber einmal die Extremitäten entwickelter sind (Yusg möchte dieses Stadium mit meinen Tieren, welche etwa $7 \mathrm{~mm}$ lange Unterschenkel- + Fußabschnitte besitzen, identifizieren), erscheint wieder eine absolute sowie relative Verlängerung der Verdauungsröhre. Iuvg glaubt, daß ich vielleicht dieses Stadium übersehen hatte: doch auch bei umfangreichem Material (s. die Tabelle 8) finde ich nur die vorher von mir geschilderten Verhältnisse. (Vielleicht sind sie bei Rana fusca, mit deren Larven ich hier [wie in Mehrzahl der Fille] experimentierte, andre, als bei Rava esculenta.)

'Tabelle 8.

Verïnderung der Darmlänge bei der fortschreitenden Entwicklung. Versuchszeit 1905. (Bezeichnung F 1905.)

\begin{tabular}{|c|c|c|c|}
\hline $\begin{array}{l}\text { Lünge der hinteren } \\
\text { Extremitäten } \\
\text { in } \mathrm{mm}\end{array}$ & $\begin{array}{c}\text { Anza'il } \\
\text { der } \\
\text { Versuchstiere }\end{array}$ & $\begin{array}{l}\text { Durchsehnittliche } \\
\text { Darmläige } \\
\text { in mm }\end{array}$ & $\begin{array}{l}\text { Verhältnis der } \\
\text { barmlänge zur } \\
\text { Körperlänge }(=1)\end{array}$ \\
\hline von $\theta$ bis 1.5 & 18 & 75 & 6.6 \\
\hline$-\quad 2.0-2.5$ & 21 & 77 & 6.7 \\
\hline$-3.0-3.5$ & 15 & 77 & 6,7 \\
\hline$-4.0-4,5$ & 22 & 83 & 7.2 \\
\hline$-\quad \tilde{\mathbf{0}} .0-5.5$ & 31 & 78 & 6.8 \\
\hline$-6.0-6.5$ & 20 & 77 & 6.7 \\
\hline - $\quad 7,0-7,5$ & 5 & 70 & 6,1 \\
\hline
\end{tabular}

Die Tabelle 8 bezieht sich auf Geschwisterlarven eines und desselben Aquariums; es wurden sämtliche Tiere von der Körperlänge $11 \mathrm{~mm}$ bis $12,5 \mathrm{~mm}$ in Abteilungen geordnet, so daß von oben nach unten immer in allgemeiner Entwicklung fortgeschrittenere Kaulquappen folgen. Man sieht deutlich, daß mit hervorsprossenden hinteren Extremitaten die absolute sowie relative Darmlänge zuerst zu-, dann kontinuierlich abnimmt. Diese Abnabme ist durch die beginnende Metamorphose verursacht. - Zugleich dient die Tafel 
zur Illustration der Beziehung zwischen Darmlänge und progressiver Entwicklung iberhaupt, worüber oben gehandelt wurde.

Fine Andeutung der von Yuna bei Rana esculenta beobachteten voriabergehenden absoluten und relativen Verminderung der Darmläinge könnte man höchstens bei der zweiten und dritten Abteilung sehen, wo Stillstand des Wachstums verzeichnet ist; doch nach Yungs Schilderung würde seine Erscheinung in spätere Zeit fallen, wo ich bei meiner kompletten Reihe schon eine kontinuierliche Herabsenkung finde. - Übrigens werden wir noch in weiteren Untersuchungen :ihnliche Andeutungen verzeichnen können.

Als Ergebnisse dieses Abschnittes können wir also folgende Sätze formulieren: 1) Größere Froschlarven besitzen nicht nur absolut, sondern auch relativ längere Verdaungsröhren als die kleineren Froschlarven derselben Entwicklnugsstufe.

2) Die Darmröhrenlänge ist ebenfalls von der allgemeinen Entwicklungsstufe abhängig; die in der Entwicklung mehr fortgeschrittenen Tiere besitzen längere Verdaungsröhre als jüngere Stadien derselben Körpergröße.

3) Bei den Froschlarven, deren Wachstum durch auBere Bedingungen, welche in kleinen Behältern herrschen, gehemmt wird, ist die Verdanungröhre absolut und relativ kürzer, als bei Tieren derselben Größe aus großen Aquarien.

Aus diesen Befunden folgen auch die MaBregeln für die Zuichtung und Vergleichung der Froschlarven, welche man mit verschiedenartiger Nahrung ernährt. Sämtliche Tiere müssen in gleich großen Bebältern erzogen werden. Man darf nurTiere derselben Körpergröße und womöglich auch derselben Entwicklungsstufe miteinander vergleichen.

4. Über den Einfluß der Fleisch- und Pflanzennahrung.

Die womöglich ausschließliche Fleischfütterung und Pflanzenfutterung fuhren zu a u Berordentlich großen Unterschieden und zwar besonders in der Längeentwicklung der Verdaungsröhre. Die Tabelle 9 illustriert dieselben sehr anschaulich.

Die Versuche 1902 und 1903 wurden an Kaulquappen von Rana esculenta, diejenigen von 1904 an Froschlarven von Rana fusca durchgeführt; es läßt sich aber kaum mit Sicherheit behaupten, daß die quantitativen Unterschiede, welche zwischen den drei Versuchsreihen bestehen, durch diesen Umstand bedingt sind. Denn - wie aus den 


\section{Tabelle 9 .}

Die absolute und relative Darmlänge bei ausschließlicher Fleischfutterung und Pflanzenfütterung (sowie bei gemischter Kost).

Versuchszeit 1902-1904.

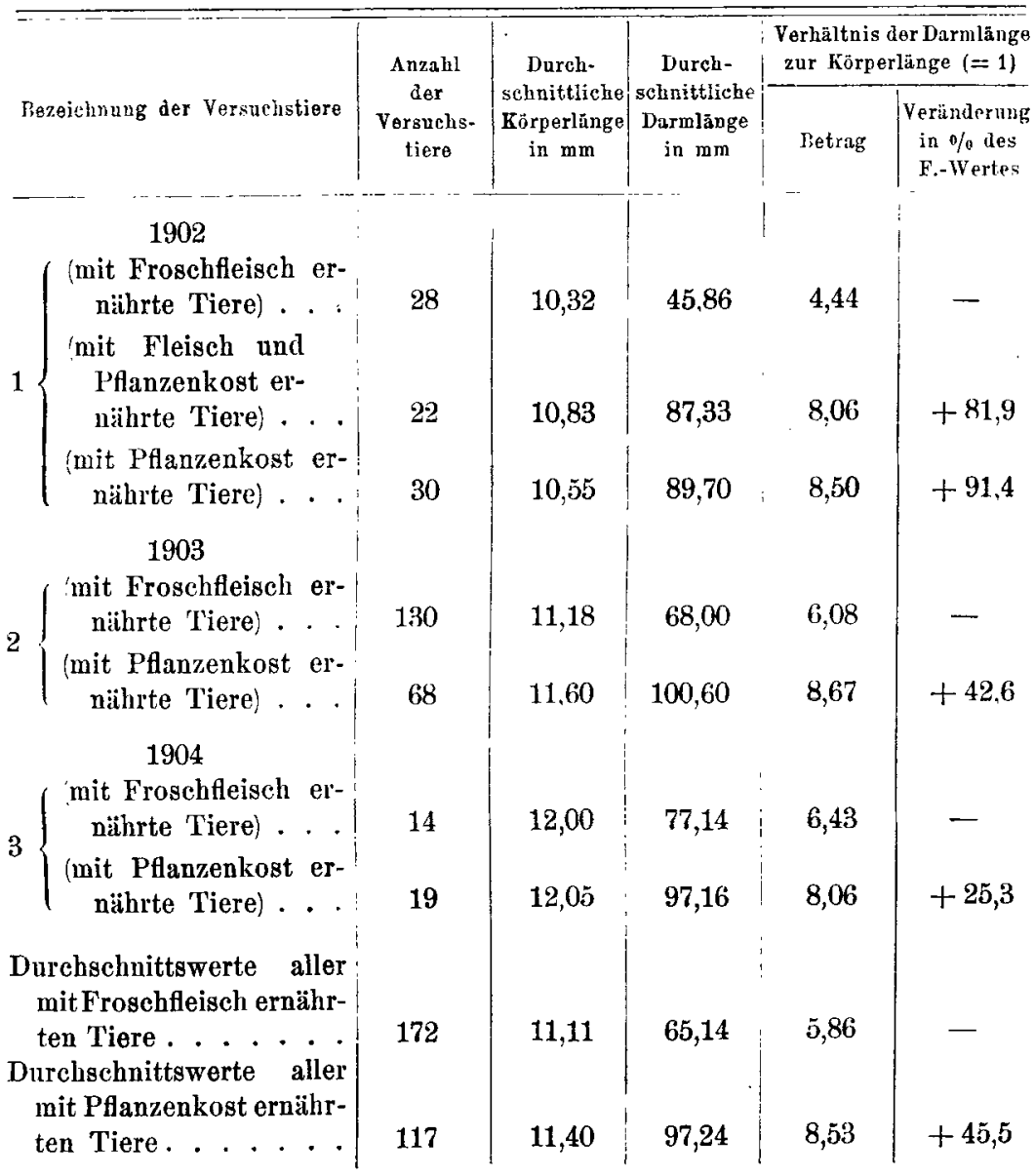

durchschnittlichen Körpergrößen zu sehen ist - es waren die Yersuchstiere von 1902 am kleinsten, diejenigen von 1904 am größten; nun besteht aber bei jüngeren Entwicklungsstadien vielleicht ein größerer Unterschied sowohl der absoluten als auch der relativen Darmlänge zwisehen den fleisch- und pflanzenfressenden Tieren, als bei späteren Stadien: dies scheint aus der Tabelle 10 hervorzugehen; es könnte sich also um eine Beziehung zur Körpergrüße handeln. 
Tabelle 10.

Die absolute und relative Darmlïnge der fleisch- und pflanzenfressenden Larven in Beziehung zur Körpergröße. Versuchszeit 1903.

\begin{tabular}{|c|c|c|c|c|c|c|}
\hline \multirow{2}{*}{$\begin{array}{l}\text { Kirrperlïnge } \\
\text { in } \mathrm{mm}\end{array}$} & \multicolumn{3}{|c|}{$\begin{array}{c}\text { Mit Fruschfleisch ernahrte } \\
\text { Tiere }\end{array}$} & \multicolumn{3}{|c|}{$\begin{array}{c}\text { Mit PAlanzennalirung ernithrta } \\
\text { Tiere }\end{array}$} \\
\hline & $\begin{array}{l}\text { Anzahli der } \\
\text { Yersuchs- } \\
\text { tiere }\end{array}$ & $\begin{array}{l}\text { dureliselin. } \\
\text { Darmlānge } \\
\text { in } \mathrm{mm}\end{array}$ & $\left|\begin{array}{c}\text { Verhältnis der } \\
\text { Darmlangs zur } \\
\text { Kurperlänge }(=1)\end{array}\right|$ & $\begin{array}{l}\text { Anzahl der } \\
\text { Versuehs- } \\
\text { tiere }\end{array}$ & $\begin{array}{l}\text { durchichn. } \\
\text { Darmlinge } \\
\text { in } \mathrm{mm}\end{array}$ & $\begin{array}{c}\text { Verhäitnis der } \\
\text { 1)armlange zur } \\
\text { Korperlange(=1) }\end{array}$ \\
\hline $5.0-5,5$ & - & - & - & 6 & 20 & 3,8 \\
\hline $6,0-6.5$ & 6 & 25 & 4,0 & 6 & 30 & 4,8 \\
\hline $7,0-7,5$ & 9 & 31 & 4,3 & 2 & 58 & 8,0 \\
\hline $8,0 \cdots 8,5$ & 5 & 41 & 4,9 & 2 & 70 & $8, \tilde{5}$ \\
\hline $9,0-9,5$ & 8 & 48 & 5,2 & - & - & - \\
\hline $10,0-10,5$ & 13 & 58 & 5.6 & 3 & 78 & 7,6 \\
\hline $11,0-11, \overline{0}$ & 12 & 68 & 6,0 & $\check{a}$ & 83 & 7,4 \\
\hline $12,0-12, \tilde{s}$ & 33 & 74 & 6.0 & 4 & 101 & 8.2 \\
\hline $13,0-13,5$ & 25 & 78 & 6.0 & 19 & 114 & 8,6 \\
\hline $14.0-14,5$ & 11 & 102 & 7,1 & $\tilde{o}$ & 124 & 8,7 \\
\hline $15,0-15,5$ & 3 & 114 & 7,4 & 13 & 151 & 9,9 \\
\hline $16,0-16, \tilde{\mathbf{b}}$ & 3 & 109 & 6,7 & 3 & 159 & 9,8 \\
\hline
\end{tabular}

Die Tabelle 10 stellt eine detaillierte Übersicht der in der mittleren Abteilung der 'Tabelle 9 in großen Durchschnittswerten angefuhrten Untersuchung ron 1903. Die absolute sowie relative Darmlänge der Pflanzenfresser nimmt bei jungen Tieren sehr rasch zu. Später erscheint aber eine dentliche Abnahme der relativen Darmlänge, da die Verdauungsröhre langsamer anwächst als die Körperlänge; bei den Fleischfressern beobachten wir in dieser Zeit sowic noch später das Stehenbleiben der relativen Darmlänge auf 6,0. Dies erinnert an Yuvas Befunde, von denen in 3. Abteilung die Rede war. --

Im ganzen stimmen diese Ergebnisse mit denen, welche YuNG: 31 ) nach- meiner ersten Abhandlung (6) über diesen Gegenstand publiziert hatte, erfreulich überein. Da dieselbe eigentlich als vorläufige Mitteilung verfaßt wurde, fehlten darin versehiedene detaillierte Angaben, z. B. über die Provenienz der Larven, die Zeit ihrer Fütterung usw., wie dieselben Yuxg auch vermißt hat. Auch die Ergebnisse bei der gemischten Nahrung (Tabelle 9) nïhern sich denjenigen in Yungs Untersuchungen: die mit gemischter Nahrung ernihrten Tiere unterscheiden sich nur wenig von den mit ausschließlicher Pflanzennahrung gefuitterten Larven; ihre Verdauungsröhre ist relativ um etwas kürzer in meinen Versuchen (s. Tabelle 9, Abteilung 1) als bei den Pflanzenfressern, während YuxG dieselbe etwas länger gefunden hat. Aber 
anch dieser Untersehied ist vielleicht zu erkliiren: denn Yuvg gab seinen mit gemischter Nahrung ernihrten Tieren anf den Boden des Aquariums Schlammerde, wogegen ich nur Fleisch und Pflanzen benutzt hatte.

Auf dieser Stelle möchte ich auf einen Versuch hinweisen, durch welchen die Notwendigkeit bewiesen wird den Versuchstieren frisches Fleisch darzubieten und durch Reinlichkeit der Behälter die Eutwicklung von Pilzflora zu verhüten. Ich habe absichtlich in einem Aquarium das Fleiseh bis zur Fialnis belassen: schon vorher erschienen darauf miichtige Rasen von Saprolegnien, wclche von den Tieren samt Fleisch gefressen wurden. Die Tabelle 11 zeigt nun, daß die Verdauungsröhre bedeutend in die Länge auswuchs. -

\section{Tabelle 11.}

Einfluß der auf Fleisch vegetierenden Pilze auf die absolute und relative Darmiänge. Versuchszeit 1903.

\begin{tabular}{|c|c|c|c|c|}
\hline liezeichnung der Versuclstiere & $\begin{array}{l}\text { Anzahl } \\
\text { der } \\
\text { Versuchs- } \\
\text { tiere }\end{array}$ & $\begin{array}{l}\text { Lurehsehnitts- } \\
\text { wert der } \\
\text { Kürperlänge } \\
\text { in } \mathrm{mm}\end{array}$ & $\begin{array}{l}\text { T)archschnits- } \\
\text { wert der } \\
\text { Darmlänge } \\
\text { in mm }\end{array}$ & $\begin{array}{l}\text { Verhı̈̈ltnis der } \\
\text { Darmlänge } \\
\text { zar } \\
\text { Körperläng+* }\end{array}$ \\
\hline $\begin{array}{l}\text { tuit faulem Froschfleisch } \\
\text { samt den darauf wach- } \\
\text { senden Pilzen ernälrte } \\
\text { Tiere... . . } 1903\end{array}$ & 9 & 12,8 & 108 & 8,4 \\
\hline $\begin{array}{cr}\text { mit reinem } & \text { Froschfleisch } \\
\text { und großer } & \text { Menge von } \\
\text { Glaspulver } & \text { gefïtterte } \\
\text { Tiere } & 1903\end{array}$ & 99 & 139 & 09 & 60 \\
\hline 11ELE $\cdot . \cdot \cdot \cdot 1000$ & & & & \\
\hline
\end{tabular}

Die Tabelle 11 enthält außerdem - gleichsam als Kontrolltiere -eine Geschwisterabteilung, welche mit frischem Froschfleisch vermengt mit Menge von Glaspulver ernährt wurde; der Einfluß des Glaspulvers auf die Verdaungsröhre ist - wie weiter dargetan werden wird ein wenig längewachstumfördernd, so daß also der Unterschied zwischen dieser und der vorangehenden Abteilung eigentlich noch größer ausfallen wiirde, falls bei der zweiten Gruppe nur reines Froschfleisch verwendet worden wäre. -

Es handelt sich also um einen Versuch mit gemischter Nalırung, dessen Ergebnis mit den vorherigen übereinstimmt. 
5. Versuche uber die mechanische Wirkungsweise der Nahrung.

Die im vorigen Abschnitte geschilderten Unterschiede in der Längeentwicklung der Verdauungsröhre der Froschlarven, je nachdem dieselben mit Fleisch- oder Pflanzenteilen ernährt worden sind, erweckten in mir sogleich bei ihrer ersten Konstatierung den Wunsch einer näheren Analyse. Wie ich in der ersten Publikation (6) geschrieben habe, rom teleologischen Standpunkte findet man das Ergebnis - die auffallende Entwicklung des Darmkanals der Pflanzenfresser in die Länge - ganz »natürlich», denn die Pflanzenkost erfordert wegen ibrer geringen Ausgiebigkeit und schwerer Verdanlichkeit eine größere Darmoberfläche. Wenn aber der Organismus so zweckmäßig reagiert, daß er die erforderliche Verdauungsoberfläche durch die Verlïngerung des Darmkanals herstellt, so wird durch diese teleologische Einsicht unser causales Bedurfnis gar nicht beriuhrt. Wir fragen nun nach dem Mechanismus dieser zweckmäßigen Erscheinung.

Über die in den lebenden Zellen der Verdauungsröhre stattfindenden Prozesse, welche dem gestaltenden Geschehen der sich verlängernden Verdauungsröhre zugrunde liegen, ist es iußerst schwer sich nähere Kenntnisse zu verschaffen. Aber die Wirkungsweise der äußeren Einflüsse, durch welche die verschiedene Nahrung verschiedene Wachstums- und Gestaltungsprozesse veranlaßt, ist wahrscheinlich leichter zu determinieren. Wenn man die Darmlänge der Fleischfiesser zum Ausgangspunkt wïhlt, kanu man die Frage aufstellen: durch welche Faktoren bewirkt die Pflanzenkost eine so merkliche Verlïngerung des Darmkanals gegenüber der Fleischkost?

Sowohl bei der Fleisch- als auch bei der Pflanzennabrung handelt es sich um sehr komplizierte Wirkungen auf die Verdauungsröhre. Wenn man auch von den sekund:aren Einflüssen absieht, welche z. B. durch die bei der Einwirkung der Verdauungssï fte auf die Nahrungsstoffe entstehenden Spaltungsprodukte ausgetibt werden, sind auch die unmittelbaren Beeinflussungen der Darmwände durch die Nahrung kompliziert. Die Nahrungsstoffe üben mechanische, osmotische und chemische Wirkungen ans, und zwar repräsentiert die Pflanzennahrung eine durchaus andre Reizgruppe als die Fleischkost. Nur auf Grund analytischer Experimente kann man die Bedeutung einzelner Wirkungsweisen abschiitzen, und 
nach der durchgeführten und gelungenen Analyse kann man hoffen die Einwirkung der gegebenen Kost als Summe der einzelnen Reize zu begreifen.

Durch den soeben angedeuteten Gedankengang habe ich mir die zul erforschenden Verhältnisse vereinfacht und einen Versuchsplan konstruiert, welcher vorzugsweise zur Sicherstellung der mech an isch en und chemischen Komponenten der Reizwirkung der Pflanzennahrung gerichtet war.

Die mechanische Wirkungsweise der Pflanzennahrung ist ohne

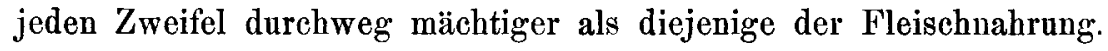
Man darf vorzagsweise auf zweierlei Art dieser Beeinflussung denken:

1) Um den gegebenen Körper ausreichend zu ernähren, muß die Pflanzennahrung in weit größerer Menge in der Zeiteinheit aufgenommen werden, als die Fleischnahrung. Dadurch wirkt die im ganzen weit voluminösere Pflanzennahrung einen größeren Druck auf die Winde des Darmkanals als die Fleischnahrung aus. Besonders die grïnen Pflanzenteile, womit meine pflanzenfressenden Versuchstiere gefuittert wurden, mußten in großen Mengen verspeist werden, und man sielt wirklich, daß diese Tiere fast fortwiihrend mit der Füllung ihrer Darmröhren beschäftigt sind; die reichlichen Excremente. dieser schwer verdaulichen und wenig ausnutzbaren Nahrung werden so oft entleert, daß man bei der Beobachtung der Tiere den Eindruck hat, daß die per os stets eingefuhhrte Nahrung gleichsam das entsprechend große Stiick des Inhalts aus dem Enddarme herauspreßt.

2) Nebst dieser allseitigen Druckwirkung stellt die Pflanzennahrung einen gewaltigen Reibungsreiz auf die Darmwand dar; besonders miissen die durch die Tätigkeit des Hornzähnchenapparates unregelmäßig zerbröckelten grünen Pflanzenteile einen starken reibenden Einfluß ausuiben, denn man findet noch in den Excrementen ganze Stücke, durch Verdaunng unverändert, mit scharfen Kanten und spitzigen Ecken usw. Über eine ähnliche Einwirkung der Cellulosewïnde, sowie uber die peristaltikfördernde Wirkung der unverdaulichen Hornspäne sind wir bei höheren Tieren informiert. [So z. B. wird die nur $25 \%$ betragende Ausnutzung von kleiehaltigem Brot im Darmkanale des Hundes zum großen Teil der rein mechanischen Wirkung der unverdaulichen Cellulose des Kleienbrots zugeschrieben (39), wogegen das kleiefreie Weizenbrot bis auf $15 \%$ verdaut wurde; ähnliche Erfahrungen wurden auch beim Menschen gemacht; nachdem man zum Fleisch Cellulose zugesetzt hatte, sah man die Kotmenge bedeutend anwachsen. - Der von den spröden Cellulosetrümmern 
auf die Darmschleimhaut ausgeübte mechanische Reiz (8) trägt in solchem Maße zur Beschleunigung der Peristaltik bei, daß nicht unbedeutende Mengen sonst an sich absorbierbaren Nährstoffe in Gemeinsehaft mit den unverdaulichen Substanzen den Darmkanal verlassen. Für den Pflanzenfresser gehört ein derartiger Ballast zu der notwendigen Bedingung ungestörter Verdauung; Kaninchen mit Milch und Zucker ernährt gingen zugrunde: die Sektion ergab eine Verstopfung des Blinddarms mit glaserkittartigen Massen. Andre Kaninchen aber, deren Milch einen Zusatz ron Hornspänen erhielt, gediehen vortrefflich; die Hornspäne haben durch ihre mechanischen Eigenschaften die Holzfaser ersetzt $(40)$. Der kurze Darm des Fleischfressers bedarf eines solchen mechanischen Reizmittels für die Peristaltik nicht. Bei der Ernährung des Menschen aber haben wir darauf zu achten, daß die Nahrung nicht zu arm sei an Holzfaser, dem natiirlichen peristaltikfördernden Mittel (41).]

Die analytischen Versuche über die Wirksamkeit der mechanischen Faktoren der griinen Pflanzennahrung habe ich in drei verschiedenen Richtungen unternommen (im Jahre 1903 und 1904). Mehrfache Versuchsreihen bestanden aus den Abteilungen:

1) Kontrolltiere: dieselben wurden mit reinem, frischem, zerriebenem Froschfleisch ernährt. Das Fleisch wurde fein zerrieben, da auch die folgenden Abteilungen dasselbe in solcher Form bekamen; außerdem wurde dadurch die kleine reibende Wirkung von Stücken, welche die Tiere von ganzen Muskeln abgenagt und verschluckt hätten, vollständig beseitigt. Die Druckwirkung dieser Nahrung mag unbedentend sein: denn es gentigt eine kleine Menge von der ausgiebigen Fleischkost, um selbst einen wachsenden Körper ausreichend zu ernähren.

2) Froschfleisch-Cellulose-Tiere: Die Nahrung dieser Abteilungen bestand ebenfalls in Frosehfleisch, doch es warde das Stick Fleisch mit vielfachem Volumen von ehemisch reinen Cellulosefasern gründlich zerrieben (mit Zusatz von etwas Wasser); die großen Nahrungsballen versammelten bald, nachdem sie in die betreffenden Behälter geworfen worden waren, sämtliche Tiere um sich herum, ähnlich wie es das reine Fleisch bei den Abteilungen 1 bewirkt. Es ist höchst wahrscheinlich, daß der Froschlarvendarm Cellulose nicht zu verdauen vermag (auch die Beschaffenheit der Excremente bei Fütterung mit grünen Pflanzenteilen zeugt davon: es werden nur die Inhalte derjenigen Zellen verdaut, welche durch die Tätigkeit des Kauapparates eröffnet worden sind; übrigens ist auch die kurze Zeit, 
während welcher die aufgenommene Pflanzennahrung im Darmkanale verweilt, kaum ausreichend, um die Celluloseverdauung zll ermöglichen: wir finden bei den Kaulquappen jene Vorrichtungen nicht, durch welche die höheren Wirbeltiere oft zur Celluloseausnutzung ausgestattet sind. - Die Nahrungsst offe waren also bei diesen Abteilungen denen gleich, welche die Kontrolltiere zu sich nahmen; sie waren aber in großem Volumen unverdaulicher Cellulosefasern verteilt, also gleichsam verdünt, ähnlich der *Verdïnnung * der Nahrungsstoffe in den cellulosehaltigen Pflanzenteilen. Doch es bestand der Unterschied, daß die Fleischsubstanz zwischen den lockeren Cellulosefasern der künstlichen Kost doch nur leicht den Verdauungssüften zugänglich war, und wirklich auch sehr gründlich ansgenutzt wurde. - Um genug Nahrung zu nehmen, mußtell die Cellulose-Tiere ihre Verdauungsröhren fortwährend mit der nahrungsarmen Kost füllen, so daß kein Zweifel besteht, daß durch diese Einrichtung ähnliche Verhïltnisse gewonnen wurden wie bei der Pflanzenernährung d. h. in bezug auf die Druckwirkung der voluminösen Nahrung auf die Darmwände. Der Einwand, welchen man machen könnte: daß nämlich die Tiere bei der großen Verdünnung der Nahrungsstoffe ungenïgend ernährt wurden, wodurch ein darmverkïrzender Einfluß eingeführt worden wäre - ist nicht stichhaltig; denn die Tiere gediehen sehr gut (siehe Abschn. IV. 2). - Die Reibungswirkung der aufgeweichten, nachgiebigen Cellulosefasern ist bei der andern mechanischen Wirkung, der Druckwirkung, gewiß unbedeutend. Ich halte deswegen diese Versuchsanordnung für sehr geeignet, um uns vorzugsweise ubber den mechanischen Faktor der Druckwirkung der Pflanzennahrung Auskunft zu verschaffen.

3) Froschfleisch-Glaspulver-Tiere: Die Nahrung dieser Abteilungen war ebenfalls frisches Froschfleisch, wie in den beiden vorhergehenden Gruppen; aber das Fleisch war mit zwei- bis vielfachem Volumen von Glaspulver grünlich zerrieben. Auch in dieser Bereitung lockte die Nahrung - besonders frisch in die Aquarien gelegt - die Versuchstiere; dieselben füllten ihre Verdauungsröhren mit diesem künstlichen, nährenden Sande, sowie sie in der Natur die Schlammerde mit den darin enthaltenen kleinen Organismen immerfort verschlucken. Doch es waren hier nur tierische Nahrungsstoffe zugegen, und zwar dieselben wie bei den Kontrolltieren. Die Verdïnnung derselben war hier kleiner gegenüber den Abteilungen 2, besonders aber war das Volumen dieser künstlichen Kost kleiner, als bei den Abteilungen 2. Während die Druckwirkung vermindert 
war - denn die Tiere brauchten nicht so große Volumina der Nahrung durch ihre Darmröhren durchzutreiben - bestand hier wieder der andre mechanische Faktor in gar übertriebener Weise: die Glasteilchen übten durch ihre unregelmäßigen, kantigen, spitzigen Oberflächen einen durchgreifenden reibenden Reizeinfluß auf die Darmwände aus. Man kann also in dieser Nahrungseinrichtung einen analytischen Versuch sehen, wodurch man tiber den Grad und die Art der Einwirkung eines starken mechanischen Reibungsreizes auf die Verdauungsröhre instruiert wird.

4) Froschfleisch-Keratin-Tiere: als Nahrungsstoffe dienten bei ihnen wiederum diejenigen der frischen Froschmuskeln; dieselben wurden aber mit etwas Keratin fein zerrieben. Der Gedanke, den Keratineinfluß zu studieren, wurde in mir durch die oben angedeuteten Kenntnisse tiber die mächtige peristaltikfördernde Einwirkung des Keratins erweckt; es ist weiter bekannt, daß dieser Stoff chemisch außerordentlich stabil ist und nur durch Verdaungssïfte einiger speziell dazu angepaßten Tiere verändert wird (z. B. die Raupe der Pelzmotte nährt sich, wie es scheint, fast ausschließlich von Keratin [42]; die Parasiten, welche Hornsubstanz fressen, z. B. Onygena equina W., besitzen vielleicht ein spezifisches Keratin lösendes Enzym).

Ich nahm von dem (von GrüBLER in Leipzig gelieferten) Präparate zwei bis drei Volumteile auf einen Teil Froschfleisch; nachdem aber die lockeren Hornspäne mit Mühe fein zerrieben wurden, sank ihr Volumen auf einen unbedeutenden Teil des Froschfleischvolumens herab. Dann wurde das Froschfleich damit gründlich zerrieben und etwas ausgetrocknet in die betreffenden Aquarien gegeben: Diese Austrocknung geschah deswegen, weil sonst die von allen Seiten begierig herbeieilenden Tiere bei ihren ungestiimen Bewegungen den flìssigen Brei ganz in das Wasser »zerstäuben " würden; wenn sie aber einmal den Hunger durch die mehr zusammenhängende, anders aber weiche Kruste gestillt haben, fressen sie dann das Übrige in Ruhe zusammen. - Ich bemerke ausdrïcklich, daß die Tiere sehr begierig auch diese künstliche Nahrung zu sich nahmen, obzwar dieselbe für den menschlichen Geruch sehr widerwärtig ist; wenn ich auch zuerst eine Abneigung beobachten konnte, verschwand dieselbe in der Kürze. - In Vergleich mit den beiden soeben geschilderten Versuchsanordnungen war nun das Volumen der Nahrung unverändert gleich demjenigen der Kontrolltiere; seine Nährhaftigkeit unterschied sich gewiß kaum von derjenigen des reinen Froschfleisches und ich sah auch immer die Tiere damit sehr gut 
gedeihen. Die kleine Zumengung des Keratins, glaubte ich, wird hier ohne jede Druckwirkung vielleicht nur die Reibungswirkung ausiiben; aber auch diese ist bei der Beschaffenheit dieses Stoffes und der Art seiner Darreichung gewiß kleiner als jene des Glaspulvers. - Im ganzen erwartete ich von diesen Keratin-Versuchen nicht viel, denn sie waren nicht genug auffällig angelegt; nur die Angaben der Physiologen über die Wirkung der Hornspäne bei den pflanzenfressenden Säugetieren haben mich zu ihnen bewogen.

5) Pflanzenfressende Kontrolltiere: dieselben sollten in Verbindung mit den fleischfressenden Kontrolltieren (Abteilung 1) das Maß für die vielleicht bei den Gruppen 2, 3, 4 zu erscheinenden Änderungen der Verdauungsröhre abgeben. Ihre Ernährung geschah auf die in IV. 2 angegebene Weise.

Die im Jahre 1903 durchgeführten Versuche, deren Gesamtergebnisse in der Tabelle 12 zusammengestellt sind, brachten mir riel Überraschung bei.

\section{Tabelle 12.}

Die ersten Versuche über die mechanische Wirkungsweise der Nahrung in der Verdauungsröhre. Versuchszeit 1903.

\begin{tabular}{|c|c|c|c|c|c|}
\hline \multirow[b]{2}{*}{ Bezeichnung der Versuchstiere } & \multirow{2}{*}{$\begin{array}{l}\text { Anzahl } \\
\text { der } \\
\text { Versuchs- } \\
\text { tiere }\end{array}$} & \multirow{2}{*}{$\begin{array}{l}\text { Durch- } \\
\text { schnittswert } \\
\text { der } \\
\text { Körperlänge } \\
\text { in mm }\end{array}$} & \multirow{2}{*}{$\begin{array}{l}\text { Durch- } \\
\text { schnittswert } \\
\text { der } \\
\text { Darmlănge } \\
\text { in mm }\end{array}$} & \multicolumn{2}{|c|}{$\begin{array}{l}\text { Verhältnis der Darmlinge } \\
\text { zur hörperlinge }\end{array}$} \\
\hline & & & & Betrag & $\begin{array}{l}\text { Veränderung } \\
\text { in \% des } \\
\text { Froschwert. }\end{array}$ \\
\hline $\begin{array}{l}\text { 1) mit reinem Froschfle is ch } \\
\text { ernärte Tiere . . . } 1903\end{array}$ & 130 & 11,18 & 68,0 & 6,08 & 一 \\
\hline $\begin{array}{l}2 \text { mit Froschfleisch und } \\
\text { großer Menge von Cellu- } \\
\text { lose ernährte Tiere... }\end{array}$ & 216 & 11,19 & 71,7 & 6.40 & $+5,2$ \\
\hline $\begin{array}{l}\text { 3. mit Froschfleisch und } \\
\text { großer Menge von Glas- } \\
\text { pulver gefitterte Tiere. }\end{array}$ & 78 & $10.8 \tilde{5}$ & 69,7 & 6,42 & $+5,6$ \\
\hline $\begin{array}{l}4 \text { mit Froschfleisch und } \\
\text { Zugabe von etwas Keratin } \\
\text { ernährte Tiere...... }\end{array}$ & 203 & 11,39 & 81,8 & 7,18 & $+18,1$ \\
\hline $\begin{array}{l}5 \text { mit Pflanzenkost er- } \\
\text { nährte Tiere...... }\end{array}$ & 68 & 11,60 & 100.6 & 8,67 & $+42,6$ \\
\hline
\end{tabular}

Was die Froschfleisch-Cellulose-Tiere betrifft, sieht man auf den ersten Blick, daß trotz der weit größeren Volummenge der Nahrung, welche ilıre Darmröhre in der Zeiteinheit passieren mußte, um ausreichende Menge der Nahrungsstoffe zu gewähren, ihre 
Verdaungsröhre fast die gleiche Länge besitzt, wie bei den fleischfressenden Kontrolltieren, welche die nötige Nahrungsstoffmenge in ganz kleinem Volumen zur Disposition hatten. Die Darmlängen - absolute wie relative - sind hier sehr anschanlich, da die Kürpergröße der beiderlei Tiere im Durchschnitte gleich ist.)

Und die Froschfleisch-Glaspulver-Tiere unterscheiden sich ebenfalls kaum von den fleischfressenden Kontrolltieren: und doch war bei ihnen wiihrend des ganzen Lebens immerfort eine weit grüßere Reibungswirkung der Nahrung tätig als bei den Kontrolltieren, welche reines Froschfleisch verzehrten. (Die Glaspulvertiere sind im Durchschnitt etwas kleiner, wodurch auch vielleicht die relative Darmlänge $\mathrm{nm}$ etwas kleiner ausgefallen ist, siehe IV. 3.)

Wenn man diese Ergebnisse von Untersuchungen iuber die Wirksamkeit der boiden mechanischen Faktoren, welche bei der Pflanzennahrung tätig sein können, zusammenfaßt, so wird man geneigt sein, dieselbe fast zu verueinen; nm so eher, als es sich um Durchschnittswerte von mehreren Versuchsreihen handelt, ron denen jede sämtliche fiunf Abteilungen enthielt. Deswegen aber müssen wir eben auch die kleine $(5 \%)$ Vergrößerung der relativen Darmlänge anerkennen: dies ist aber ein sehr kleiner Betrag, wenn wir bedenken, daß die relative Darmlänge bei den pflanzenfressenden Kontrolltieren gegenüber den fleischfressenden um fast 430 ; anstieg!

Bei dieser unbedeutenden Verlängerung der Darmröhre durch sehr starke Druck- und Reibungswirkung wird das Ergebnis der Keratinzugabe um so mehr befremden: die relative Darmlänge finden wir hier u m $18 \%$ vergrößert. Allerdings sind die Keratintiere im Durchschnitt ein wenig größer als die fleischfressenden Kontrolltiere.)

Von diesen Resultaten dürfen wir schließen: a) die mechanische Wirkung der Cellulose und des Glaspulvers auf das Längewachstum der Verdaungsröhre ist gering; da wir in diesen beiden Versuchsanordnungen die mechanische Einwirkung der Pflanzennahrung sogar ibertrieben zu haben glauben, ist es geboten, anderswo als in der mechanischen Seite der Pflanzennahrung ihren darmverlängernden EinfluB zu suchen;

b) aus gleichen Gründen können wir schwer in der stark darmverlängernden Wirkung der kleinen Keratinzugabe 
Experimentelle Untersuchungen ïber die Variabilität der Verdauungsröhre. 661

die Tätigkeit des mechanischen Faktors erblicken; denn die VolumvergröBerung und dadurch bedingte erhöhte Druckwirkung kommt hier auBer Betracht, und die reibende Wirkung ist kaum derjenigen des Glaspulvers gleichzusetzen. -

Um mich über diese Erscheinungen weiter zu orientieren, unternahm ich im Jahre 1904 neue Untersuchungen, ron denen besonders die mit Glaspulverfütterung ausgedehnter waren; denn (wie aus der kleineren Anzahl der Versuchstiere dieser Abteilung in Tab. 12 zu sehen ist) es ist mir die Mehrzahl dieser Tiere im Jahre 1903 ausgestorben und zwar durch epidemienartige Krankheit, von der ich in IV. 2 berichtet habe.

Tabelle 13.

Weitere Untersuchungen über die mechanische Einwirkung (des Glaspulvers) auf die Darmläng'e. Versuchszeit 1904.

\begin{tabular}{|c|c|c|c|c|c|}
\hline \multirow[b]{2}{*}{ Bezeichnung ter Versuchstiere } & \multirow{2}{*}{$\begin{array}{l}\text { Anzahl } \\
\text { der } \\
\text { Versuche- } \\
\text { tiere }\end{array}$} & \multirow{2}{*}{$\begin{array}{l}\text { Duruh- } \\
\text { schnittswert' } \\
\text { der } \\
\text { Körperlänge } \\
\text { in min }\end{array}$} & \multirow{2}{*}{$\begin{array}{l}\text { Durch- } \\
\text { sehnittswert } \\
\text { der } \\
\text { Darmlange } \\
\text { in mm }\end{array}$} & \multicolumn{2}{|c|}{$\begin{array}{l}\text { Verhältnis der Uarmlänge } \\
\text { zñ Körperlänge }\end{array}$} \\
\hline & & & & Detrag & $\begin{array}{l}\text { Verïnderung } \\
\text { in } \% \text { des } \\
\text { F.-Wertes }\end{array}$ \\
\hline $\begin{array}{l}\mathbf{F}_{: !} \\
\text {mit Froscht. ermihnte Tiere }\end{array}$ & 35 & 11,60 & 59,00 & $\tilde{5}, 1$ & - \\
\hline $\begin{array}{l}\text { ( } \\
\text { mit Froschfleisch und großer } \\
\text { Menge von Glaspulver ge- } \\
\text { fiitterte Tiere) }\end{array}$ & 27 & 12,16 & 69,92 & 5,7 & $+11,7$ \\
\hline$\frac{F_{10}}{\text { mit Froschf. ernährte Tiere) }}$ & 21 & 11,69 & 63,43 & 5,4 & - \\
\hline $\begin{array}{l}G_{10} \\
\text { mit Froschfleisch und großer } \\
\text { Menge von Glaspulver ge- } \\
\text { fütterte Tiere) }\end{array}$ & 29 & 10,83 & 61,00 & $\tilde{5}, 6$ & $+3,7$ \\
\hline $\begin{array}{c}\mathrm{F}_{3} \\
\text { mit Froschfl. ernährte Tiere) }\end{array}$ & 16 & 12,72 & 82,87 & $6, \check{0}$ & - \\
\hline $\begin{array}{l}\mathrm{G}_{3} \\
\text { (mit Froschfleisch und großer } \\
\text { Menge ron Glaspulver ge- } \\
\text { fuitterte Tiere) }\end{array}$ & 31 & 12,32 & 77,38 & 6,3 & $-3,0$ \\
\hline $\begin{array}{l}\text { Durchschnittswerte aller } \mathrm{F} \\
\text { mit Froschfleisch gefiitterten) }\end{array}$ & 72 & 12,00 & 68,43 & 5,70 & - \\
\hline $\begin{array}{l}\text { Durchschnittswerte aller } G \\
\text { (mit Froschfleisch und großer } \\
\text { Menge von Glaspulver ge- } \\
\text { fütterten) }\end{array}$ & 87 & 11,77 & 69,43 & 5,89 & $+3,3$ \\
\hline
\end{tabular}


Die Tab. 13 zeigt die Übersicht von drei Versuchsreihen einzeln sowie ihre großen Durchschnittswerte. Die einzelnen Versuchsreihen differieren voneinander erheblich, aber der allgemeine Durchschnitt nähert sich stark dem in der Tab. 12 verzeichneten Ergebnisse: die relative Darmlänge wird durch sehr große Mengen des Glaspulvers, vermengt mit Froschfleisch, nur etwa um $3 \%$ größer als bei den fleischfressenden Kontrolltieren. - (Die großen Differenzen der einzelnen Versuchsreihen sind teilweise durch die Körpergröße bedingt: Diese beträgt bei den Glaspulvertieren der ersten Abteilung 12,16 mm gegen 11,60 der Kontrolltiere, es werden von den $+11,70_{0}$ der Darmverlängerung nach den Abschätzungen in IV. 3 etwa 6-70,0 auf die größere Körpergröße ausfallen. Auf der andern Seite sind die $-3 \%$ der dritten Abteilung teilweise durch die kleinere Körpergröße der betreffenden Glaspulvertiere bedingt. Deswegen bekommen wir dann in dem großen Durchschnittswerte eine Ausgleichung, welche sich den Verhältnissen 1903 nähert.)

Die mit Froschfleisch und Zugabe von Keratin gefutterten Tiere stimmen in der Entwicklung der Darmlänge vollständig mit denjenigen vom Jahre 1903 ubberein:

Tabelle 14.

Untersuchungen iiber die Einwirkung der Keratinzugabe zum Fleisch auf die Darmlängeentwicklung. Versuchszeit 1904.

\begin{tabular}{|c|c|c|c|c|c|}
\hline \multirow[b]{2}{*}{ Bezeichnung der Versuchstiere } & \multirow{2}{*}{$\begin{array}{l}\text { Anzahl } \\
\text { der } \\
\text { Versuchs- } \\
\text { tiere }\end{array}$} & \multirow{2}{*}{$\begin{array}{c}\text { Durch- } \\
\text { schnittswert } \\
\text { der } \\
\text { Körperlānge } \\
\text { in mm }\end{array}$} & \multirow{2}{*}{$\begin{array}{l}\text { Dureh- } \\
\text { sehnittswert } \\
\text { der } \\
\text { Darmlänge } \\
\text { in } \mathrm{mm}\end{array}$} & \multicolumn{2}{|c|}{$\begin{array}{l}\text { Verhältnis der Darmlänge } \\
\text { zur Körperlänge }\end{array}$} \\
\hline & & & & Betray & $\mid \begin{array}{l}\text { Veränderung } \\
\text { dess. in \% } \\
\text { A. F.-Wertes }\end{array}$ \\
\hline $\begin{array}{c}\mathbf{F}_{1} \\
\text { mit Froschfieisch ernährte } \\
\text { Tiere) }\end{array}$ & 35 & 13,23 & 85,14 & 6,3 & - \\
\hline $\begin{array}{l}\mathrm{Ke}_{1} \\
\text { (mit Froschfleisch und Zusatz } \\
\text { von Keratin ernährte Tiere) }\end{array}$ & 10 & 11,85 & 85,10 & 7,2 & $+14, \ddot{3}$ \\
\hline $\begin{array}{c}\mathrm{F}_{2} \\
\text { (mit Froschfleisch ernährte } \\
\text { Tiere }\end{array}$ & 36 & 12,32 & 72,77 & $\mathbf{5}, 8$ & - \\
\hline $\begin{array}{l}\mathrm{Ke}_{2} \\
\text { (mit Froschfleisch und Zusatz } \\
\text { von Keratin ern:ihrte Tiere) }\end{array}$ & 42 & 11,88 & 94,71 & 7,9 & $+36,2$ \\
\hline
\end{tabular}

In dieser Tabelle fällt die Bedeutung der Herkunft der Tiere auf: diejenigen auf zweiter Stelle aufgeführten haben mit $36 \%$, also 
um 22\% stärkerer relativen Darmverlängerung reagiert. (Da die Keratintiere durchwegs kleiner sind, würde bei gleicher Größe eine noch stärkere Darmverlängerung - auch relative siehe IV. 3 - zu erwarten sein.)

Demnach besteht ïber die Ergebnisse 1903 kein $\mathrm{Z}$ weifel. -

YcxG (31) ist ebenfalls auf den Gedanken gekommen, den Kaulquappen Cellulose in Form von Filtrierpapier darzubieten. Doch er hat ihnen zugleich keine Nährstoffe dazu beigemengt, so daß diese Tiere in seinen Versuchen als Hungertiere denjenigen, welche iberhaupt ihre Verdauungsröhre leer hatten zur Seite zu stellen sind. Drei Fleischfresser und drei Pflanzenfresser hat er auf solche Weise am 30. Mai angefangen mit Filtrierpapier zu *füttern«; am 21. Juli besaßen die vormaligen Pflanzenfresser im Durchschnitte die Darmlänge von $103 \mathrm{~mm}$, anstatt der hypostasierten $116 \mathrm{~mm}$ bei anhaltender Pflanzenernährung; die Kontrolltiere, welche $\mathfrak{u b e r h a u p t ~ n i c h t s ~ i n ~}$ ihre Verdauungsröhre während dieser Zeit aufnehmen konnten, wiesen die durehschnittliche Darmlänge von $48 \mathrm{~mm}$ auf. Die ehemaligen Fleischfresser zeigten eine Darmlänge von $85 \mathrm{~mm}$ gegenïber der hypostasierten $78 \mathrm{~mm}$ : ihre Darmlänge hat sich also um etwas vergrößert. - Meine ausgedehnten Untersuchungen haben nur eine unbedeutende Förderung des Darmlängewachstums bei den mechanisch wirkenden Speisen sichergestellt. Es handelt sich in Yusas Resultaten eher um eine Hemmung des Verkürzungsprozesses, welcher durch den Hunger eingeleitet zu werden pflegt, als um eine positive Förderung des Längewachstums. Jedenfalls aber ist es nicht berechtigt, wenn aus dieser Beobachtung von YuNG der Schluß gefolgert wird, daß »die chemischen Wirkungen bei der Erscheinung * (d. h. der auffälligen Längeentwicklung der Verdauungsröhre bei Pflanzenfütterung) »eine seknndäre oder überhaupt keine Rolle spielen«.

Bei der Besprechung meiner und Yuxas Untersuchungen über die mechanischen Faktoren der Nahrung erwähnt DrIesch (44) die Forschungen Childs an Cestoplana, welche bei Hunger ihre Darmäste teilweise einbüßt; dies ist ein Beispiel einer Inaktivitätsatrophie: der Hauptstamm des Darmes der Cestoplana wird zwar durch Nichtgebrauch kleiner, schwindet aber nicht, was seitens Curlos auf Rechnung des Umstandes gesetzt wird, daß er stets Flüssigkeit enthalte. Nach Driesch ist CHILd, freilich ohne wirklichen Beweis, geneigt, die funktionelle Darmorganisation seiner Objekte als Mecbanom orphose, 
im Gegensatz zu meinen Ergebnissen aufzufassen. CHILD soll einen Beweis seiner Meinung in dem Verhalten des Darmes in Querbruchstïcken aus dem Hinterende des Tieres sehen: hier gehen auch alle Seitenäste ein, bis noch der Hauptast, immer Flüssigkeit enthaltend, ubrig ist; nun wird aber das Ganze immer kleiner und endlich kommt es dazu, daß die Darmflüssigkeit das Darmlumen ganz und prall ausfültt. Dann übt sie ja aber wieder einen Druck aus und nun kommt es in der Tat zu einer Sprossung von Seitenästen, die zwar zarter und weniger zahlreich als die alten sind. Mit Recht fragt DRiesch, ob hier aber wirklich nur die mechanischen Verhältnisse wirken. - Falls aber in der zuerst angeführten CHiloschen Beobachtung wirklich die Füllung mit Flüssigkeit die Ursache für die Erhaltung des reduzierten Darmes der Cestoplana abgibt, so liegt hier nur eine Tatsache vor, welche der Yungschen Beobachtung. an hungernden, nur mit Cellulose "gefütterten "Kaulquappen zur Seite zu stellen ist: ich gebe gern zu, daß die Druckwirkung des Darminhalts die Reduction des Darmkanals bei Inanition aufhalten oder sogar einstellen kann, doch damit wird noch keinesfalls der Beweis geliefert, daB der mechanische Reiz irgendwelche bedentende positive Wachstumsänderungen der Darmröhre bewirkt.

Bei den Froschlarven wenigstens und bei ihrer Fitterung mit Pflanzenkost glaube ich nach deu eindeutigen Ergebnissen meiner Versuche der mechanischen Reizwirkung der Nahrung nur eine untergeordnete Bedeutung zuschreiben zu muissen. Es ist allerdings möglich, daß bei manchen andern Tieren, z. B. den Wirbellosen, andre Bedingungen vorkommen. Es wäre überhaupt sehr erwünscht, wenn man an vielen andern Objekten die Erforschung der gestaltenden Wirkungsweisen der Nahrung unternehmen würde.

\section{Versuche uber die chemische Wirkungsweise der} Nahrung.

Die im vorigen Abschnitte geschilderten Experimente iber den mechanischen Einfluß der Nahrung führten zu keinen so bedeutenden Darmverlängerungen, da $B$ wir uns daraus diejenige bei Pflanzenernährung vorkommende erklären könnten.

Den eigentiumlichen Einfluß der Keratinzugabe selbst haben wir schwer als mechanische Einwirkung begreifen können. Ich kann mich nicht dem Eindruck erwehren, daß vielleicht diese darm- 
verlängerude Keratinwirkung eher chemisch als mechanisch bedingt ist. Für diese Meinung sprechen nach bisherigen Untersuchungen allerdings nur noch einige Beobachtungen: die Leber der mit Keratinzugabe ernährten Tiere hat (frisch) eine dunkelbraune Farbe, und die Excremente sowie der Darminhalt sind ebenfalls anders braun gefärbt als bei andern Kaulquappen. Doch in Anbetracht der Angaben uber die Unverdaulichkeit des Keratins durch die Verdauungssäfte der Wirbeltiere läßt sich vor der Hand nichts Bestimmtes über die Art seiner vermeintlichen chemischen Wirkungsweise auf die Verdaungsröhre der Kaulquappe aussagen.

Die Analyse der chemischen Wirkungsweise der Nahrung ist aber noch schwerer durchzufiuhren als bei den mechanischen Faktoren. Es handelt sich um sehr tiefgreifende Unterschiede in der quantitativen sowie qualitativen chemischen Zusammensetzung des Froschfleisches einerseits, der grünen Pflanzenteile (von Stellaria media) anderseits.

Um diese Verhältnisse einigermaßen beurteilen zn können, führe ich zuerst allgemein die Unterschiede an und dann gebe ich einige spezielle Analysen.

Die Lnterschiede bestehen in den quantitativen und qualitativen Differenzen 1) des Proteingehaltes, 2) des Kohlenhydrat- und Fettgehaltes, 3) der andern organischen Bestandteile, 4) der anorganischen Verbindungen. - Von diesen möglichen chemischen Faktoren. könnte man schon voraus besonders auf die Einwirkung der differenten Proteine denken, nachher auf die Einwirkung der verschiedenen Stoffwechselprodukte und der anorganischen Verbindungen.

Tabelle 15.

\%-Zusammensetzung des Fleisches und der griunen Pflanzenteile.

\begin{tabular}{c|c|c|c|c|c|c|c}
\hline \hline & Wasser & $\begin{array}{c}\text { Organische } \\
\text { Stickstoff- } \\
\text { substanzen }\end{array}$ & Fett & Zucker & $\begin{array}{c}\text { Stickstoffreie } \\
\text { Extraktirstoffe }\end{array}$ & $\begin{array}{c}\text { Holz- } \\
\text { faser }\end{array}$ & Asche \\
\hline $\begin{array}{c}\text { Fischfleisch } \\
\begin{array}{c}\text { (Iittelwerte v. Karp- } \\
\text { fen- und Hechtfleisch; }\end{array}\end{array}$ & 77,21 & 20,36 & 0,89 & - & 0.92 & - & 1,08 \\
$\begin{array}{c}\text { grüne Pflanzenteile } \\
\text { Mittelwerte v. Spinat } \\
\text { und Kopfalat) }\end{array}$ & 92,29 & 2,28 & 0,42 & 0,08 & 2,72 & 0,75 & 1,48 \\
\hline
\end{tabular}

Die Tab. 15 betrifft die vorzugsweise quantitativen Unterschiede in der Zusammensetzung des Fleisches und der grünen Pflanzenteile (nach verschiedenen Angaben [45] im Durchschnitt dargestellt). 
Über die Proteinsubstanzen der Laubblätter, welche in unsern Untersuchungen den größten Anteil der Pflanzenkost ausmachten, ist bisher sehr wenig bekannt (CzAPEK, 43); selbst die Angaben iiber die quantitativen Verhältnisse sind auf diesem Gebiete bisher sehr unvollkommen, denn es wird kaum der Eiweißgehalt der Blätter richtig bestimmt, wenn man den Gesamtstickstoff mit 6,25 multipliziert, wie es bisher geschehen ist. - In den Wirbeltiermuskeln kommen nach den neueren Forschungen $(46,47)$ das Myosin und das Myogen durchwegs vor, das lösliche Myogenfibrin (bei Fischen und Amphibien präformiert, bei höheren Wirbeltieren als sekundäres Umwandlungsprodukt des Myogens) und das Myoproteid nur bei Fischen in reichlichen Mengen. Die Menge des Myogens iibertrifft um das Mehrfache diejenige des Myosins. - Nebst diesen besser bekannten Eiweißkörpern des Plasmas gibt es aber in dem bei der Extraktion der oben angefuihrten Eiweißstoffe ungelöst bleibenden "Stroma " nicht genügend studierte Proteinstoffe.

Von nicht proteinartigen organischen Stickstoffverbindungen kommen im Fleisch folgende vor: die Phosphorfleischsäure (Carniferrin; Eisenverbindung dieser Substanz), Inosinsäure, das Carnosin, Kreatin, Kreatinin, der Harnstoff u. a. Setzen wir den Gesamtstickstoff des Fleisches gleich 100, so fällt davon auf die Proteinstoffe (des Rindfleisches) etwa 87,48\%, auf die ubrigen lüslichen Stoffe $12, \tilde{5} 2 \%$ ans (Salkowskr); Frentzel und Schreuer schätzen den auf die stickstoffhaltigen Extraktivstoffe kommenden Stickstoffanteil auf $7,79 \%$ (HAMMARSTEN, 48).

In den grünen Pflanzenteilen beträgt der Gesamtstickstoff (nach Ennerlings Analysen [49] bei Ticia faba im Juni) $4,54 \%$ der Trockensubstanz: davon macht der Aminosäurestickstoff etwa $0,37 \%$ aus. Von den hierher gehörenden Stoffen ist besonders das Asparagin (das Amid der Aminobernsteinsäure) zu erwähnen, welches eine bedentende Rolle bei dem Stickstoffwechsel der Pflanze spielt.

Gegen diese bedeutenden Unterschiede in dem Gehalte an organischen Stickstoffverbindungen im Muskel und in grünen Pflanzenteilen treten die ibrigen organischen Bestandteile in den Hintergrund. Der Cellulose der Pflanzenteile kommt höchstwahrscheinlich keine chemische Wirkung auf die Verdauungsröhre zu. Als stickstofffreie Extraktivstoffe werden die übrigen Kohlehydrate, die organischen Säuren usw. angeführt. Dieselben sind im Muskel durch Inosit, Glykogen, Zucker und Milchsäure repräsentiert. - Fett kommt sowohl im Froschfleisch als auch in den Blättern nur in geringen Mengen vor. 
Die anorganischen Salze, welche in den Muskeln gefunden werden, weisen besonders hohe Mengen von Kalium und Phosphorsäure anf, danach kommen Natrium, Magnesium und endlich Calcium, Chlor und Eisenoxyd. Das Kaliumphosphat scheint das im Muskel vorherrschende Salz zu sein; der Gehalt an Magnesium ist bedeutend größer als der an Calcium. Die Schwankungen der rerschiedenen Elemente sind uberhaupt sehr beträchtlich. Noch bedeutender sind dieselben in den grïnen Pflanzenteilen. Hier ist es in den meisten Fällen Calcium, das den hervorragendsten Anteil an der Zusammensetzung der Asche nimmt, es erfährt auch während des Wachstums der Blätter am ausgiebigsten eine Vermehrung; der Kaliumgehalt der Laubblätter ist regelmäßig ebenfalls ein sehr hoher. (In der Literatur fand ich eine vollkommene Analyse der mineralischen Bestandteile des Froschfleisches [50]: in 100 Teilen trockenes Fleisch kommen $0,1186 \mathrm{CaO}, 2,0292 \mathrm{~K}_{2} \mathrm{O}, 0,2180 \mathrm{MgO}$ usw. vor; bei Stellaria media[49] beträgt $\mathrm{CaO} 4,8 \%, \mathrm{MgO} 21,8 \%$ usw. der Reinasche. Es ist nicht möglich, aus den vorhandenen Angaben einen vollständigen Vergleich zu konstruieren; bei den Pflanzenteilen ist z. B. der Schwefel nur in Aschenanalysen bestimmt, so daß es unbekannt ist, wie derselbe auf Eiweißkörper, Sulfide, Sulfate usw. rerteilt ist.)

Wie dieser gedrängten Übersicht zu entnehmen ist, müssen die analytischen Versuche, welche die chemischen Faktoren der grünen Pflanzenteile gegenüber der Fleischnahrung bestimmen sollen, auf den gröBten Unterschieden in der Zusammensetzung der beiderlei Kost basieren; sonst würde man sich in der verwirrenden Mannigfaltigkeit der angedenteten Differenzen verlieren.

In der ersten Reihe habe ich den Pflanzenproteinen meine Aufmerksamkeit gewidmet. Dieselben sind bisher weniger bekannt als die tierischen Proteine. Doch über ihre chemischen Unterschiede gegenüber den analogen Tierproteinen kann man kaum zweifeln. Es bestehen schon verschiedene diesbezügliche Angaben (z. B. tiber die quantitativen Verhältnisse der Zersetzungsprodukte der tierischen und pflanzlichen Eiweißkörper [51], uiber qualitative Verschiedenheiten [521). Auch die Untersuchungen uiber die Bildung der Antikörper im tierischen Organismus nach der parenteralen Einführung der pflanzlichen Proteine zengen von erheblichen biochemischen Unterschieden derselben, auch wenn man bisher in der Eiweißchemie bei weitem nicht so tief eingedrungen ist, um diese Differenzen anschaulich machen zu können.

Die Hautgruppe meiner chemisch-analytischen Ver- 
suche ist auf dem Gedanken gegründet, daB man bei der Fütterung mit künstlich dargestellter Pflanzenproteinsubstanz eine ähnliche Darmröhrenverlängerung erhalten wird, wie bei der Ernährung mit grünen Pflanzenteilen falls die Proteine hier iberhaupt eine merkliche Rolle spielen. Ich habe also eine Reihe von Versuchsreihen angestellt, welche man denjenigen in der 5. Abteilung (ubber die mechanischen Faktoren der Nahrung! geschilderten zur Seite stellen kann:

\section{A. Versuche mit $\gg$ Pflanzenproteinsubstanz $\propto$.}

Die Kontrolltiere wurden, wie iiberhaupt, mit reinem zerriebenem Froschfleisch ernährt. Die Versuchstiere bekamen ein Gemisch von Froschfleisch und künstlich dargestellter "Pflanzenproteinsubstanz". Dieselbe wurde von Grübler \& Co. in Leipzig bezogen; sie wird aus Kürbissamen dargestellt und repräsentiert ein Gemisch ron verschiedenen Proteinstoffen, worunter iiber $40 \%$ auf ein leicht lösliches Vitellin kommt (s. weiter den Abschnitt B). Ein Stückchen Froschfleisch wurde mit mehrfachem Volumen des Pulvers der Proteinsubstanz zerrieben; die Kaulquappen gewöhnten sich leicht diese Nahrung aufzunehmen, und sie ließen sich später auch mit dem reinen Präparate füttern. Die Darreichung von Stïckchen Froschfleisch garantierte mir, daß die Tiere nicht an Mangel gewisser für das Leben nötigen Stoffe leiden werden; denn, wie ich kaum auseinanderzusetzen brauche, die Ernährung mit künstlichen Präparaten ist immer . gefährlich; diese Erfahrung habe ich besonders in den Versuchen mit reinen Proteinen gemacht, während die "Pflanzenproteinsabstanz*, ein mehr naturliches Gemisch, als Nahrung geeigneter ist.

B. Versuche mit verschiedenen Pflanzenproteinen.

Diese Untersuchungen haben bei weitem nicht einen so ginstigen Verlauf gebabt als diejenigen mit :Pflanzenproteinsubstanz $«$; obzwar ich ganz regelmäßig zu den Präparaten Stuckchen Froschfleisch zugesetzt hatte, so daß es vielleicht zu keinen Störungen infolge des Mangels an unentbehrlichen Stoffen kam, erkrankten die Versuchstiere fribher oder später, und falls sie nicht ausgestorben sind, führten sie gewöhnlich ein kümmerliches Dasein. Die reinen Proteine, wie sie in diesen Präparaten dargereicht wurden, scheinen geradezu giftig zu wirken. Es handelt sich keineswegs um eine spezifische Toxität der pflanzlichen Proteine: auch die mit isolierten tierischen Eiweißkörpern (plus Zugabe von Froschfleisch) ernährten Tiere weisen solche Störungen des Allgemeinzustandes auf. 
Experimentelle Untersuchungen über die Variabilität der Verdauungsröhre. 669

Tabelle 16.

Versuche über die Einwirkung der Pflanzenproteine auf die Darmlïnge. Versuchszeit 1904.

\begin{tabular}{|c|c|c|c|c|c|c|}
\hline & \multirow[b]{2}{*}{ Bezeichnung der Versuchstiere } & \multirow{2}{*}{$\begin{array}{l}\text { Anzalil } \\
\text { der } \\
\text { Tersuchs- } \\
\text { tiere }\end{array}$} & \multirow{2}{*}{$\begin{array}{l}\text { Durch- } \\
\text { schnitt-wert } \\
\text { der } \\
\text { Kurperlänge } \\
\text { in mm }\end{array}$} & \multirow{2}{*}{$\begin{array}{l}\text { Dureh- } \\
\text { schnittswert } \\
\text { der } \\
\text { Dirmlinge } \\
\text { in mm }\end{array}$} & \multicolumn{2}{|c|}{$\begin{array}{c}\text { Verbältnis der Darmläng } \theta \\
\text { zur Körperlänge }\end{array}$} \\
\hline & & & & & Betrag & $\begin{array}{l}\text { Veranderung } \\
\text { in o'o des } \\
\text { F.-Wertes }\end{array}$ \\
\hline & $\left(\begin{array}{c}F_{3} \\
\text { m.Froschtl ernährte Tiere }\end{array}\right.$ & 16 & 12.72 & 82.87 & $6 . \check{0}$ & - \\
\hline 1 & $\left\{\begin{array}{c}\mathrm{Pr}_{3} \\
\text { imit Pflanzenproteinsub- } \\
\text { stanz }+ \text { Zusatz v. Frosch- } \\
\text { fleisch ernährte Tiere }\end{array}\right.$ & 30 & 11,43 & 86.10 & 7.5 & +15.4 \\
\hline & {$\left[\begin{array}{c}\mathrm{F}_{4} \\
\text { m. Froschfi.ernährte Tiere }\end{array}\right.$} & 31 & 12.00 & 70,48 & 5,8 & - \\
\hline 2 & $\left\{\begin{array}{c}\mathrm{Pr}_{4} \\
\text { (mit Pflanzen)roteinstb- } \\
\text { stanz }+ \text { Zusatz v. Frosch- } \\
\text { fleisch ernährte Tiere }\end{array}\right.$ & 33 & 11,98 & 80,94 & 6,7 & $+15,5$ \\
\hline & $($ im.Froschfl.ernährte Tiere & 36 & 12,61 & 87,44 & 6.9 & 一 \\
\hline 3 & $\left\{\begin{array}{c}\operatorname{Pr}_{\breve{r}} \\
\text { (mit Pflanzenproteinsub- } \\
\text { stanz + Zusatz v. Frosch- } \\
\text { fleisch ernährte Tiere) }\end{array}\right.$ & $4 \dot{0}$ & 11,82 & 93.07 & 7,8 & $+13,0$ \\
\hline & $\left(\begin{array}{c}\mathbf{F}_{6} \mathrm{c} \\
\text { (mitFroschfleisch }+ \text { großer } \\
\text { Menge von reiner Cellulose } \\
\text { gefütterte 'Tiere: }\end{array}\right.$ & $1 \breve{5}$ & 12,73 & 87,40 & 6,8 & 一 \\
\hline 4 & $\left\{\begin{array}{c}\mathrm{Pr}_{6} \mathrm{c} \\
\text { (mit Pflanzenproteinsub- } \\
\text { stanz }+ \text { großer Menge von } \\
\text { Cellulose }+ \text { Zugabe von } \\
\text { Froschfl. gefütterte Tiere) }\end{array}\right.$ & 12 & 12,66 & 96,50 & $\begin{array}{c}\vdots \\
\vdots \\
\vdots \\
\vdots\end{array}$ & $+11,8$ \\
\hline & $\left(\frac{\mathrm{F}_{\bar{t}}}{\text { (m. Froschfl. ernährte Tiere) })}\right.$ & 29 & 11,14 & 63,48 & 5,6 & - \\
\hline 5 & $\left\{\begin{array}{c}V_{\bar{\tau}} \\
\text { mit pflanzl. Vitellin }+Z u- \\
\text { gabe von Froschfleisch er- } \\
\text { nährte Tiere? }\end{array}\right.$ & 9 & 11,39 & 85,44 & 7,5 & $+33,9$ \\
\hline & $\left(\begin{array}{c}\mathrm{F}_{8} \\
\text { (m.Froschtl. elnährte Tiere) }\end{array}\right.$ & $2 \check{0}$ & 12,66 & 82.76 & $6, \overline{0}$ & - \\
\hline 6 & $\left\{\begin{array}{c}\mathrm{Cg}_{8} \\
\text { (mit Conglutin }+ \text { Zugabe } \\
\text { von Frosehfleisch ernährte } \\
\text { Tiere) }\end{array}\right.$ & 38 & 12,37 & $85 \check{.79}$ & 6,9 & +6.1 \\
\hline
\end{tabular}


Von den Proteinstoffen benutzte ich: das Vitellin (von GrüBLER, ans Kürbissamen dargestellt; dieser Stoff macht einen Teil der oben benutzten Proteinsubstanz aus), das Legumin (ein Nucleoalbumin), das Conglutin (ein Phytovitellin). Die mit »Pflanzenfibrin " (= Glutenkasein Rirruadsen, Zymom Tadder, im Pflanzenleim enthalten, bleibt bei Behandlung des Klebers mit kaltem verdinntem Weingeist ungelöst zurück) und teilweise auch die mit Gluten - allerdings ebenfalls mit Zugabe von Fleisch - ernährten Tiere sind in einigen Wochen ausgestorben, sowie die mit Blutfibrin, Chondrin u. a. tierischen Pr̈̈̈paraten gefuitterten Larven.

Die Tabelle 16 zeigt die Ergebnisse der einzelnen Versuchsreihen von 1904. Da die mit Pflanzenproteinsubstanz ernährten Tiere fast durchwegs um etwas kleiner sind als die Kontrolltiere, gelten die gefundenen VerlängerungenderVerdauungsröhre a fortiori (s. IV. 3). Man sieht die Bedeutung der Körpergröße, wenn man z. B. die Abteilung 1 mit 2 vergleicht: die durchschnittliche Darmlänge ist bei 1 nur um $3,23 \mathrm{~mm}$ größer gegenuber den Kontrolltieren, dagegen bei 2 um 10,46 mm; da aber die Körpergröße der Pflanzenproteintiere der 2. Abteilung (fast) derjenigen der Kontrolltiere gleich ist, dagegen in der 1. Abteilung merklich kleiner ist, erhält man die Veränderung der relativen Darmlängen in beiden Gruppen gleich $\left(+15,4\right.$ und $\left.+15, \tilde{5}^{0}, 0\right)$.

Die 4. Abteilung enthält einen kombinierten Versuch über die Einwirkung des chemischen und mechanischen Faktors: beiderlei Larven - die Kontrolltiere sowie die Pflanzenproteintiere - bekamen zugleich mit den Nahrungsstoffen große Mengen von Cellulose; die Vergrößerung der relativen Darmlänge ist ähnlich wie bei den vorigen Abteilungen ausgefallen.

Bei dem Vitellinversuch der 5 . Abteilung blieben leider nur wenige, sonst aber ganz gesunde Versuchstiere am Leben; von der bedeutenden Vergrößerung der relativen Darmlänge ist wohl ein wenig abzurechnen, da die Versuchstiere um etwas größer sind als die Kontrolltiere.

Die Ergebnisse sind summarisch in der Tabelle 17 dargestellt.

Im Jahre 1905 habe ich nochmals diese Versuchsanordnung wiederholt und die Resultate bestätigt.

Wie aus der Tabelle 18 ersichtlich ist, bewirkt das Phytovitellin, welches unter dem Namen "Vitellin aus Pflanzen " von Grübler dargestellt wird, wiederum eine bedeutende Verlängerung des Darmkanals, so daß wir ohne Zweifel den darmverlängernden Einfluß der "Pflanzenproteinsubstanz"daranf - vorzugs- 
Experimentelle Untersuchungen über die Variabilität der Verdauungsröhre. 671

Tabelle 17.

Gesamtübersicht über die Einwirkung der Pflanzenproteine auf die Darmlänge. Versuchszeit 1904.

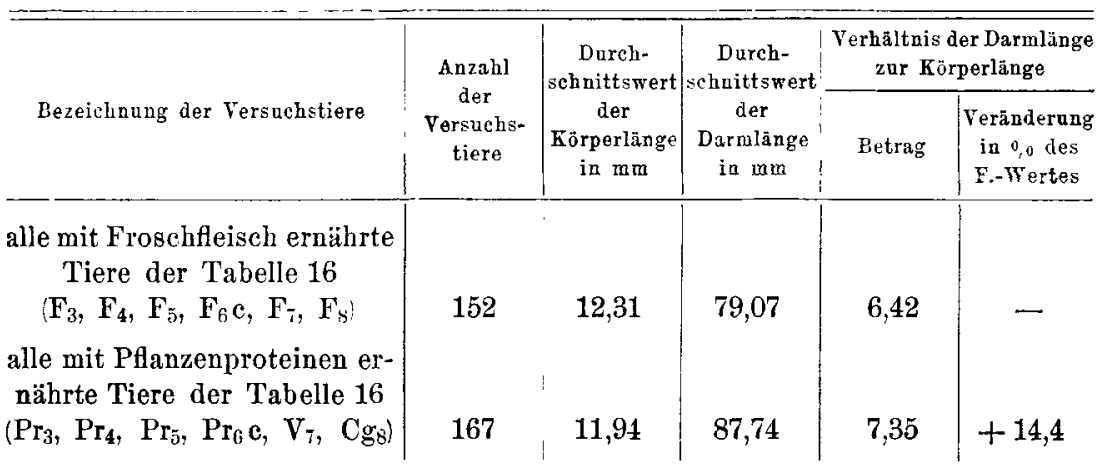

Tabelle 18.

Weitere Untersuchungen uber die Einwirkung der Pflanzenproteine auf die Darmlänge. Versuchszeit 1905.

\begin{tabular}{|c|c|c|c|c|c|}
\hline \multirow[b]{2}{*}{ Bezeichnung der Versuchstiere. } & \multirow{2}{*}{$\begin{array}{l}\text { Anzahl } \\
\text { der } \\
\text { Versuchs- } \\
\text { tiere }\end{array}$} & \multirow{2}{*}{$\begin{array}{c}\text { Durclt- } \\
\text { schnittliche } \\
\text { Körperlänge } \\
\text { in mm }\end{array}$} & \multirow{2}{*}{$\begin{array}{c}\text { Durch- } \\
\text { schnittliche } \\
\text { Darmlänge } \\
\text { in } \mathrm{mm}\end{array}$} & \multicolumn{2}{|c|}{$\begin{array}{l}\text { Verhâlttinis der Darmlänge } \\
\text { zur Körperlänge }(=1)\end{array}$} \\
\hline & & & & Betrag & $\begin{array}{l}\text { Veränderang } \\
\text { in \% des } \\
\text { F.-Wertes }\end{array}$ \\
\hline 1905 & & & & & \\
\hline (mit Froschfl. ernährte Tiere) & 99 & 11,11 & 63,21 & 5,69 & - \\
\hline $\begin{array}{l}\text { (mit Pfianzenvitellin }+ \text { Zugabe } \\
\text { von Froschfl. ernährte Tiere) }\end{array}$ & 23 & 11,37 & 81,35 & 7,15 & $+25,6$ \\
\hline $\begin{array}{l}\text { (mit Legumin }+ \text { Zugabe von } \\
\text { Froschfleisch ernährte Tiere) }\end{array}$ & 12 & 11,62 & 74,08 & 6,37 & $+11,9$ \\
\hline
\end{tabular}

Tabelle 19.

Weitere Untersuchungen über die Einwirkung der Pflanzenproteinsubstanz auf die Darmlänge. Versuchszeit 1905.

\begin{tabular}{|c|c|c|c|c|c|}
\hline \multirow[b]{2}{*}{ liezeichnung der Versuchstiere. } & \multirow{2}{*}{$\begin{array}{l}\text { Anzahl } \\
\text { der } \\
\text { Versuchs- } \\
\text { tiere }\end{array}$} & \multirow{2}{*}{$\begin{array}{l}\text { Durch- } \\
\text { schnittliche } \\
\text { Körperiānge } \\
\text { in } \mathrm{mm}\end{array}$} & \multirow{2}{*}{$\begin{array}{l}\text { Darch- } \\
\text { sclinittliche } \\
\text { Darmlānge } \\
\text { in } \mathrm{mm}\end{array}$} & \multicolumn{2}{|c|}{$\begin{array}{l}\text { Verhâltnis der Darmlange } \\
\text { zur Korperlänge }(=1)\end{array}$} \\
\hline & & & & Betrag & $\begin{array}{l}\text { Verinderung } \\
\text { in } 0 / 0 \text { des } \\
\text { F.-Wertes }\end{array}$ \\
\hline $\begin{array}{c}190 \tilde{z} \\
\text { (mit Froschfleisch ernährte } \\
\text { Tiere }\end{array}$ & 188 & 11,13 & 74.59 & 6.68 & _ \\
\hline $\begin{array}{c}\text { (mit Pfanzenproteinsubstanz } \\
\text { ernährte Tiere) }\end{array}$ & 132 & 12,02 & 100,16 & 8,33 & $+24,7$ \\
\hline
\end{tabular}


weise - beziehen dürfen. Das Legumin dagegen übt eine merklich kleinere Wirkung aus.

Daß die mit »Pflanzenproteinsubstanz ernährten Larven ausgezeichnet gedeiben, dessen Beweis wird durch die Tabelle 19 dargebracht: die durchschnittliche Kürperlinge ist bei den mit künstlicher Nahrung gefütterten Kaulquappen bedeutend größer (um 0,9 mm). Um die eigentliche darmverlängernde Wirkung der Pflanzenproteine abzuschätzen, müßte man auf die in IV. 3 geschilderte Beziehung der Körper- und Darmlänge Rüicksicht nehmen; wären die Kontrolltiere $12 \mathrm{~mm}$ groß anstatt $11,13 \mathrm{~mm}$ (im Durchschnitte), so würde ihre Darmlänge etwa $83 \mathrm{~mm}$ statt 74,59 ausfallen, demnach die relative Darmlinge ungefähr 6,9 statt 6,68; es witrde also die Vergrößjerung: der relativen Darmlïnge bei der Futterung mit Pflanzenproteinsnbstanz etwa $20 \%$ anstatt $24,7 \%$, betragen. -

Die Fitterung mit Kleberprotein "Gluten * hat in einem gelungenen Versuche keine Änderung der Darmlänge bewirkt.

\section{Versuche mit Asparagin.}

Im Jahre 1904 habe ich an Larven von Pelolates fuscus verschiedene Fütterungsversuche angestellt; doch es haben sich diese Tiere als ungeeignet zu solchen Versuchen erwiesen; unter den nach einigen Wochen Fütterung ausgestorbenen Aquarien befand sich eins, wo die Tiere mit großen Hengen von Asparagin ernährt wurden.

Im Jahre 1905 habe ich den Asparaginversuch an Larven von Rana fusca ernenert und derselbe ist - abgesehen von einer Periode von gestörter Entwicklung der Tiere - mit Erfolg zu Ende geführt worden.

Tabelle 20.

Versuche über den Einfluß des Asparagins auf die Darmlänge. Versuchszeit 1905 .

\begin{tabular}{|c|c|c|c|c|c|}
\hline \multirow[b]{2}{*}{ Bezeichnung der Versuchstiere. } & \multirow{2}{*}{$\begin{array}{l}\text { Anzalll } \\
\text { der } \\
\text { Versuch:- } \\
\text { tiese }\end{array}$} & \multirow{2}{*}{$\begin{array}{l}\text { Durch- } \\
\text { schnittliche } \\
\text { Köperlänge } \\
\text { in } \mathrm{mm}\end{array}$} & \multirow{2}{*}{$\begin{array}{l}\text { Durch- } \\
\text { sehnittliche } \\
\text { Darmlänge } \\
\text { in } \mathrm{mm}\end{array}$} & \multicolumn{2}{|c|}{$\begin{array}{l}\text { Verhältnis der Darmlänge } \\
\text { zur Körperlänge }(=1)\end{array}$} \\
\hline & & & & Eetrag & $\begin{array}{l}\text { Yeränderung } \\
\text { in } \% \text { des } \\
\text { F. Wertes }\end{array}$ \\
\hline $\begin{array}{c}1905 \\
\text { mit Frosehfleisch ernïhrte } \\
\text { Tiere) }\end{array}$ & 99 & 11.11 & 63,21 & $\check{\mathbf{s}}, 69$ & - \\
\hline $\begin{array}{l}\text { mit Froschfleisch }+ \text { Zugabe } \\
\text { Asparagin ernührte Tiere }\end{array}$ & 54 & 11,52 & 75.02 & 6,51 & $+14,4$ \\
\hline
\end{tabular}


Es wurde den Versuchstieren ein Gemisch von Stickchen Fleisch und mehrfachem Volumen von Asparagin einmal oder zweimal täglich vorgelegt; das Asparagin löst sich allerdings allmählich im Wasser des Aquariums auf, aber es werden trotzdem große Mengen davon mit den Muskelfasern in die Verdauungsröhre aufgenommen, wie ich mich leicht überzeugen kounte. Da die Tiere uur soviel zu fressen bekamen, als sie kurz nach der Vorlegung der Nahrung aufnehmen konnten, waren sie immer bei vollem Appetit als die Zeit der Fütterung gekommen war, und verschluckten das Gemisch mit wilder Begier. Die Excremente der Asparagintiere waren etwas abweichend gefärbt ron denjenigen der Kontrolltiere.

Die gefundene Verlängerung der Verdaungsröhre bei den Asparagintieren würde etwas kleiner ausfallen, wenn die Kontrolltiere die gleiche Körpergröße gehabt hätten: nach den in IV. 3 gemachten Erfahrungen kann man die Vergrößerung der relativen Darmlänge bei den Asparagintieren auf etwa 10\% schätzen. -

Dic an omnivoren und carnivoren Säugetieren angestellten Versuche mit Asparagin haben ergeben, daß dasselbe weder bei proteinreichen, noch proteinarmen Rationen eine Eiweißersparnis zur Folge hat, ja es trat rielmehr stets eine Steigerung des Eiweißumsatzes auf, ähnlich wie nach starken Kochsalzgaben hervor (503). Nach den neueren Untersuchungen von VöLTz (54) bei Hunden soll das Asparagin in Mischung mit Albumin gegeben unter Umständen eine gewisse Menge Eiweiß vor dem Zerfall schützen können, während es bei gleichzeitiger Verabreichung von Kasein und andern nucleinhaltigen eiweißreichen Stoffen eine Steigerung des Eiweißverbrauchs bewirkt. Bei den Wiederkäuern wurde wiederholt sichergestellt, daß das Asparagin (ja selbst Ammoniumacetat), einem eiweißarmen, aber kohlehydratreichen Futter zugelegt die Verdaung der Kohlehydrate und der Rohfaser steigert, wobei es gleichzeitig zu einem stärkeren Eiweißansatz kam. Diese Steigerung des Eiweißansatzes läßt sich nur zum Teil durch die Förderung der Kohlehydrate- und Rohfaserverdauung erklären; man kann nebstdem an die vermittelnde Tätigkeit der Mikroorganismen des Darmkanals denken, welche sich von Asparagin gut ernälıren können, wodurch die Eiweißkörper vor ihnen geschtitzt werden, und welche außerdem, nachdem sie an dem einen Orte die stickstoffhaltigen Substanzen nicht eiweißartiger Natur assimiliert haben, dieselben an einer andern Stelle des Verdauungsschlauches in Form von Eiweiß der Verdauungstätigkeit preisgeben. Doch bei etwas eiweißreicheren Futtermischungen, wie sie gewöhnlich vor- 
kommen, ließ das Asparagin keine Eiweißansatz fördernde Wirkung erkennen.

Nach diesem Bestande der Kenntnisse über die Bedeutung des Asparagins für die Ernährung der Tiere kann man kaum erwarten, daß dieser Stoff irgendwelche wichtige Rolle als Nahrungsstoff in unsern Versuchen an Froschlarven gespielt hat. Aber als chemischer Reiz mochte das Asparagin trotzdem direkt oder indirekt auf die Darmoberfläche einwirken und allmählich jene merkliche Wachstumsänderung der Verdauungsröhre verursachen, welche wir soeben den Kontrolltieren gegeniber konstatiert haben.

D. Versuche mit Mineralstoffen.

In Anbetracht des Unterschiedes im Gehalte an Mineralstoffen zwischen der Muskelsubstanz und den grünen Pflanzenteilen wurde im Jahre 1904 ein Versuch unternommen, wo zu dem Froschfleisch große Mengen der in grïnen Pflanzenteilen vorkommenden Mineralstoffe zugesetzt wurden: die Phosphate (des Kalium, Natrium, Calcium), die Nitrate (des Kalium und Natrium), weiter Calciumsulphat und Calciumoxalat. Der positive Erfolg dieses orientierenden Versuches hat mich dann im Jahre 1905 zu einer schon eher als analytisch zu bezeichnenden Untersuchung bewogen. Da in den grünen Pflanzenteilen das Calcium im Vordergrunde steht, bereitete ich ein Gemisch von Calciumphosphat, Calciumnitrat, Calciumsulphat und Calciumoxalat, ungefaihr zu gleichen Teilen, und zu diesem Gemisch setzte ich ein Stück Froschfleisch zu, wobei aber das Volumen der Salze mehrfach größer war. Die Tiere gewöhnten sich leicht an diese Nahrung und bald sah man ihre hellweißen Verdauungsröhren durch die Körperwand durchschimmern. Bald nachdem die Nahrung in das Aquarium gelegt worden war, verschwand sie und die weißen Exkremente, nur hier und da mit Kotpartikeln vermischt, wurden wiederum verschluckt: es ist merkwürdig, wie diese Tiere durch unwiderstehlichen Instinkt dazu getrieben werden selbst ganz unverdauliche Teilchen in die Verdauungsröhre aufzunehmen.

Wie soeben bemerkt wurde, lege ich auf den Versuch 1905 größeres Gewicht. Die auffallende Vergrößerung der relativen Darmlänge möchte noch höher ausfallen, wären die Versuchstiere im Durchschnitte den Kontrolltieren gleich: man darf sie gegen $25 \%$ abschätzen.

Dagegen würde der Unterschied bei den Mineralstofftieren 1904 auf etwa $12{ }_{0}$ (anstatt $15,9^{0}, 0$ ) herabsinken. Es besteht für mich 
Experimentelle Untersuchungen über die Variabilität der Verdanungsröhre. 675

Tabelle 21.

Versuche über den Einfluß der Salze auf die Darmlänge.

\begin{tabular}{|c|c|c|c|c|c|}
\hline \multirow[b]{2}{*}{ Bezeiehnung der Versuchstiere } & \multirow{2}{*}{$\begin{array}{l}\text { Anzahl } \\
\text { der } \\
\text { Tersuchs- } \\
\text { tiere }\end{array}$} & \multirow{2}{*}{$\begin{array}{l}\text { Durch- } \\
\text { schnittliche } \\
\text { Sörperlänge } \\
\text { in } \mathrm{mm}\end{array}$} & \multirow{2}{*}{$\begin{array}{l}\text { Durch- } \\
\text { schnittliche } \\
\text { Darmläge } \\
\text { in } \mathrm{mm}\end{array}$} & \multicolumn{2}{|c|}{$\begin{array}{l}\text { Verhältnis đer Darmlănge } \\
\text { zur Körperlănge }(=1)\end{array}$} \\
\hline & & & & Betrag & $\begin{array}{l}\text { Veränderung } \\
\text { in \% des } \\
\text { F.-Wertes }\end{array}$ \\
\hline $\begin{array}{c}190 \tilde{s} \\
\text { (mit Froschfleisch ernährte } \\
\text { Tiere }\end{array}$ & 99 & 11,11 & 63,21 & 5,69 & - \\
\hline $\begin{array}{c}\text { (mit Froschfleisch }+ \text { starkem } \\
\text { Zusatz von in Pflanzen vor- } \\
\text { kommenden Calciumsalzen } \\
\text { ernährte Tiere) }\end{array}$ & 128 & 10,66 & 71,51 & 6,71 & $+17,9$ \\
\hline $\begin{array}{c}1904 \\
\text { (mit Froschfleisch ernährte } \\
\text { Tiere. }\end{array}$ & 18 & 11,75 & 72,11 & 6,13 & - \\
\hline $\begin{array}{c}\text { mit Froschfleisch + Zusatz } \\
\text { von verschiedenen in Pflanzen } \\
\text { vorkommenden Salzen er- } \\
\text { nährte Tiere; }\end{array}$ & 55 & 12,11 & 86,16 & 7,11 & $+15,9$ \\
\hline
\end{tabular}

kein Zweifel, daß die bedeutende Darmverlängerung 1905 von dem mächtigen Überschuß des Calcium herrihrt, das in den Mineralstoffen 1904 in weit geringerer Menge zugegen war.

\section{E. Anhang.}

Auf dieser Stelle will ich die Fütterungsversuche mit Semmel bertihren, welche allerdings keine größere Bedeutung besitzen, da die Versuchstiere in großer Anzahl starke Störungen der Entwicklung sowie der Ernährung aufweisen. Die einen hören auf zu fressen und rerkümmern, die Entwicklung wird sistiert, man findet große, hellrosafarbige Leber bei ihnen; die andern entwickeln sich weiter, aber zeigen sebr oft Deformationen besonders am proximalen Teile des Schwanzes, ihre Leber ist blaßgelb gefärbt, die Metamorphose scheint rorzeitig zu kommen, wenigstens findet man oft ungemein kurze und augenscheinlich in Metamorphose begriffene Verdauungsröhren bei ibnen, während die hinteren Extremitäten noch anf ein von der Metamorphose entfernteres Stadium hindeuten.

Die Semmel enthält etwa $90_{0}$ Proteinstoffe, 1\% Fett, $60 \%$. Koblehydrate, ist also eine sehr kondensierte Nahrung; das Fleisch stellt ebenfalls eine sehr ausgiebige Nahrung dar, doch rorzugsweise in 
Form der Proteine, während die Kohlehydrate nur in geringer Menge hier vorkommen.

Tabelle 22.

Versuche mit Semmelernährung.

\begin{tabular}{|c|c|c|c|c|c|c|}
\hline & \multirow[b]{2}{*}{ Bezeichnang der Versuchstiere } & \multirow{2}{*}{$\begin{array}{l}\text { Anzahl } \\
\text { der } \\
\text { Versuchs- } \\
\text { tiere }\end{array}$} & \multirow{2}{*}{$\begin{array}{c}\text { Durch- } \\
\text { schnittliche } \\
\text { Körperlänge } \\
\text { in mm }\end{array}$} & \multirow{2}{*}{$\begin{array}{c}\text { Durch- } \\
\text { schnittliche } \\
\text { Darnlänge } \\
\text { in mm }\end{array}$} & \multicolumn{2}{|c|}{$\begin{array}{l}\text { Verhăltnis der Darmlänge } \\
\text { zur Kơrperlănge }(=1)\end{array}$} \\
\hline & & & & & Betray & $\begin{array}{l}\text { Yeränderung } \\
\text { in } \% \text { des } \\
\text { F.-Wertes }\end{array}$ \\
\hline \multirow[t]{2}{*}{1} & $\left\{\begin{array}{c}1904 \\
\text { mit Froschfleisch ern̈̈hrte } \\
\text { Tiere }\end{array}\right.$ & 32 & 12.40 & 84,84 & 6.84 & - \\
\hline & (m. Semmel ernährte Tiere & 22 & 11.55 & 72,50 & 6,27 & $-8,3$ \\
\hline \multirow[t]{2}{*}{2} & $\left\{\begin{array}{c}1904 \\
\text { mit Froschfleisch ernährte } \\
\text { Tiere })\end{array}\right.$ & 18 & 13,11 & 80,94 & 6,17 & - \\
\hline & (m. Semmel ernährte Tiere) & 21 & 11,77 & 74,47 & 6,32 & $+2,4$ \\
\hline
\end{tabular}

Die beiden Versuchsanordnungen (deren Ergebnisse die Tabelle 22 verzeichnet) zeigen etwas abweichende Resultate, aber man kann doch ersehen, daß die Darmlänge der mit Semmel ernährten Tiere sich nicht viel von derjenigen der Kontrolltiere unterscheidet: da aber die Tiere, welche die Durchschnittszahlen bilden, ausgewählt werden mußten - es sind dies diejenigen, welche am meisten normal zu sein schienen - so sind die sämtlichen Zahlen sehr unverläßlich. Übrigens zeugen auch die bedeutend kleineren Körpergrößen der mit Semmel ernährten Tiere davon, daß hier eine Störung des allgemeinen Wachstums bestand.

7. Weitere Versuche über die chemische Wirkungsweise der Nahrung.

Nach den Ergebnissen der Fütterungsversuche mit Pflanzenproteinen, mit Asparagin und mit den Calciumsalzen kann man schon die bedeutende Vergrößerung der absoluten sowie relativen Darmlänge, wie dieselbe durch die Pflanzennahrung bervirkt wird, viel leichter causal begreifen, als es die Untersuchung tiber die mechanischen Faktoren zuließ. Und zwar ist man berechtigt besonders in den von tierischen Eiweißkörpern differenten Pflanzenproteinen die Hauptursache derjenigen Wachstumsprozessezu sehen, welche die Verlängerung der Verdaungoröhre bei der Pflanzenkost bedingen. 
Auf Grund dieses Befundes wagte ich es, den Gedanken über ähnliche Einwirkungen verschiedener tierischer Eiweißkörper experimentell zu prüfen.

Die Futterungsversuche mit womöglich reinen tierischen Proteinen scheiterten allerdings an den gewaltigen Störungen, welche diese zuviel erkünstelte Nahrung (ähnlich wie die Ernährung mit reinen pflanzlichen Proteinen) hervorruft. Aber um so giüstiger ist die Untersuchung in andrer Richtung gelungen: gegenüber den mit Froschfleisch gefütterten Kontrolltieren stellte ich vier Abteilungen, denen Muskelsubstanz von andern Tierarten vorgelegt wurde. Eine solche Nahrung ist weit natürlicher als künstliche Präparate, und obzwar es unter den verschiedenartigen Muskelgeweben mehrfache Abweichungen im Gehalte an nicht proteinartigen organischen sowie an anorganischen Bestandteilen gibt, so wird ohne Zweifel der gröBte Unterschied doch nur in der Verschiedenheit der Plasmasowie der Stroma-Proteinstoffe bestehen, welche den Hauptteil der trockenen Muskelsubstanz ausmachen. Man kann nach den Ergebnissen der Versuche mit pflanzlicher Proteinsubstanz die eventuellen Verschiedenheiten der Längeentwicklung der Verdaungsröhre bei der Fütterung mit Muskelsubstanz verschiedener Tiere vorzugsweise der chemischen Wirkungsweise der verschiedenen darin enthaltenen Eiweißkörper zuschreiben.

Im Jahre 1905 unternahm ich solche ansgedehnte Untersuchungen. Die Abteilungen der Versuchstiere waren auf folgende Weise geordnet:

1) Kontrolltiere: mit reinem zerriebenen Froschfleisch ernährt.

2) Fischfleischtiere: mit reinem zerriebenem Fleisch von Rhodeus amarus, einem kleinen im großen Aquarium in Vorrat gehaltenen Süßwasserfisch, ernährt.

3) Pferdefleischtiere: mit reinem zerriebenem Pferdefleisch ernährt, das womöglich frisch gekauft wurde.

4) Muschelfleischtiere: mit fein zerriebenen Schliebmuskeln und muskulösem Randabschnitt des Fußes von Anodonta gefüttert.

5) Krebsfleischtiere: mit zerriebenen Abdominal- und Scherenmuskeln von Astccus fluviatilis ernährt.

6) Pflanzenproteintiere: über dieselben wurde schon früher berichtet (s. die Tabelle 19). 
Tabelle 23.

Fütterangsversuche mit verschiedenen Fleischarten und mit Pflanzenproteinsubstanz. Versuchszeit 1905 .

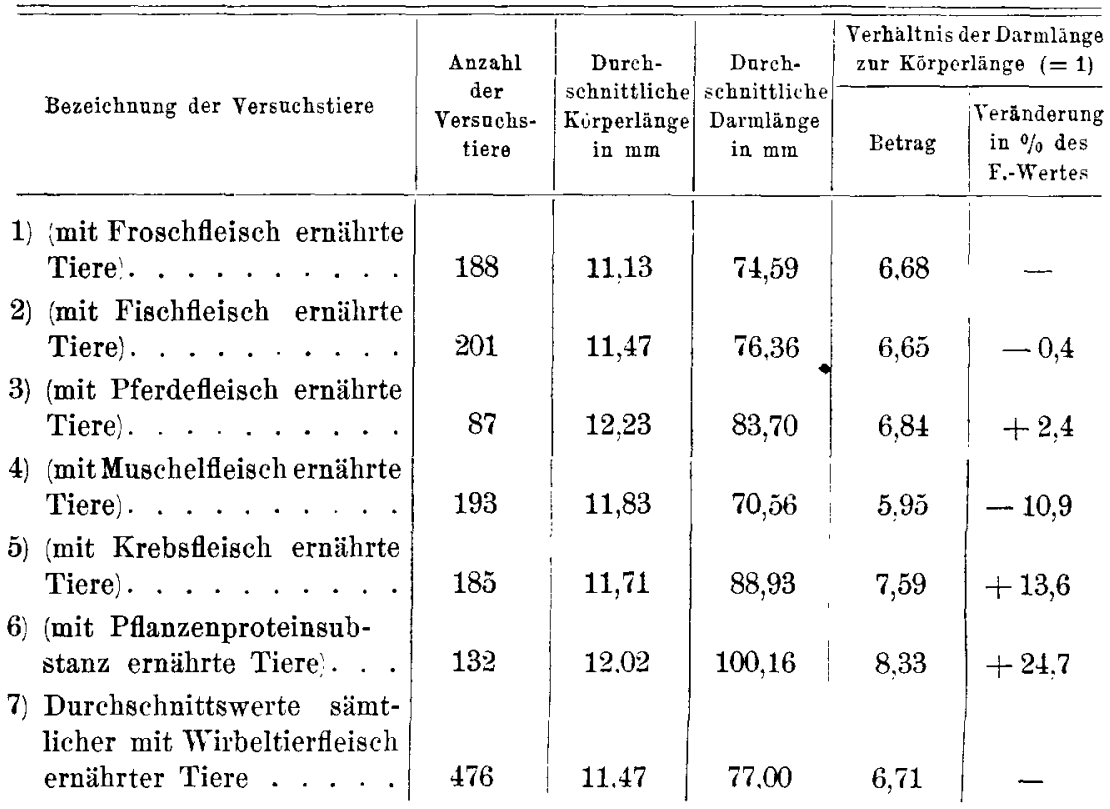

Wie schon in IV. 2 erwähnt wurde, zeigten die Pferdefleischtiere - besonders in späterer Zeit - weit öftere Fälle von abnormaler Entwicklung, Störung der Ernährung, als die übrigen Fleischtiere. Die Pflanzenproteintiere waren sehr uppig, erst am Ende der Versuchszeit sah man unter ihnen zahlreichere verkümmernde Indiriduen. Die Fischfleischtiere waren in ihrer Entwicklung gegenüber den andern Fleischtieren im ganzen etwas verspätet, aber sie sahen anders gut aus und in der letzten Versuchszeit haben sie rasch die iibrigen eingeholt. - (Die siebente Abteilung - durch Tiere gebildet, welche mit "Pflanzenfibrin « ernährt wurden - ist bald in der Entwicklung hinter den übrigen geblieben, wies immer mehr verkümmerte und kranke Individuen auf und konnte überhaupt nicht zu irgendwelchen Schlüssen verwendet werden.) -

Die einzelnen Versuchsabteilungen sind eigentlich direkt untereinander kaum vergleichbar, da sie abweichende durchschnittliche Körperlängen besitzen; man muß also darauf Rücksicht nehmen, was über die Beziehung der Darmlänge zur Körpergröße in IV. 3 sichergestellt worden ist. 
Von den mit Wirbeltierfleisch gefuitterten Larven haben die Pferdefleischtiere die größte Körperlänge, worauf man auch die gegenüber den Kontrolltieren um etwas längere Verdaunngsröhre beziehen muß. Im ganzen aber ist klar zu sehen, daß die absolute sowie relative Darmlänge bei den sämtlichen mit Wirbeltierfleisch ernährten Kaulquappen ungefähr übereinstimmt. Wir sind rollkommen berechtigt von diesen drei Abteilungen große Durchschnittswerte zu ziehen, welche in der 7. Zeile der Tabelle 23 eingetragen sind: und mit diesen großen Durchschnittswerten könnte man dann mit Vorteil die übrigen Abteilungen rergleichen.

Dem gegeniber bewirkt die Muskelsubstanz der Wirbellosen bedeutende Differenzen in der Längeentwicklung der Verdauungsröhre: und zwar die Muskeln der beiden benutzten Repräsentanten der Wirbellosen üben eine entgegenges etzte Wirkung aus. Während das Krebsfleisch stark darmverlängernd einwirkt, so daß sich der Darmkanal dieser Tiere stark demjenigen der Pflanzenproteintiere nähert, bemerken wir bei den mit Muschelfleisch gefutterten Kaulquappen eine Verkürzung der Darmröhre bedeutend unter den Betrag der Kontrolltiere (und iberhaupt der mit Wirbeltierfleisch ernährten Larven).

Dies ist der erste Fall, wo wir im Vergleich mit den Frosehfleisch-Kontrolltieren nebst den vielen darmverlängernden Einflüssen auch einen darmverkürzenden kennen gelernt haben!

Die Muschelfleischtiere sowie die Krebsfleischtiere sind aber im Durchschnitte etwas größer als der Durchschnittswert sämtlicher mit Wirbeltierfleisch ernährten Tiere. Bei den Muschelfleischtieren sollen wir also die Verkürzung der Verdauungsröhre noch höher anschlagen, den Krebsfleischtieren aber von der Darmverlängerung etwas abnehmen. -

Der Schluß also, welchen wir auf Grund der Untersuchungen über die chemische Wirkungsweise der Pflanzennahrung gefaßt haben - daß es sich nämlich vorzugsweise um die Proteinejnwirkung handeln wird - glauben wir durch diese Versuchsanordnung bestätigt zu haben.

Wir möchten nun fragen, ob tatsächlich auch zwischen den Muskeleiweißkürpern der verschiedenen Tiere irgendwelche chemische Unterschiede bekannt sind. Bei den Wirbeltieren kommen nach den bisherigen Kenntnissen nur kleinere Unterschiede vor (s. oben die Abteilung I). Die Wirbellosenmuskeln werden aber nach den 
neueren Untersuchungen, was ihre Plasmaproteine betrifft (das Stroma ist uberhaupt nicht geprüft worden), sehr von den Wirbeltiermuskeln abweichend sein (46): in den Muskeln von Octopoden, Sepien (und Holothurien) kommt kein typisches Myosin vor, nach Przibrax (47) ist bei den Wirbellosen auch kein typisches Myogen vorhanden, ebensowenig konnte auch das lösliche Myogenfibrin bei ihnen mit Sicherheit nachgewiesen werden. Es werden also zwischen den Wirbeltier- und Wirbellosenmuskeln gewaltige Unterschiede der Eiweißkörper vorkommen: dem entsprechen auch die Ergebnisse unsrer Versuche, wo wir in der morphogenetischen Reaktion des Darmkanals gleichsam den Hinweis auf näher unbekannte chemische Differenzen erblicken dürfen.

Die neueren Forschungen über die Antikörperbildung nach der parenteralen Einfuihrung von Muskelserum verschiedener Herkunft in den Kaninchenorganismus (s. z. B. 55) beweisen aber, daß die Eiweißkörper des Muskelplasmas selbst z. B. von zwei höheren rerwandten Säugetieren chemisch different sein müssen, sowie daß auch die Eiweißkörper der rerschiedenen Organe desselben Tieres untereinander sich unterscheiden.

Die - im Vergleich mit den Kontrolltieren - darmverlängernde Einwirkung des Krebsfleisches und die darmrerkiirzende Einwirkung des Muschelfleisches möchten unsrer Meinung nach von bedeutenden chemischen Differenzen der Muskel-Proteine dieser Tiere zeugen (62).

8. Über die Einwirkung der Nahrung auf die Weite der Verdaungsröhre.

Wir haben bisher nur uiber die Änderungen der absoluten und relativen Darmlänge als Folgen der vorzugsweise chemischen Einwirkung der Nahrung gehandelt.

Schon in meiner ersten Publikation über diesen Gegenstand $(6)$ habe ich ausdrücklich betont, daß die Verdaungsröhre der pflanzenfressenden Frosehlarven bedeutend länger und enger ist als diejenige der Fleischfresser; dies ist auch an den schematischen Bildern zu sehen, die ich beigelegt habe. Ich habe auch aber ganz grob und annähernd - die Änderung der Darmoberfläche und des Darminhaltes bei den pflauzenfressenden Tieren gegenüber den Kontrolltieren abgeschätzt. Diese Angaben sind allerdings sehr unvollkommen, und deshalb habe ich im Winter dieses Jalres genaue Messungen ausgeführt; dieselben betreffen jedesmal 10 Tiere von den 
Experimentelle Untersuchungen ïber die Variabilität der Verdauungsröhre. 681

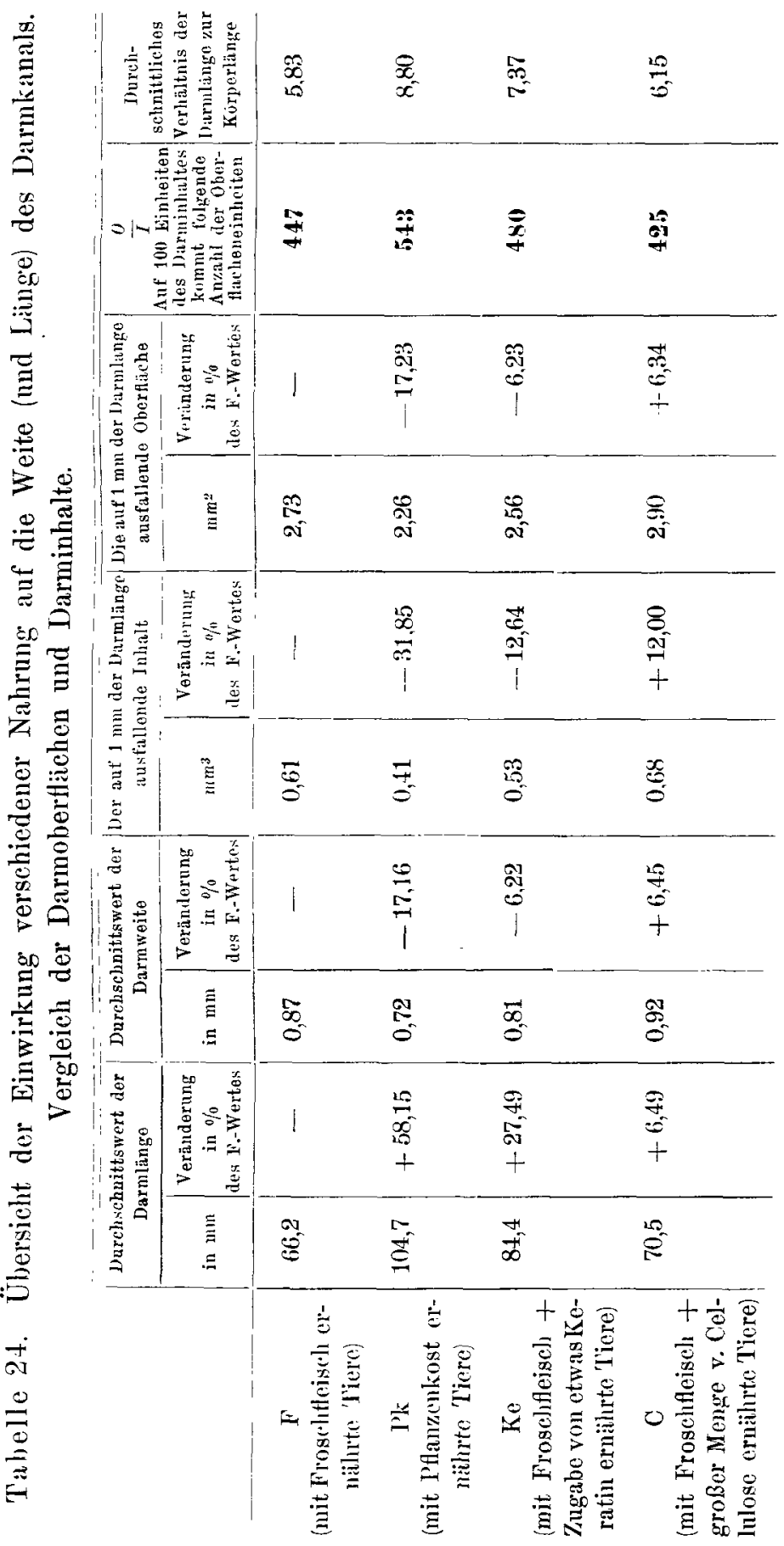


Hauptabteilungen der Versuche über mechanische und chemische Faktoren der Nahrungseinwirkung. Es ist unmöglich, das ganze Material von dieser Seite ans zu bearbeiten, denn die Messungen der Weite der Verdauungsröhre sind weit schwerer durchzuführen als die Längebestimmungen. Es handelt sich iibrigens um fester basierte Durchschnittswerte, welche man schon von je zehn Individuen jeder Abteilung erhalten kann. Man muß allerdings diese Individuen auswählen, aber nur nach der Körpergröße, damit man sie ohne großen Fehler vergleichen könnte: also zu den zehn ganz zufällig genommenen Kontrolltieren sucht man dann in jeder Abteilung zehn womöglich gleich große Individuen aus.

Jede Zeile der Tab. 24 enthält die Durchschnittswerte von zehn Larven der betreffenden Abteilung.

Die Darmlängen der Pflanzenfresser, der Keratin- und der Cellulosetiere bilden, wie klar zu sehen ist, eine absteigende Reihe; dies wird besonders an den $\%$-Vergleichszahlen veranschaulicht. Wir haben gesehen, daß die Cellulose nur unbedeutende Verlängerung des Darmkanals hervorruft.

Aber neue Verhältnisse werden uns in der zweiten Columne der Tabelle gezeigt: während nämlich die Pflanzenkost eine starke, das Keratinfleisch eine schwächere Verengerung der Verdaungsröhre bewirken, übt die Cellulose eine merkliche Darmerweiterung aus. Wir konstatieren also, daß die mächtige mechanische Wirkung der großen Cellulosemengen, in denen das Fleisch in sehr starker *Verdünnung* vorkam, hauptsächlich in der Vergrößerung des Darmdurchmessers und nur nebensächlich in kleiner Verlängerung des Darmkanals sich kundgibt.

In der dritten Kolumne wird der auf $1 \mathrm{~mm}$ Darmlänge ausfallende Darminhalt für die einzelnen Abteilungen angegeben. Hier finden wir die soeben besprochene Tatsache der darmerweiternden Einwirkung großer Cellulosemassen sehr schön dargestellt, wogegen bei der Pflanzenkost und bei der Keratinfleischfütterung eine entgegengesetzte Erscheinung zutage tritt.

In der vierten Kolumne wird derselbe Befund anders ausgedrtickt: in den auf $1 \mathrm{~mm}$ Darmlänge kommenden Darmoberflächen.

Der in der fünften Kolumne angeführte Koeffizient $-O$ d. h. Vergleichszahl der Darmoberfläche zum Darminhalt, ist am meisten geeignet, die stattfindenden komplizierten Änderungen in der Beschaffenheit der Verdauungsröhre anszudrücken. 
Experimentelle Untersuchungen über die Variabilität der Verdauungsröhre. 683

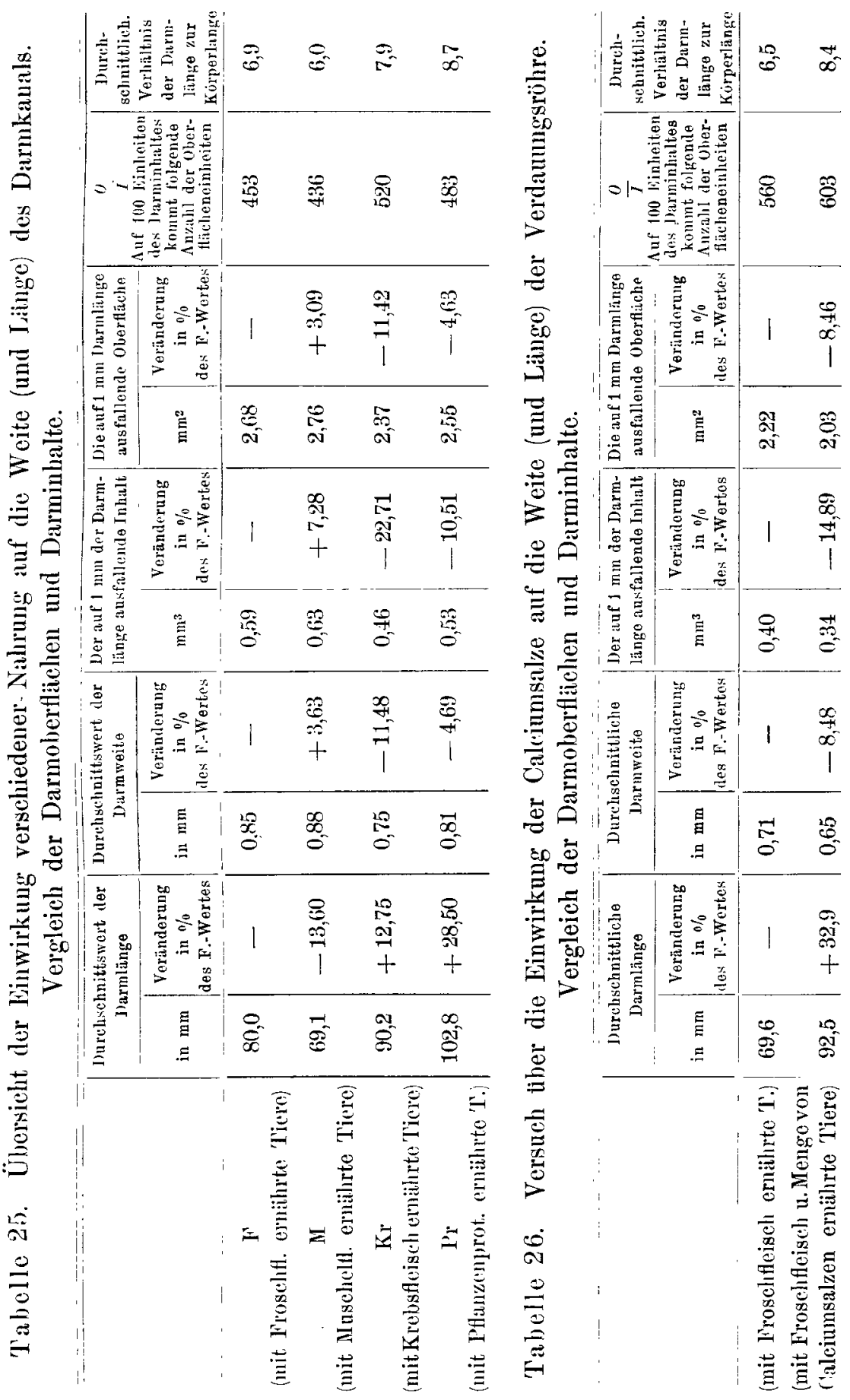


Eine gleiche Struktur besitzt die Tabelle 25.

Zuerst beobachtet man die darmverkürzende Beeinflussung des Muschelfleisches, die darmrerlängernde Einwirkung des Krebsfleisches und gar der Pflanzenproteinsubstanz.

In der zweiten Kolumne findet man eine stark verengende Wirkung des Krebsfleisches, bedeutend höhere Wirkung als diejenige der Pflanzenproteinsubstanz. Das Muschelfleisch aber wirkt ein wenig darmerweiternd: man begreift gleich, daB es sich hier keineswegs um eine mechan ische Beeinflussung handeln wird wie bei der Cellulose, sondern höchstwahrscheinlich um eine chemische Wirkungsweise.

Die dritte und vierte Kolumne illustrieren das Verhalten des Darminhalts und der Darmoberfläche auf $1 \mathrm{~mm}$ der Darmlänge. Aber es ist besonders der Koeffizient $\frac{O}{I}$, welcher uns in erster Reihe die Umwandlungen der Verdanungsröhren klarlegt: die verhältnismäßig kleine Vergrößerung der Darmlänge, aber große Verengerung der Darmweite fuhren bei den Krebsfleischtieren zu bedeutenderer Vergrößerung der relativen Darmoberfläche $(5,20)$, als die verhältnismäßig starke Verlängerung, aber kleinere Verengerung des Darmkanals bei den Pflanzenproteintieren. -

Nachdem in den vorhergehenden Abschnitten gezeigt wurde, daß die Pflanzenkost eine Darmverlängerung viel eher durch ihre chemische als mechanische Einwirkung hervorruft, können wir nun vielleicht eben dasselbe behaupten, was die darmverengernde Beeinflussung der Pflanzenkost betrifft.

Bezüglich des Einflusses großer Cellulosemengen auf die Weite des Darmkanals haben wir soeben gesehen, daß derselbe merklich positiv ist; ebenfalls die Glaspulverfutterung, wie man schon durch bloße Inspektion der Verdauungsröhren konstatieren kann, führt zu keiner Verengerung derselben, eher im Gegenteil. Dagegen durch die Pflanzenproteinsubstanz konnte eine kleine Verengerung des Darmkanals erzielt werden. Und auch die Calciumsalze führen zu einer deutlichen Verkleinerung der Darmweite (s. Tab. 26).

Wenn man die Koeffizienten $\frac{O}{I}$ zur Hand nimmt, so kanı man ungefähr folgende Abschätzung machen: durch die Pflanzenkost wurde diese Größe (s. Tab. 24) um 21,50,0 erhöht. Die Pflanzenproteinsubstanz hat eine positive Ïnderung nur um $6,60^{\circ}, 0$ bewirkt (s. Tab. 25 ). 
Die Calciumsalze verursachen, wie die Tab. 26 zeigt, eine Vergrößerung. um $7,7 \%$. Es müssen also nebst diesen zwei chemischen Faktoren, deren darmverengernde Einwirkung sichergestellt ist, in der Pflanzenkost noch andre in gleichem Sinne wirkende Stoffe anwesend sein; um so mehr, als die Voluminosität der Pflanzenkost wahrscheinlich in entgegengesetzter Richtung tätig ist (s. die Cellulosewirkung in der Tab. 24).

9. Über die Struktur der Darmwand, Größe der Leber usw.

Nach den Untersuchungen von Ratxer und Reuter (56) beruht das mächtige Längenwachstum des Mitteldarms zur Dünndarmspirale bei den Anurenlarven auf starkem Wachstum des Epithelrohrs. Bindegewebe und Darmmuskulatur bleiben zurïck und erscheinen so auseinandergedrängt, daß man auf dem Querschnitt des Darms kaum etwas davon sieht. Jedenfalls bildet die Muscularis keine geschlossene Schicht, ebenso ist das Bindegewebe des Larvendarms ungemein spärlich und zart.

Um die eventuellen Unterschiede der Darmwandstruktur bei den mit verschiedener Nahrung ernährten Tieren aufzufinden, habe ich Serienschnitte durch die Verdanungsröhren gleich großer und gleich entwickelter Tiere angefertigt und dieselben einerseits mittels Zeichenapparats abgebildet, anderseits einfach die Darmwanddicke mit Hilfe des Projektionsapparates verglichen. Es herrschen aber in den einzelnen Abschnitten des Darmkanals bedeutende Unterschiede nicht nur der Darmweite, sondern auch der Darmwanddicke, nnd zwar sowohl des Epithels als auch der Muskelschicht; ebenfalls gibt es große Unterschiede in der Anzahl der Epithelzellen bei gleich großen Durchschnitten an verschiedenen Stellen der Darmröhre. Dadurch wird die Vergleichung sehr erschwert; dazu kommen noch die großen Abweichungen der Längeentwicklung der Darmröhre bei den Fleischund Pflanzenfressern, wo man nur mit Mühe die einander entsprechenden Abteilungen ungefähr bestimmen kann.

Im ganzen kann ich Ratrers und Recters Angaben sowohl bei den fleischfressenden als auch bei den pflanzenfressenden Tieren bestätigen: der bedeutend in die Länge ausgewachsene mittlere Abschnitt der Verdaungsröhre ist fast nur durch das Epithelrohr repräsentiert, welches dazu noch in langen Strecken aus sehr niedrigen Zellen besteht, so daß die Darmwand äußerst dünn ist. Im Anfangsteil des Mitteldarmes ist die Epithelschicht hoch und es werden hier auch niedrige Längsfalten rorgefunden; die 
Muskelschicht ist zuerst so entwickelt, daß sie beinahe die Dicke der Epithelschicht erreicht, aber bald verdinnt sie sich und geht beinahe verloren; zuweilen werden noch in weiterem Verlauf Strecken mit deutlicher Muskelschicht gefunden, regelmäßig gegen das Ende der Darmröhre. Es gelang nicht, irgendwelche bestimmt ansgedrückte Unterschiede weder in der totalen Dicke noch in der Höhe der Epithelzellen und in der Ausbildung der Muskelschicht usw. bei den fleisch- und pflanzenfressenden Tieren sicherzustellen. Im ganzen werden bei den pflanzenfressenden Larven gröBere Abschnitte >ohne Muskelschicht gefunden als, bei den fleischfressenden, so daß man vielleicht sagen könnte, daß der schon bei fleischfressenden Tieren eingeleitete Prozeß der Dünndarmspiralenbildung, welcher vorzugsweise durch das Wachstum des Epithelrohres zustande kommt, durch die Pflanzennahrung bedeutend gefördert wird; es werden auch bei den pfanzenfressenden Kaulquapen weit größere Strecken von sehr niedriger Epithelschicht - zugleich mit aufallender Verengerung der Darmweite - gesehen als bei den Fleischfressern.

Bei der histologischen Bearbeitung des Materials schien mir zuerst, $\mathrm{da} B$ bei den pflanzenfressenden Tieren die Leber und dà̀ Pancreas mächtiger entwickelt sind als bei den fleischfressenden Tieren, sowie daß sie einige abweichende Charaktere histologischer und cytologischer Art aufweisen. Aber weitere Untersuchungen haben diese vermeintlichen Unterschiede immer unbestimmter gemacht.

Auch in der Größeentwicklung der Leber und des Pancreas bestehen vielleicht keine Unterschiede. Ich habe von den Fleischfressern und Pflanzenfressern je 25 Tiere ausgesucht, und zwar so, daß immer ein Paar der Körpergröße sowie der Entwicklung nach gleich war; dann bestimmte ich das totale Gewicht jeder Abteilung und das Gewicht der ausgenommenen Leber und Pancrease.

Die 25 Fleischfresser haben $6,993 \mathrm{~g}$ gewogen, ihre Leber und Pancrease 0,243 g; die 25 Pflanzenfresser haben 6,863 g gewogen, ihre Leber und Pancrease 0,213 g.

Wenn wir die Gewichte der Drïsen auf Totalgewicht beziehen, bekommen wir $3,46 \%$ bei den Fleischfressern, $3,10 \%$ bei den Pflanzenfressern.

Houssay (25) hat bei der Fleischfütterung der Hühner selbst bei der zweiten fleischfressenden Generation fast keine Änderung der relativen Größe der Leber gefunden. MLudrel (57) aber glaubt, für 
Experimentelle Untersuchungen über die Variabilität der Verdauungsröhre. 687

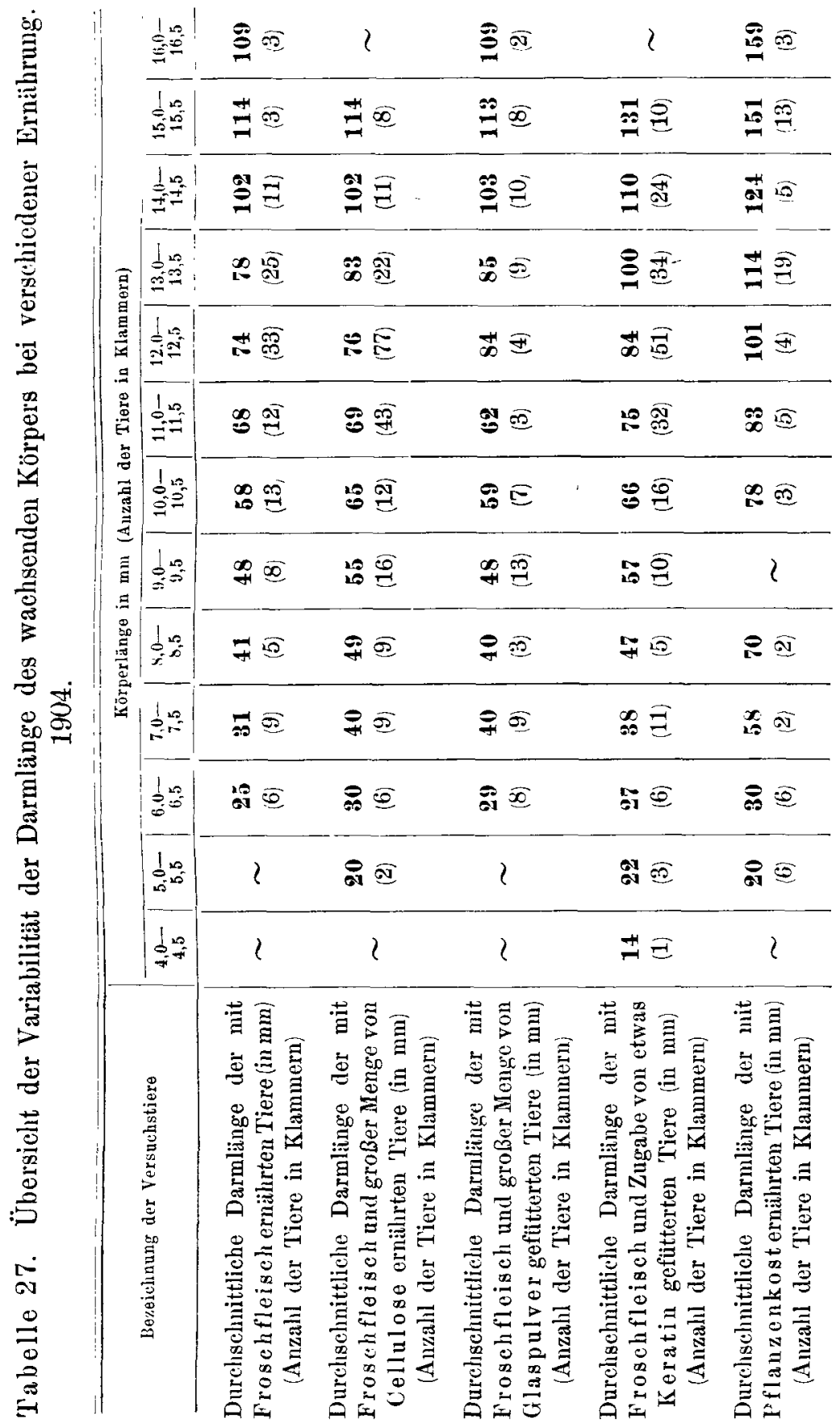


die mit Fleischkost ernährten Tiere eine Vergrößerung der Leber sichergestellt zu haben. -

Auch die histologische Durchmusterung der Excretionsorgane hat keine irgendwie anffallende Unterschiede ergeben.

10. Einige Beispiele der Variabilität der Darmlänge bei fortschreitender Entwicklung (und wachsender Körpergröße).

Nachdem im Abschnitt IV. 3 die für die Beurteilung der Darmlängeänderungen bei verschiedenartiger Fütterung nötigen Kenntnisse über die Beziehung der Darmlänge zur fortschreitenden Entwicklung und wachsender Körpergröße gegeben worden sind, wollen wir nun noch einige Beispiele dieser Variabilität den verschiedenen Fütterangsversuchen entnehmen (Tab. 27-29).

\section{Tabelle 28.}

Übersicht der Variabilität der Darmlänge des wachsenden Körpers bei Ernährung mit verschiedenen Fleischarten und mit Pflanzenproteinsubstanz. 1905 .

\begin{tabular}{|c|c|c|c|c|c|c|}
\hline \multirow{2}{*}{ Bezeichnung der Versuchstiere } & \multicolumn{6}{|c|}{ Kürperlänge in mm (Anzahl der Tiere in Klammern) } \\
\hline & $5,0-$ & $\begin{array}{c}10,0- \\
10,5\end{array}$ & $\begin{array}{l}11,0- \\
11,5\end{array}$ & $\begin{array}{l}12,11-5 \\
12,5\end{array}$ & $\begin{array}{c}13,0- \\
13,5\end{array}$ & $\begin{array}{c}14,0-- \\
14,5\end{array}$ \\
\hline $\begin{array}{c}\text { Durchschnittliche Darmlänge der mit } \\
\text { Froschfleisch ernährten Tiere (Anzahl } \\
\text { der Tiere in Klammern) }\end{array}$ & $\begin{array}{l}\mathbf{5 1} \\
(25)\end{array}$ & $\begin{array}{c}63 \\
(39)\end{array}$ & $\begin{array}{l}77 \\
(6 \pm)\end{array}$ & $\begin{array}{l}87 \\
48\end{array}$ & $\begin{array}{l}95 \\
(6)\end{array}$ & $\begin{array}{c}103 \\
6\end{array}$ \\
\hline $\begin{array}{l}\text { Durchschnittliche Darmlïnge der mit } \\
\text { Fischfleisch ern̈̈hrten Tiere }\end{array}$ & $\begin{array}{l}\mathbf{4 9} \\
13 ;\end{array}$ & $\begin{array}{r}\mathbf{5 9} \\
(34\end{array}$ & $\begin{array}{r}74 \\
66\end{array}$ & $\begin{array}{c}85 \\
(68\rangle\end{array}$ & $\begin{array}{r}101 \\
(12)\end{array}$ & $\begin{array}{c}105 \\
(8)\end{array}$ \\
\hline $\begin{array}{c}\text { Durchschnittliche Darmlïnge der mit } \\
\text { Pferdefleisch ernährten Tiere }\end{array}$ & & $\begin{array}{l}62 \\
10\end{array}$ & $\begin{array}{l}\mathbf{7 3} \\
(30)\end{array}$ & $\begin{array}{l}\mathbf{8 1} \\
31\end{array}$ & $\begin{array}{r}93 \\
(12)\end{array}$ & $\begin{array}{c}101 \\
6)\end{array}$ \\
\hline $\begin{array}{l}\text { Durchschnittliche Darmlänge der mit } \\
\text { Nuschelfleisch erü̈hrten Tiere }\end{array}$ & $\begin{array}{l}45 \\
12\end{array}$ & $\begin{array}{r}55 \\
(15)\end{array}$ & $\begin{array}{l}67 \\
(51)\end{array}$ & $\begin{array}{l}73 \\
(79)\end{array}$ & $\begin{array}{l}81 \\
(30)\end{array}$ & $\begin{array}{l}87 \\
(6)\end{array}$ \\
\hline $\begin{array}{c}\text { Durchschnittliche Darmlänge der mit } \\
\text { Krebsfleisch ernährten Tiere }\end{array}$ & $\begin{array}{l}51 \\
(15)\end{array}$ & $\begin{array}{l}67 \\
(19)\end{array}$ & $\begin{array}{l}83 \\
(42)\end{array}$ & $\begin{array}{l}97 \\
80)\end{array}$ & $\begin{array}{r}\mathbf{1 0 9} \\
26 !\end{array}$ & $\begin{array}{c}115 \\
(3)\end{array}$ \\
\hline $\begin{array}{l}\text { Durchschnittliche Darmlïnge der mit } \\
\text { Pflanzenproteinsubst, ernährten Tiere }\end{array}$ & $\begin{array}{l}58 \\
i 7\end{array}$ & $\begin{array}{l}50 \\
(7 !\end{array}$ & $\begin{array}{r}86 \\
(27)\end{array}$ & $\begin{array}{r}105 \\
57\end{array}$ & $\begin{array}{l}118 \\
(32)\end{array}$ & $\begin{array}{c}121 \\
(2)\end{array}$ \\
\hline $\begin{array}{l}\text { Durchschnittl. Darmlänge sämtli } \\
\text { mit Wirbeltierfleisch ernährten } T\end{array}$ & $\begin{array}{l}\mathbf{5 0} \\
(38)\end{array}$ & $\begin{array}{l}61 \\
83)\end{array}$ & $\begin{array}{c}\mathbf{7 4} \\
(160\end{array}$ & $\begin{array}{c}85 \\
(147)\end{array}$ & $\begin{array}{c}94 \\
(30)\end{array}$ & $\begin{array}{c}103 \\
(20)\end{array}$ \\
\hline
\end{tabular}

Bei den pflanzenfressenden Tieren steigt die Darmlänge anfangs rasch, dann langsamer und später wieder schneller; wir werden dabei 
Experimentelle Untersuchungen über die Variabilität der Verdauungsröhre. 689

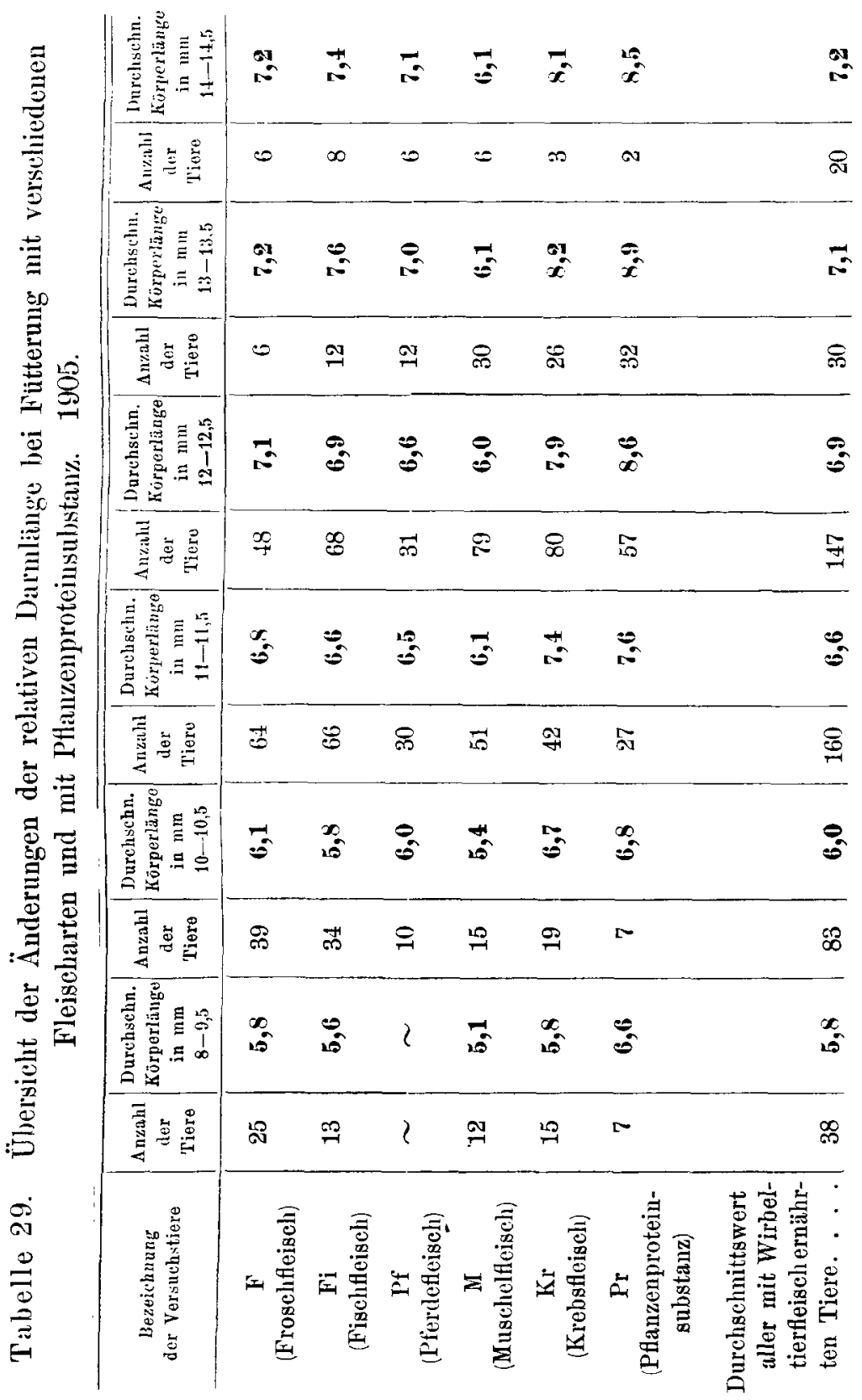


auf die in IV. 3 berührte Beobachtung Yuxgs erinnert. Eine ähnliche „Stagnation * des Darmkanalwachstums wird bei den Cellulosetieren bei der Körperlänge 10,0-11,5, ebenfalls bei den Glaspulvertieren bemerkt; bei den Kontrolltieren fällt sie zwischen 11,0-13,5.

Die Tabelle 28 sowie die 29. stellen eine detaillierte Übersicht der mit rerschiedenen Muskeln gefütterten Tiere dar.

\section{v. Schluk.}

In der Einleitung habe ich den Versuch gemacht, die Komplexität (Rocx) des Problems der morphologisch-physiologischen Beziehungen der Verdaungsröhre zur Nahrung anzudeuten. Ich will jetzt die Ergebnisse meiner im vorigen Abschnitte geschilderten experimentellen Untersuchungen im Sinne jener theoretischen Auseinandersetzung in aller Kürze besprechen.

Die eigentliche Funktion der Verdaungsröhre besteht in der Verarbeitung der aus der AuBenwelt stammenden Nabrungsstoffe zu geeigneten ernährenden Bestandteilen des »inneren Mediums (Clacde Bernard). In dem einfachsten Falle handelt es sich um bloßen Transport der absorbierbaren Nahrungsstoffe von der Darmoberfläche in das innere Medium; oft muB aber die rerdauende Darmoberfläche die Nahrungsstoffe vorher bearbeiten: dies geschieht durch spezifische in den Drüsenzellen entstehende physicochemisch wirkende Instrumente - die Enzyme der Verdauungssäfte, wonach die Spaltungsprodukte absorbiert werden. Endlich werden in den Darmepithelien selbst an den absorbierten Stoffen oft weitreichende synthetische Prozesse verrichtet, indem besonders die Spaltungsprodukte der fremden Proteine zu arteignen Eiweißkörpern assimiliert werden.

Es ist ohne weiteres klar, daß rerschiedene Nahrung diese Tätigkeiten der Verdauungsröhre in verschiedener Weise beanspruchen wird. Dabei stellt die der Quantität und Qualität nach hochgradig verschiedene Nahrung eine sehr variable komplexe Gruppe von direkten Reizfaktoren vor, und die in dem Darmkanal entstehenden Spaltungsprodukte werden ebenfalls ungemeine Mannigfaltigkeit der Reizwirkung aufweisen.

Auf der andern Seite aber kann eine und dieselbe Nahrung in verschieden organisierten Verdauugsröhren ohne Zweifel verschiedenartige Reizgruppen darbieten und hochgradig verschiedene Ansprüche an ihre Tätigkeiten erheben. 
Von den experimentell hervorzurufenden morphologisch-physiologischen Änderungen der Beschaffenheit der Verdauungsröhre ist an der ersten Stelle die Beeinflussung ihres Längewachstums zu nennen, dann auch die Einwirkung auf das Wachstum in die Weite: durch Kombinierung dieser zwei Wirkungen kann man in hohem Maße die Ausgestaltung der Verdanungsröhre verändert sehen. Daneben können noch Änderungen in der Dicke der Darmwand usw. erscheinen.

Die größten Unterschiede in der Ausbildung der Verdanungsröhre werden bei den omnivoren Froschlarven einerseits durch reine Fleisch-, anderseits durch reine Pflanzennahrung erzielt.

Um die komplexe Erscheinung des bedeutend geförderten Längewachstums und der zugleich stattfindenden Verengerung der Darmröhre bei den pflanzenfressenden Larven nach W. Rouxs Programm causal-analytisch zu erforschen, wurden vor allem die einfachsten möglichen Wirkungsweisen - die mechanischen - gepriff. Aber sowohl eine übertriebene Druckwirkung einer sehr voluminösen Nahrung als auch eine hochgradige Reibungswirkung derselben führen - bei Fütterung mit denselben (chemischen) Nahrungsstoffen, mit welchen allein die Kontrolltiere ernährt werden - zu keiner bedeutenden Verlängerung der Verdauungsröhre; es kommt auch keine Verengerung des Darmkauals zustande, im Gegenteil scheint die roluminöse Nahrung durch ihre Druckwirkung eine Erweiterung desselben hervorzurufen.

Durch die Ergebnisse der Keratinfutterung wurde die Aufmerksamkeit auf die chemischen Reizquellen der Nahrung gelenkt und tatsächlich auch durch weitere causal-analytische Versuche ihre Wirksamkeit in drei Richtungen für die Pflanzenkost sichergestellt. Die pflanzlichen Proteine und die Calciumsalze bewirken sowohl die Verlängerung als auch die Verengerung der Verdaungsröhre; auch das Asparagin bedingt eine merkliche Verlängerung derselben.

Diese causal-analytischen Betrachtungen sowie die darauf gegründeten experimentellen Untersuchungen betrafen die Wirkungsweise der Nahrung hauptsächlich als einer aus der Außenwelt in den Organismus aufgenommenen Reizgruppe; ich habe absichtlich diesen möglichst einfachen Standpunkt eingenommen, um auf womöglich einfachem Wege in die Komplexitit der Wirkungsweise der Nahrung eine Einsicht machen zu können.

Die chemische Wirkungsweise der pflanzlichen Nahrung wird aber sehr wabrscheinlich kompliziert sein, so daß unsre causale 
Analyse vielleicht nicht nur nicht sämtliche beteiligte chemische Faktoren erschlossen hat, sondern daß auch bei den sichergestellten Reizen die Analyse gar nicht in die Tiefe eingedrungen ist. Zum Beispiel kann man bei den Pflanzenproteinen kaum an bedentende direkte chemische Einwirkung auf die Darmwand denken; denn die Proteine selbst sind überhaupt chemísch sehr indifferente Stoffe. Es ließe sich eher der Gedanke begründen, daß die Spaltungsprodukte dieser Proteine eine chemische Reizquelle bilden, und daß die Spaltungsprodukte der pflanzlichen Proteine sozusagen specifisch darmverlängernd und darmverengernd wirken. Allerdings wissen wir bisher sehr wenig über die Verschiedenheit der bei Einwirkung der Verdauungssiffte entstehenden Spaltungsprodukte der tierischen und pflanzlichen Eiweißkörper.

Wenn wir diesen $\gg$ reizphysiologischen Standpunkt verlassen und der verdauenden Tätigkeit der Darmwand unsre Aufmerksamkeit zuwenden, erscheinen uns neue Möglichkeiten, die Ergebnisse der beschriebenen experimentellen Untersuchmngen zu begreifen. Die drei unterschiedenen Hauptfunktionen der Darmepithelien - Secretion der Verdaungssäfte, Absorption und Assimilation - werden ohne Zweifel bei den sowohl der quantitativen als auch der qualitativen Seite nach so verschiedenen Nahrungen, wie sie das Fleisch und die grïnen Pflanzenteile repräsentieren, in quantitativer sowie qualitativer Hinsicht sehr verschiedenartig in Anspruch genommen. Dadurch aber werden die sämtlichen Lebenstätigkeiten der Verdauungszellen entsprechend verändert, und als dessen Ausdruck sehen wir dann die Wachstums- und Gestaltungsprozesse der ganzen Verdauungsröhre bei der andauernden Fleisch- und Pflanzenfütterung verschiedenartig durchlaufen.

Es gibt zahlreiche Untersuchungen in der Physiologie der Ernährung, welche sich mit der Verdaulichkeit, Ausgiebigkeit und Ausnutzbarkeit der Fleisch- und Pflanzenkost beschäftigen. Im ganzen hat man gefunden, daß die Pflanzennahrung iiberkutupt und besonders die aus griinen Pflanzenteilen bestehende Nahrung schwerer verdaulich, weniger ausgiebig und schlechter ausnutzbar ist. Die Versuche berühren allerdings in erster Reihe die höheren Wirbeltiere; aber die an omnivoren Sängetieren und Vögeln gewonnenen Errebnisse dürfen wir gewiß auf die omnivoren Froschlarven ausdehnen.

Es scheint, daß die schlechte Ausnutzbarkeit der Pflanzennahrung. und ihre schwere Verdaulichkeit nicht nur durch die sozusagen mehr mechanische Beschaffenheit derselben bedingt sind: auch wenn 
wir davon absehen, daß die in den Cellulosewänden enthaltenen Nahrungsstoffe für die Verdauungssäfte nicht genügend zugänglich sind, daß sie in starker *Verdünnung * vorkommen, und durch die rege Peristaltik, welche durch die mechanische Reizwirkung der Cellulosetrümmer ausgelöst wird, verhältnismäßig rasch mit dem ganzen Darminhalt ausgestoßen werden, finden wir eine Reihe von Angaben vor uiber die eher chemisch begründete schwerere Verdaulichkeit der Pflanzenproteine.

Dazu lassen sich verschiedene Befunde anführen ubber die Beziehung der Secretion der Verdaunngssäfte zur Beschaffenheit der Nahrung: so z. B. hat Pawlov (58) auf Brotzufuhr im Magen die Secretion eines viel stärker wirkenden Saftes konstatiert als nach Fleisch; die Quantität und die Qualität der Verdauungssäfte richtet sich oft nach der Natur der Nahrung.

Wenn schon die Kenntnisse iiber chemische Differenzen der Proteine - und besonders der tierischen und pflanzlichen Proteine bisher ganz ungeniigend sind, und wenn es daher auch unbekannt ist, inwieweit die tierisehen und pflanzlichen, und uberhaupt die verschiedenen Eiweißkörper durch Verdauungssäfte eines und desselben Tieres in rerschiedene Proteosen, Peptone usw. umgewandelt werden, so kann man über die Assimilationsprozesse in den Darmepithelien nur gewisse Vermutungen aussprechen. Es läßt sich glauben, daß die Konstruktion der arteignen Proteine aus den Trümmern der artfremden Nahrungseiweißkörper verschieden große »Assimilationsarbeit « erfordern wird; am meisten ist der Gedanke begründet, daß die Konstruktion z. B. der Froschlarvenproteine aus den pflanzlichen Eiweißkörpern eine andre Assimilationsarbeit" erfordert, als die Konstruktion der Froschlarvenproteine aus den Froscheitreißkörpern. Die Verdauung d. h. Spaltung, Absorption und Assimilation - der Froschmuskel-, Fischmuskel-, Pferdemuskel-, Krebsmuskel- und Muschelmuskelproteine, der »Pflanzenproteinsubstanz*, der Eiweißkörper der grünen Pflanzenteile wird höchstwahrscheinlich sehr verschiedene Funktionierung der Verdaungsröhre der Froschlarve bedeuten.

Durch die fortdauernde Darreichung der griünen Pflanzenteile wird der Darmwand der Froschlarven eine größere $»$ Verdauungsarbeit « auferlegt als bei der Froschfleischfütterung. Bei gleich großem Körper würde also ein pflanzenfressendes Individuum verhältuismäBig eine grö̈Bere Darmoberfläche "brauchen" d. h. auf die Einheit des Darminhaltes). 
Und das pflanzenfressende Individum entwickelt in der Tat eine solche Verdaungsfläche. Nach den in IV. 8 dargelegten Berechnungen ist die Darmoberfläche der pflanzenfressenden Tiere um $21^{0}, 0$ größer als diejenige der fleischfressenden Kontrolltiere.

Diese Erscheinung der mächtigen Entfaltung der Kontaktfläche der Verdauungszellen gegenuiber der schwerer verdaulichen und schlechter ausnutzbaren Nahrung könnte man vielleicht mit etwas Recht zu der Kategorie der sunktionellen Anpassungen " von (59a und b) Wilhelm Roux beirechnen. Lnter der »funktionellen Anpassung * versteht Roux *direkte Anpassung der Organismen an Funktionen durch Ausuibung derselben "; unter der Anpassung im allgemeinen wird gemeint »eine Veränderung der Lebewesen, welche die Dauerfähigkeit der betreffenden Lebewesen größer macht als sie unter denselben Umständen ohne diese Änderung sein würde ; »direkte Anpassung ist die Anpassung des einzelnen Individuums an während seines Lebens auf dasselbe einwirkende Umstiande*. Durch Veränderungen der Funktionsweise oder -größe der Organe an ihnen entstandene, den Akt der Funktionierung ïberdauernde gestaltliche Ïnderungen sind daher nach Rocx $(59 \mathrm{c})$ nur soweit als funktionelle Anpassungen « zu betrachten, als sie die Wiederholung der Funktion ihrer Art oder Größe nach erleichtern, verbessern oder sicherer machen. Alle andern durch die Funktionsvollziehung bewirkten gestaltlichen Änderungen des beztuglichen Organs bezeichnet er als gestaltliche Nebenwirkungen der Funktionierung. Mit diesen haben wir es, wie wir sehen werden, in den Ergebnissen unsrer Versuche mehrfach zu tun. -

Daß durch die Vergrößerung der Verdaungssläche, wie dieselbe durch Verlängerung und Verengerung der Darmröhre bei Yflanzenfütterung zustande kommt, die Dauerfähigkeit der Kaulquappen größer gemacht wird als ohne diese Änderung, folgt aus den Beobachtungen. Daß diese Veränderung durch Ausübung der Funktion verursacht ist, dürfen wir daraus schließen, daß es vorzugsweise die chemischen Reize, und unter diesen hervorragenderweise die Reizwirkungen der wichtigsten Nahrungsstoffe - der pflanzlichen Proteine sind, welche in den causal-analytischen Untersuchungen eine analoge Veränderung der Darmröhre hervorrufen.

Allerdings stellt unser Fall der "funktionellen Anpassung « ein mehrfach verwickelteres Beispiel als diejenigen, welche Roux anfiihırt, ror. Es läßt sich nach Roux beobachten, daß die funktio- 
nellen Anpassungen »sich auf Größe, Gestalt, Struktur und Qualität der Organe erstrecken «; es werden weiter »durch die Verstärkung der Funktion nicht alle Dimensionen der Organe gleichmäßig vergrößert, auch da, wo, wie bei Muskeln und Bändern, der Raum es verstattete, sondern bloß diejenigen Dimensionen, welche die Größe der Funktion besorgen; dabei ist das Verhältnis derartig, daß an denjenigen Organen, deren ,spezifische Funktion' durch eine Dimension besorgt wird, wie bei den Sehnen, Drüsen und Nerven, die Größe der Funktion von den beiden andern Dimensionen vollzogen wird, und daß umgekehrt in den andern Organen, welche, wie Epidermis, Gefäßwandung, Fascien usw. die spezifische Funktion mit zwei Dimensionen verrichten, die Größe der Funktion durch die dritte Dimension bestimmt wird. * Die Verdauungszellen würde man am besten den Drüsen der ersten Abteilung zur Seite stellen können: ihre spezifische Funktion wird »durch eine Dimension * besorgt (und zwar die Secretion in der einen, die Absorption in der andern Richtung, sowie die Abgabe der assimilierten Stoffe); demnach würde die Funktion der Verdauugszellen vergröfert werden, wenn sie sich in den zwei andern Dimensionen, d. h. flächenhaft ausdehnen würden: nun könnte man die tatsächlich gemessene totale Vergrößerung der Darmoberfläche bei der Pflanzenernährung als den Ausdruck der funktionellen Anpassung ansehen.

Nach dieser Betrachtungsweise wird also den Darmepithelien die aktive Rolle bei dem Längswachstum der Verdaungssröhre zugeschrieben, während die übrigen Komponenten der Darmwand vielleicht passiv nachfolgen. Es wäre allerdings schwer, diese Vermutung exakt nachzuweisen; die Schlüsse über aktive oder passive Beteiligung: der einzelnen Gewebe beim Wachstum eines zusammengesetzten Organs sind immer indirekt, denn man hat vor Augen nur einzelne fixierte Stadien des Geschehens. Doch in Anbetracht der oben angefuhrten Strukturverhältnisse des Mitteldarmes der Kaulquappen, wo es sich vorzugsweise um außerordentliche Entfaltung des Epithelrohres bei seinem Längswachstum handelt, gewinnt der eben gemachte Schluß große Wahrscheinlichkeit.

Die Oberflächenvergrößerung der Darmröhre geschieht bei den Froschlarven durch gleichzeitige Verlängerung und Verengerung des Darmkanals; nach meinen bisherigen Untersuchungen ist der andre Modus - die Ausdehnung der epithelialen Oberfläche durch Faltenbildung - kaum sicherzustellen, wie denn 
überbaupt in den Verdauungsröhren der Kaulquappen nur sehr niedrige Falten und rorwiegend in der Magenabteilung aufzufinden sind. Diesem Umstande hat man es vielleicht zu verdanken, daß sich der erste Modus - Verlängerung und Verengerung der Verdauungsröhre so auffällig kundgibt. Es ist möglich, daß bei andern Objekten, wo schon normalerweise die Darmoberfläche durch Darmzotten bedeutend vergrößert ist, bei Einwirkung der Nahrung vorzugsweise die Zottenbildung gefördert sein wird (z. B. es könnten zahlreichere, schlankere Zotten entstehen): daun würde vielleicht die Darmröhre in toto keine auffällige Differenzen in der Längsentwicklung zeigen. -

Ich will durch diese Bemerkungen nur darlegen, daß man sich bei der Überlegung über den Mechanismus, durch welchen die Gestaltungsvorgänge der Verdaunngsröhre bei Fütterung mit sehr abweichend beschaffener Nahrung zustande kommen, rollständig im Gebiet der Hypothesen befindet. Roux und andern ist es gelungen in einigen Fällen der sfunktionellen Anpassung « die rorhandenen "funktionellen Strukturen (der Knochen, der Fascien, der Blutgefäße, der Schwanzflosse des Delphins, der Höhlenmuskeln usw.) dem mechanischen Verständnis nahe zu bringen. Aber bei unsern Versuchsergebnissen liegen keine deutlichen sunktionellen Strukturen* vor; wir haben es hier iuberhaupt sehr wenig mit den verhältnismäßig durchsichtigeren mechanischen, bzw. Druck- und Zugeinwirkungen zu tun; die Funktion der Verdauungszellen ist unvergleichlich komplizierter, es stehen bisher noch wichtige Kenntnisse uber die Physiologie der fertigen Elemente aus usw. Um so mehr ist es geboten auf diesem Gebiete neue Forschungen zu unternehmen und das bisher Komplexe zu analysieren.

Von meinen analytischen Versuchsanordnungen schätze ich am höchsten die Sicherstellung, daß die Pflanzenproteine und überhaupt die Proteine eine bedeutende Einwirkung a uf die Ausgestaltung der Verdaungsröhre ausuben. Denn die Proteine sind die wichtigsten Nahrungsstoffe und man darf daher die durch sie herrorgerufenen Gestaltungsreaktionen als Anpassungserscheinungen an die Funktion ansehen. Die abweichend von tierischen Eiweißkörpern beschaffenen Proteine der Pflanzennahrung bewirken wahrscheinlich durch Verniittlung der geänderten Funktion die morphologische Anpassung " des Darmkanals. Doch daneben habe ich eine ähnliche Änderung des Längewachstums auch durch Asparagin, Kalksalze (vielleicht auch durch chemische Einwirkung des Keratins) erhalten: man 
kann darin allerdings schon schwieriger »Anpassungserscheinungen " erblicken, da man nicht die Beziehung zur Austubung der Funktion einsieht. Nichtsdestoweniger ist es möglich, daß diese Faktoren der Pflanzennahrung zugleich mit den Proteinstoffen in derselben Richtung tätig sind.

Von den mechanischen Einflissen kann man kaum behaupten - nach den Ergebnissen meiner analytischen Versuche daß sie bei der Pflanzenfuitterung irgendwie bedentend gestaltend beteiligt sind; ich konnte bisher auch keine funktionelle Beziehung der Nahrungsmenge und der Beschaffenheit der Darmwand auffinden, obzwar ich die Möglichkeit im Auge behielt, daß durch den mechanischen Einfluß der Nahrung die Muskelschicht der Darmwand oder das Bindegewebe derselben verändert werden könnte. Höchstens bewirkt eine voluminöse Nahrung eine merkliche Erweiterung des Lumens; aber diese Wirkung wird bei der Pflanzenfutterung rollständig vermißt: falls sie besteht, so ist sie durch weit stärkere darmverengernde Beeinflussungen (höchstwahrscheinlich chemischer Wirkungsweise) weit überkompensiert. -

Von den Ergebnissen der Fütterung mit verschiedenen Muskelsubstanzen verdient Beachtung eine Reihe von Umständen: 1) die chemisch dem Froschfleische ohne Zweifel näheren Fleische von Fisch und Pferd gleichen einander in bezug auf die Beeinflussung der Längsentwicklung der Darmröhre. 2) Dem Krebsfleische kommt eine au Berordentlich darmverengernde Einwirkung zu, nebst einer deutlichen darmverlängernden Beeinflussung; aber es ist derzeit unmöglich, diese Erscheinung in funk tio neller Hinsicht näher zu beleuchten. 3) Das Muschelfleisch führt zur Verkürzung and Erweiterung des Darmkanals, im Gegensatze zum Krebsfleisch und im Vergleiche mit Wirbeltierfleisch; es bestehen hier ebenfalls keine Andeutungen, welche uns die Möglichkeit einer näheren Analyse dieser Erscheinung im Sinne einer Anpassung an die Funktion gewähren künnten.

Es sind - was das Verhältnis der Länge nnd der Weite bei der Ausgestaltung der Verdauungsröhre betrifft - vier Fülle denkbar: I. Verlängerung und gleichzeitige Verengerung: dadurch wird die Darmoberfläche relativ größer; ohne daß das Volumen der Darmröhre bedeutend anzuwachsen braucht; dies würde von "größerer* Funktion zeugen und könnte als Ausdruck der »morphologischen Anpassung " zur verstärkten Verdaunngstätigkeit gelten. II. Verkürzung und gleichzeitige Erweiterung: dadurch wird die Darmoberfläche relativ kleiner, ohne gleichzeitige auffallende Ver- 
änderung des Volumens der Darmröhre; diese Erscheinung könnte als Folge der verminderten Aktivität des Darmkanals aufgefaßt werden (Analogon der »Inaktiritätsatrophie"). III. Verlängerung mit Erweiterung; IV. Verkürzung und Verengerung. Von diesen Fällen fanden wir den Fall I bei Pflanzen- (Pflanzenprotein-) und Krebsfleischfütterung unter den Versuchsanordnungen bei verhältnismäßig natürlicher Nahrung (nebst dem bei Calciumsalzen, Keratin), II. bei Muschelfleischfutterung, III. bei Celluloseversuchen, $\mathrm{nur}$ a ngedeutet, IV. iiberhaupt nicht sichergestellt. Es verdient vielleicht etwas Beachtung, daß die zwei ersten teleologisch klarliegenden Fälle so bestimmt bei im ganzen »natürlicber * Ernährung vorgekommen sind.

Wollten wir also diese Fälle in funktionelle physiologischmorphologische Beziehung zur Nahrung bringen, so könnten wir sagen: eine schwer verdauliche und schlecht ansnutzbare Nabrung, wie die aus grunen Teilen bestehende Pflanzennahrung, ruft eine relative Vergrößerung der Darmoberfläche hervor; man könnte vielleicht auch das Krebsfleisch für schwer verdaulich halten. Dem gegenuiber würde die Verkleinerung der relativen Darmoberfläche bei der Ernährung mit Muschelfleisch dafür sprechen, daß diese Kost sehr leicht verdaulich und ansnutzbar ist. Leider fehlen bisher exakte Untersuchungen über die Verdaulichkeit und Ausnutzbarkeit des Krebs- und Muschelfleisches selbst bei Menschen; aber ungenaue Erfahrung gibt an, daß man das Muschelfleisch viel leichter verzehrt als das Krebsfleisch. Bei meinen Muschelfleischtieren habe ich übrigens eine merkwürdige Beobachtung machen können: in ihrem Aquarium befanden sich fast keine Excremente (auker gleich nachdem ihnen neue Nahrung gegeben wurde: und da schien es sozusagen, als ob die frisch aufgenommene Nahrung den distal gelegenen Darminhalt herausgepreßt hätte; die, Larven haben auch diese "Excremente ", falls sie nicht bald entfernt wurden, wieder verschluckt und fast ohne Rückstand verdaut). Dem gegenüber war der Boden der andern Aquarien, und besonders derjenige der mit Krebsfleisch und Pflanzenproteinsubstanz ernährten Tiere mit reichlichen Exkrementen bedeckt, so daß öftere Reinigung nötig war. -

Vom causalen Standpunkte aus darf ich die beschriebenen morphologischen Ïnderungen der Verdauungsröhre überwiegend als >Chemomorphosen " bezeichnen; die "Mechanomorphosen" fielen weit unbedeutender aus. - 
W. Roux hat die Selbstregulation als eine universelle elementare Eigenschaft der Lebewesen in die Biologie eingeführt (59a u. c) und durch viel Beobachtungen gestaltliche Selbstregulationen, zu denen auch die hier behandelten * funktionellen Anpassungen " gehören, nachgewiesen. Driesch (60) hat die Regulationen weiterhin theoretisch bearbeitet. Er läßt das »Selbst dabei aber weg, da er im Unterschied zu Rocx der Meinung ist, daß keine reine Selbsttïtigkeit der materiellen Substrate, sondern Wirkungen einer unbewußten seelischen Tätigkeit darin vorlägen. Er definiert die Regulation als »einen am lebenden Organismus geschehenden Vorgang oder die Änderung eines solchen Vorgangs, durch welchen oder durch welche eine irgendwie gesetzte Störung seines vorher bestandenen ,normalen' Zustandes ganz oder teilweise, direkt oder indirekt kompensiert und so der ,normale Zustand oder wenigstens eine Annäherung an ihn wieder herbeigeführt wird $<$. In dieser Definition ist es allerdings notwendig den Begriff »Störung « zu beleuchten: darunter versteht DrIEsch »nicht nur eine dem Organismus als solchem, seiner Form oder Masse nach zugefügte Veränderung, sondern eine Störung kann auch eine Veränderung ron Faktoren der Außenwelt sein, indem durch sie sein Funktionsgetriebe gestört wird «. Die durch verschiedenartige Nahrung hervorgerufenen Gestaltungsreaktionen der Verdauungsröhren gehören nach seiner Benennung zu den sadaptiven Regulationen"; es handelt sich wohl hauptsächlich um quantitativ gekennzeichnete morphologische Effekte mit funktionsändernden Folgen, aber vielleicht wird man auch mit qualitativen, derzeit nicht bestimmbaren (weil vielleicht mehr funktionell als morphologisch ausgedrückten) Änderungen $z \mathfrak{u}$ tun haben. Denn bei einigen von den geschilderten Versuchsanordnungen werden bedeutende qualitative Änderungen der Reize vollfuhrt, wodurch kaum nur quantitative Änderungen der Objekte hervorgerufen werden.

\section{Literaturverzeichnis.}

1) Salvioli, G., Eine neue Methode fiir die Untersuchung der Funktionen des Dünndarms. Du Bois-R. Arch. f. Phys. 1880. Suppl.-B. S. 95.

2, Neumeister. R., Zur Physiologie der Eiweißresorption und zur Lehre von den Peptonen. Zeitschr. f. Biol. N. F. Bd. 9. 1890. S. 308.

3 Hofmeister, F., Das Verhalten des Peptons in der Magenschleimhaut. Zeitschr. f. physiol. Chem. Bd. 6. 1882. S. 69.

4. Glatssner, K., Über die Umwandlung der Albumosen durch die Magenschleimhaut. Horm. Beitr. z. chem. Phys. Bd. I. 1902.

5. Hamburger, F., Arteigenheit und Assimilation. Wien 1903. S. 33-36. 
6) BABÁk, E., Über den Einfluß der Nahrung auf die Länge des Darmkanals. Biolog. Centralbl. Bd. 23. 1903. S. 477.

7) Oppes, A., Lehrbuch der vergleichend. mikrosk. Anatomie der Wirbeltiere. Bd. II. Schlund u. Darm. Jena 1897.

8) Ellexberger, W., Vergleichende Physiologie der Haussüugetiere. Bd. I. Berlin 1890.

9) Thanhofeer, L. v., Grundziige der vergleich. Physiologie und Histologie. Stuttgart 1885.

10) Gegexraur, C., Vergleichende Anatomie (1. Wirbeltiere. Bd. II. Leipzig 1901.

11) Bцосн, A., in den mir unzngiinglichen Bulletins et mémoires de la Socićté d'anthropologie 1904. Zitiert nach dem Referat in Revue scientif. II. 1905. p. $281,282$.

12) Ellenberger-Baum, Handbuch der vergleichend. Anatomie der Haustiere. Berlin 1903.

13) Gadow, H., in Bronns Klassen u. Ordnungen des Tierreichs. Bd. IV.

14) Lönnberg, E., On some points of relation between the morphological structure of the intestine and the diet of reptiles. Bihang Till $\mathrm{K}$. Svenska Vet. Akad. Handlingar. Bd. 28. IV. 8. Stockholm 1902.

15) Werser, F., Die relative Darmlänge bei insekten- und pflanzenfressenden Orthopteren. Zoolog. Miscellen. VII. Biolog. Centralbl, Bd. XIV. 1894. S. 116-119.

16. Fürth. 0. v., Vergleich. chem. Phṛsiologie der niederen Tiere. Jena 1905. S. 238 usw.

17) Sussdorf, Das Lïngenwachstum des Darmkanals in Anpassung an die riumlichen Verhältnisse der Bauchhöhle und die Ernïhrung. Jahresh. d. Vereins f. vaterl. Naturk. in Württemberg, 57. Jahrg. 1901. S. XCI-XCII.

18) Nuns, A., Lehrbuch der vergleich. Anatomie. Bd. I. Heidelberg 1886.

19) Nach Wiedersherm, Der Bau des Menschen als Zeugnis für seine Vergangenheit. 1893. S. 142.

20) Darwin, Ch., Das Variieren der Tiere und Pflanzen im Zustande der Domestikation. Bd. I. 1899. S. 53.

21) Kassowitz, M., Allgemeine Biologie. Bd. II. Wien 1899.

22) Ferm, C., und Repetro, R., Über die Einwirkung der Nahrungsweise auf die Entwicklung des Verdauungsapparates. FxGelix. Arch. f. Physiol. 1901. Suppl.-Bd. S. 84 .

23) Semper, K., Die natïrlichen Existenzbedingungen der Tiere. Bd. I. 1880.

24) BRandes, G., Über den vermeintlichen Einfluß veränderter Emïhrung auf die Struktur des Vogelmagens. Biol. Centralbl. Bd. 16. 1896.

25) Hocssay, F., Variations organiques chez les poules carnivores de seconde génération. Compt. Rend. Ac. Sc. 135. 1902. p. 1357-135̃9.

26) Weiss, G., Sur l'adaptation fonctionelle des organes de la digestion. Compt. Rend. de la Soc. de Biol. 53. 1901. p. 908-909.

27) Houssar, F., Sur la ponte, la fécondité et la sexualité chez des poules carnivores. Compt. Rend. Ac. Sc. 137. 1903. p. 934-936.

28) Nó́. J., Valeur de l'influence du régime sur la longueur de lintestin. Compt. Rend. de la Soc. de Biol. 55. p. 250.

29) BARfurth, D., Versuche über die Verwandlung der Froschlarven. Arch. f. mikr. Anat. Bd. 29. 1887. S. 1-28.

30) - Der Hunger als fürderndes Prinzip in der Natur. Arch. f. mikr. Anat. Bd. 29. 1887. S. 28-34. 
31) Yuxa, E., De linfluence de l'alimentation sur la longueur de l'intestin. Expériences sur les larves de Rana esculenta. Compt. Rend. du 6. Congr. Internat. de Zool. Berne 1904.

32) — De linfluence du régime alimentaire sur la longueur de lintestin chez les larves de Rana esculenta. Compt. Rend. Ac. Sc. 1904. 7. Nov.

33) PAgks, C., Histoire d'un mouton mignard. Compt. Rend. de la Soc. de Biol. 54. 1902. p. $6504-655$.

34) Distant. W. L., Zoologist 1899. Zitiert nach Revue scientif. 1899. II. p. $568-569$.

35) Hofryaxx, C. K, Broxas Klassen u. Ordnungen der Amphibien. 1873 -78.

36) Y'xar, E.. Contribution à l'histoire de l'influence des milieux physico-chimiques sur les êtres vivants. II. Influence des différentes espèces d'aliments sur le développement de la grenouille. Arch. de zool. expérim. et génér. II. S. I. T. 1883.

37) Davenpor', Ch. B., Experimental morphology. P. II. New York 1899.

38) Noḱ, J., Influence prépondérante de la taille sur la longueur de lintestin. Compt. Rend. de la Soc. de Biol. 54. 1902. p. 1489-1491.

39) Vort. C., Physiologie des allgem. Stoffwechsels u. der Ernährung. BErM. Handb. d. Physiol. Bd. VI. 1. S. 473.

40) Knieniex, W. v., Über Verwertung der Cellulose im tierischen Organismus. Zeitschr. f. Biol. Bd. 21. 1888. S. $81-8 \tilde{\text {. }}$

41; Bunge, G. v.. Lehrbuch d. Physiologie d. Menschen. 1901. Bd. II. S. 77.

42. Czapek, F., Der Stickstoff im Stoffwechsel der Pflanze. Ergebn. đ. Physiol. II. 1. 1903. S. 655 .

43: — Biochemie der Pflanzen. II. 'T. 1905. S. 201.

44) Driesch, H., Die Entwicklungsphysiologie 1902-1905. Ergebn. d. Anat. u. Entw. 1905.

45) Vierondt, H., Daten und Tabellen. Jena 1888.

46) Fürth, 0. v., Zur Gewebschemie des Muskels. Ergebn. d. Phỵsiol. I. 1. 1902. S. 114 usw.

47) Przibran, H., Versuche zur ehemischen Charakterisierung einiger Tierklassen des natürlichen Systems auf Grund ihres Muskelplasmas. Horn. Beitr. z. chem. Physiol. Bd. II. 1902. p. 143-147.

48) Hammarsten, 0., Lehrb. d. physiol. Chemie. S. 408-409. Wiesbaden 1904.

49) Czaper, F., Biochemie der Pflanzen. II. T. 1905. S. 209-210, 790 usw.

50, Katz, J., Die mineralischen Bestandteile des Muskelfleisches. PrLüG. Arch. f. Physiol. Bd. 63. 1896. S. 58-59.

51) Hofueister, F., Über Bau und Gruppierung der Eiweißkörper. Ergebn. d. Physiol. I. 1. S. 774. 1902.

52. Schulze, E., und Winterstein, E., Über die bei der Spaltung der Eiweißsubstanzen entstehenden basischen Produkte. Ergebn. d. Physiol. I. 1. 1902. S. 45 .

53) Kellaser, 0., Die Ernährnng der landwirtschaftlichen Nutztiere. Berlin 1906. S. $121 \mathrm{usw}$.

54) Völtz, W., Über den Einfluß versehiedener Eiweißkörper und einiger Derivate derselben auf den Stickstoffumsatz, mit bes. Berücksichtigung des Asparagins. PruÜg. Areh. f. Physiol. Bd. 107. 1905.

55) Uhlenhuth, Das biologische Verfahren zur Erkennung und Cnterscheidung von Menschen- und Tierblut usw. Jena 1905. S. 24 usw. 
56) Maurer, F., Die Entwicklung des Darmsystems in Hertwigs Handb. der Entwicklungsgesch. S. 162 usw.

57) Maurel, E., Rapport du poids du foie au poids total de l'animal. Compt. Rend. Ac. Sc. 135̃. p. 1002-1005. 1902.

58) Pawlow, J. P., Die Arbeit d. Verdaungsdrüsen. Wiesbad. 1898. S. 133-135. 59a) Roux, W., Der Kampf der Teile im Organismus. Leipzig 1881.

59 b) - Gesammelte Abhandlungen iber die Entwicklungsmechanik der Organismen. 1895. Bd. I.

59 c) — Über die Selbstregulation der Lebewesen. Arch. f. Entw.-Mech. XIII. S. $610-650$.

59 d) Die Entwicklungsmechanik, ein neuer Zweig der biologischen Wissenschaft. Leipzig 1895.

60) Driesch, H., Die organischen Regulationen. Leipzig 1901. S. 92 usw.

61) ВавÁK, E., Experimentelle Untersuchungen über den Einfluß der Nahrung auf die Länge des Darmkanals. Centralbl. f. Physiol. Bd. 18. 1905.

62. - Über die morphogenetische Reaktion des Darmkanals der Froschlarve auf Muskelproteine verschiedener Tierklassen. Hofx. Beitr. z. chem. Phys. Bd. 7. 1905. 